\title{
PARTICIPATORY EFFECTS OF POLITICAL SATIRE REVISITED IN THE AGE OF DIGITAL MEDIA: \\ THE ROLE OF HARD NEWS, POLITICAL EXPRESSION AND SOCIAL MEDIA
}

A Dissertation
presented to
the Faculty of the Graduate School
at the University of Missouri-Columbia
In Partial Fulfillment
of the Requirements for the Degree
Doctorate of Journalism
by
HEESOOK CHOI
MAY 2019


The undersigned, appointed by the dean of the Graduate School, have examined the dissertation titled

PARTICIPATORY EFFECTS OF POLITICAL SATIRE REVISITED IN THE AGE OF DIGITAL MEDIA: THE ROLE OF HARD NEWS, POLITICAL EXPRESSION AND SOCIAL MEDIA

Presented by Heesook Choi,

A candidate for the degree of

Doctor of Philosophy,

And hereby certify that, in their opinion, it is worthy of acceptance.

Dr. Esther Thorson, Chair

Dr. Tim Vos

Dr. Yong Volz

Dr. Elizabeth Behm-Morawitz

Dr. Ben Warner 


\section{DEDICATION}

To all the people who have helped me become who I am today.

Nobody has been more important to me in the pursuit of this journey than my family. I would like to thank my parents, Sagil Choi and Jongok Choi, whose love and guidance are with me in whatever I pursue. I am grateful to my twin sister, Kyungsook Choi, and her husband and newly adopted brother-in-law, Daniel Wolkenfeld, for their unending support and inspiration along the way. I am also thankful to my brother, Sunwoo Choi, and his wife, Jichan Park, as well as my vast extended family for their moral and emotional support during my journey.

And to my eternal cheerleaders, my late grandparents, Chanwook Choi and Sunweol Kim, who played an important role in my life. I miss our interesting and longlasting chats on what I was up to. They were always keen to know what I was doing and how I was proceeding. Although it was likely that they never grasped what it was all about, their unconditional love strengthened my resolve to succeed in life. My late grandfather, Chanwook Choi, used to ask me when I would pursue my doctoral degree, and here I am now with the degree he asked for... I will miss forever their screams of joy whenever I reach a significant milestone. 


\section{ACKNOWLEDGEMENTS}

This work would not have been possible without the support of many people.

Firstly, I would like to express my sincere gratitude to my advisor, Dr. Esther Thorson, for her continuous support for my Ph.D. study. I have taken more time than expected on my dissertation and her unflagging support and faith in me was uplifting. Her belief in my work and intellect, as well as her patience in my overcoming obstacles I have faced during my program, helped me grow into my full potential. I would not be where I am today without her.

Besides my advisor, I would like to thank the rest of my dissertation committee. Each of them has taught me a great deal about both scientific research and life in general. I am grateful to Dr. Tim Vos for enlightening me about important concepts central to media studies with cryptic questions. I would also like to thank Dr. Yong Volz who helped me with my first academic research paper and provided me with emotional and moral support throughout my program. My sincere thanks are also extended to Dr. Elizabeth Behm-Morawitz for introducing me to the various important concepts of new media technologies, which became an important part of my dissertation. And a very special acknowledgement goes out to Dr. Ben Warner for his patient guidance, enthusiastic encouragement and useful critiques of my research work. He has been a great help in doing the data analysis using structural equation modeling.

A very special gratitude goes out to Dr. Margaret Duffy and Dr. Glenn Leshner who taught me early on the importance of making clear conceptual and operational definitions in scientific research. That training prepared me well for my dissertation. 
I would also like to extend my sincere appreciation to my mentors and friends who have lifted me up when it was necessary. I am grateful to Dr. Soo Jung Moon and Dr. Ki Deuk Hyun, who saw something in me that I did not see in myself and led me to this academic journey. They motivated me to get through my program and accomplish my goals. I am appreciative to Dr. Beverly Horvit, my teaching faculty mentor, for her support for and interest in my Ph.D. study. I also thank Columbia Toastmasters, especially Ralph Kreigh, Lorie Kaplan, Randima Dinalankara, Seth Jarboe, and Elizabeth Depke, for their emotional and moral support, as well as encouragement. I forward special recognition to both Ann Mehr and David Mehr who kept me grounded with caring, humor and dog walks for the past year. David Mehr, who is a doctor and researcher himself, even provided me with his insightful feedback to better contextualize my findings. And finally, many thanks to Dr. Yulia Medvedeva who has lifted me up, as a friend and colleague, with moral and emotional support, no matter where she was.

Thank you all for your support and encouragement! 


\section{TABLE OF CONTENTS}

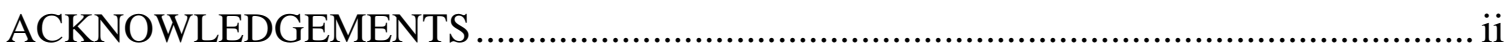

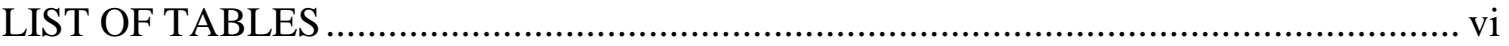

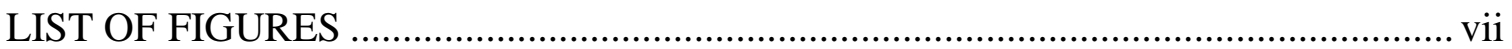

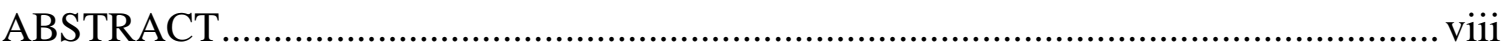

\section{Chapter}

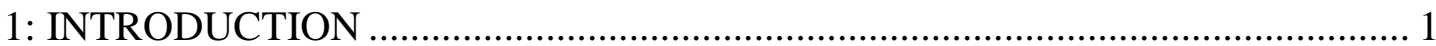

Significance of The Present Study .................................................................... 7

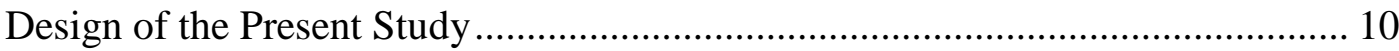

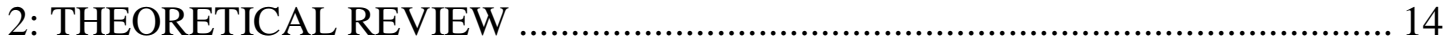

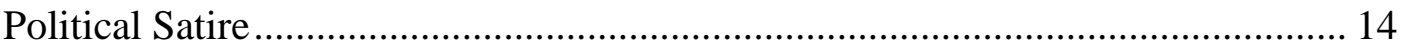

Social Media and Political Participation......................................................... 37

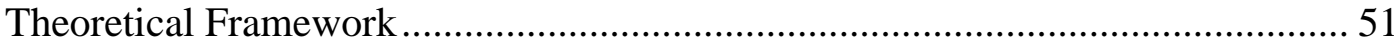

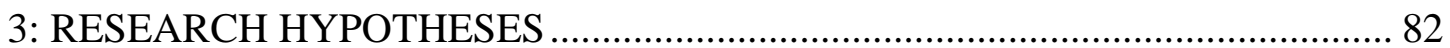

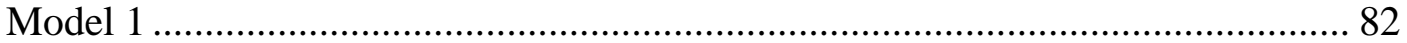

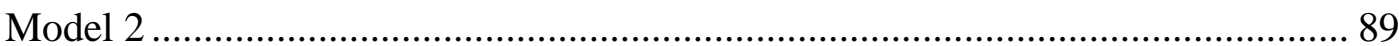

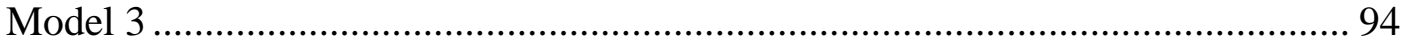

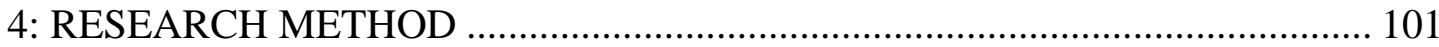

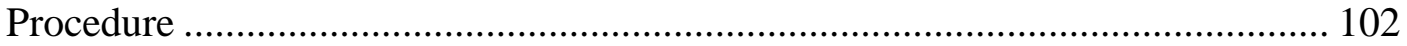

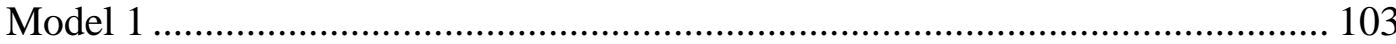

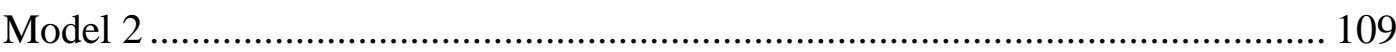

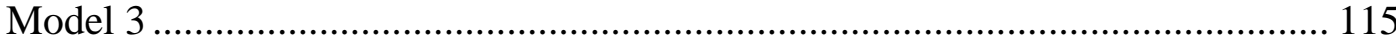

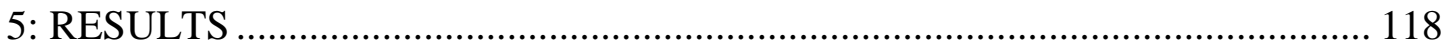




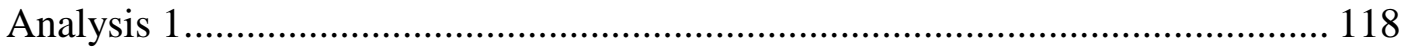

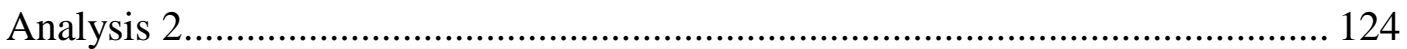

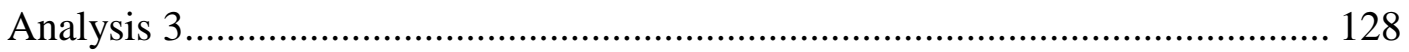

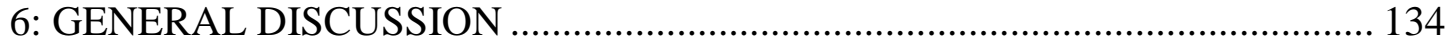

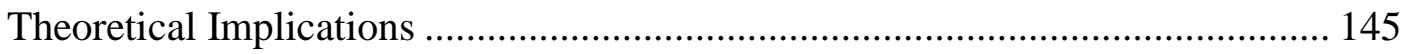

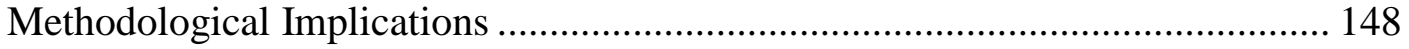

Practical Implications.......................................................................... 148

Limitations and Future Research .......................................................... 149

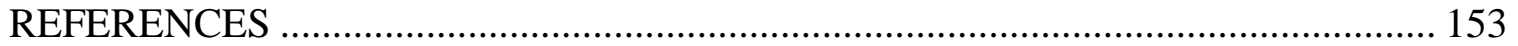

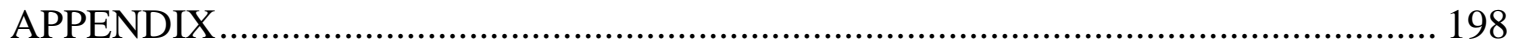

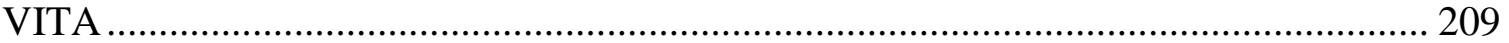




\section{LIST OF TABLES}

Table

Page

1. Factor Loadings for Maximum Likelihood of Late-Night Talk Show Scales ...... 185

2. Correlation Matrix of Key Variables in Model 1 .............................................. 186

3. Latent Regression Paths for Final SEM Model 1............................................ 187

4. Significant Indirect Effects of Hard News Use ................................................ 188

5. Correlation Matrix of Key Variables in Model 2 ............................................ 189

6. Latent Regression Paths for Final SEM Model 2 .............................................. 190

7. Significant Indirect Effects of Gentle Satire Viewing ...................................... 191

8. Correlation Matrix of Key Variables in Model 3 .............................................. 192

9. Latent Regression Paths for Final SEM Model 3 ............................................. 193

10. Significant Indirect Effects of Curated Viewing of Political Satire .................... 194 
Figure

\section{LIST OF FIGURES}

1. Hypothesized model for Model 1 ....................................................................... 195

2. Final model for Model 1 .................................................................................... 195

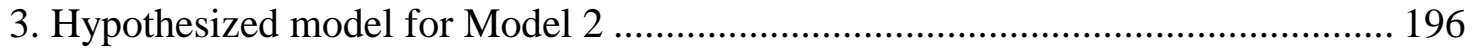

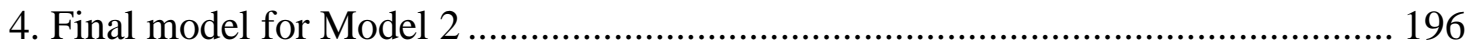

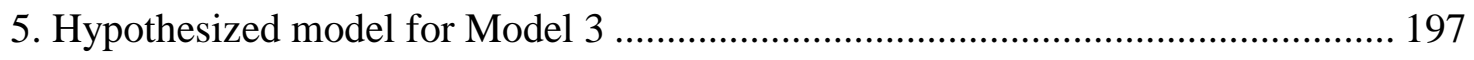

6. Final model for Model 3............................................................................... 197 


\title{
PARTICIPATORY EFFECTS OF POLITICAL SATIRE REVISITED IN THE AGE OF DIGITAL MEDIA: THE ROLE OF HARD NEWS, POLITICAL EXPRESSION AND SOCIAL MEDIA
}

\author{
Heesook Choi \\ Dr. Esther Thorson, Dissertation Supervisor
}

\begin{abstract}
This study examines the participatory effects of political satire, specifically latenight talk shows, in the age of digital media. Based on the O-S-R-O-R (background Orientation-Stimulus-Reasoning-outcome Orientation-Response) model of communication effects, this study theorizes and tests structural relationships in which audience factors (e.g., partisanship, hard news use) guide political satire viewing, and information processing activities (e.g., political talk, social media expression) and cognitive outcomes (e.g., political knowledge, political efficacy) channel the impact of the audience factor-driven political satire viewing on participation. More importantly, this study examines, for the first time, the role of social media in both political satire viewing and political expression, and its influence on participation. Data from a nationally representative survey $(N=573)$ suggest that hard news use is an essential prerequisite for the participatory effects of political satire viewing. In addition, partisanship is a key predictor of political satire viewing, and media channel matters, such that those who watch late-night talk shows on television are less likely to participate in politics, while those who watch late-night talk shows in the social media environment are more likely to participate in politics through political expression on social media. These findings highlight the importance of understanding who receives what messages from where and how in the contemporary media environment to better explain the effects of media.
\end{abstract}




\section{Chapter 1: Introduction}

An integral part of representative democracy is an information environment in which citizens can have free and easy access to political information, so that they can make sense of politics, form sound opinions about important social and political issues, and actively participate in political and civic life (Delli Carpini, 2004). In this regard, extensive research has demonstrated the link between news use and democratic outcomes, such that news use increases political knowledge, efficacy, and participation (Delli Carpini \& Keeter, 1996; Eveland \& Scheufele, 2000; Hardy \& Scheufele, 2005; Jung, Kim, \& Gil de Zúñiga, 2011; Moeller, de Vreese, Esser, \& Kunz, 2014; Prior, 2007; Verba, Schlozman, \& Brady, 1995).

With the rise of cable television and the Internet, however, the normative implications of news use for enhancing democratic citizenship have been fiercely debated for the past decades (Baum, 2002, 2003b; Prior, 2007). The rise of new media and market pressure have fragmented the audience, decreased consumption of traditional news, and dramatically changed media coverage of political affairs (Patterson, 2000; Plasser, 2005; Prior, 2005). News is far from being monolithic and audiences have now unprecedented choice not only between news and entertainment (Prior, 2007), but also between partisan perspectives and more balanced perspectives (Stroud, 2011; Wojcieszak, Bimber, Feldman, \& Stroud, 2016). In addition, the rise of social media has made media experience more complicated than ever. The proliferation of media platforms and channels and the near-limitless political information available in the networked media environment have even added an additional layer of complexity in the study of media 
effects (Thorson \& Wells, 2015). Accordingly, it is getting more difficult to explain the effects of media in the contemporary media environment without fully understanding who receives what messages from where and how (Lee, 2013).

Ample research has examined what these changes in the media environment mean to democracy, which is premised on free flow of information, well-informed citizens, and active citizen participation in the political process, and the verdict is mixed. On one hand, optimists state that increases in available political information would improve political knowledge and hence participation (Baum, 2003b; Gil de Zúñiga, Jung, \& Valenzuela, 2012). Further, the new media environment increases incidental exposure not only to political information, but to heterogeneous viewpoints, which could facilitate political discourse and hence increase involvement in the political process (Kim, 2011; Kim, Chen, \& Gil de Zúniga, 2013; Lee, 2012). On the other hand, pessimists argue that people's unprecedented choice not only between entertainment and news, but between partisan perspectives and more balanced perspectives make them either apolitical or polarized (Garrett \& Stroud, 2014; Iyengar \& Hahn, 2009; Kim et al., 2013; Prior, 2007; Stroud, 2011; Sunstein, 2009). In particular, the decline in the size of the traditional news audience has been viewed as a threat to representative democracy by many pundits and scholars who have interpreted this as a sign of waning sense of democratic citizenship. This is because those who tune out politics for entertainment will not be represented in the political process and this will influence the quality of public opinion, which is the strong foundation of democracy (Prior, 2007).

This concern led to a surge in the study of soft news, political entertainment news, or "new news" (Kalb, 1998) to examine its political effects, mostly focusing on political 
knowledge, a strong predictor of political participation (Delli Carpini \& Keeter, 1996; Verba et al., 1995), but the findings are debatable. Specifically, use of an oversimplified dichotomy, hard vs. soft news, seems ineffective. Soft news is defined loosely in comparison to hard news, such as being "typically more sensational, more personalitycentered, less time-bound, more practical, and more incident-based" than hard news (Patterson, 2000, p. 4). Its reporting style is more episodic, frame-oriented, and -focused with a human-interest angle, making news stories more appealing and comprehensible (Gross, 2008). Despite common use by media scholars, however, there is no consensus on how to operationalize soft news. One good example is the debate on the effects of soft news on political knowledge (Baum, 2002, 2003a; Prior, 2003, 2007). On one side of the spectrum is Markus Prior $(2003,2007)$, who suggests that soft news programs do not provide sufficient information needed when making informed decisions about politics, categorizing TV news magazines (e.g., 60 Minutes) into a hard news index. On the other side is Matt Baum (2002, 2003), who argues that consumption of soft news is associated with political learning, especially, of politically inattentive individuals, categorizing TV news magazines (e.g., 20/20) into a soft news index. Simply put, since most scholars seem to rely on an intuitive understanding of what soft news is in simple comparison to what hard news is, their findings are not compatible although they seem to look at the similar aspects of the changes made in the media industry (Reinemann, Stanyer, Scherr, \& Legnante, 2012). In addition, not all soft news programs are created equal and it is important to distinguish between various types of political entertainment programs based on the nature and amount of political content and the way it is delivered (Holbert, 2005). 
In response to this call for a more systematic and multidimensional approach in the study of effects of soft news or political entertainment news, great scholarly attention has been paid to the democratic effects of political satire, mostly late-night talk shows, for the past decade or so (Holbert, 2013). This is because it inherently possesses the features of news and entertainment. That is, it provides scathing criticism of the government and politics in an entertaining and engaging manner to the point where it is even perceived as an "alternative journalism" (Baym, 2005), often in the form of public journalism (Faina, 2013) or advocacy journalism (Kilby, 2018) to encourage audience engagement in civic and political life. However, the democratic effects of political satire are inconclusive yet (Holbert, 2013), which indicates that late-night talk shows are not associated with those various forms of citizenship for all sectors of the citizenry at all times (Holbert, 2013; Moy, Xenos, \& Hess, 2005).

There are quite a few reasons for the mixed results. First, since, again, political satire is not monolithic either, satire type can be a key antecedent of political outcomes (Boukes \& Boomgaarden, 2015; Holbert, Hmielowski, Jain, Lather, \& Morey, 2011). For example, harsh or Juvenalian satire is likely to facilitate political participation, while gentle or Horatian satire is not (Cao \& Brewer, 2008; Hoffman \& Young, 2011). The vast majority of existing studies, however, have focused on one or two programs, paying relatively less attention to the satirical tone. Second, consumption of political satire requires the assumed knowledge of the audience (Caufield, 2008). For example, exposure to news - cable news, newspapers, or local news - is likely to predict exposure to latenight talk shows (Hmielowski, Holbert, \& Lee, 2011; Young \& Tisinger, 2006). Studies offered to date, however, have generally failed to systematically examine the link 
between hard news use and political satire viewing and its influence on political outcomes, mainly juxtaposing hard news use and political satire viewing to simply highlight the possible differences between the two in terms of their political effects (Hoffman \& Young, 2011). Lastly, unlike the research on news use and political participation, the research on the effects of political satire on participation has been lacking an effort to understand the underlying psychological processes between political satire viewing and political participation (Feldman, 2013), mainly relying on one or two conventional cognitive and attitudinal variables which are often included in the strict media effects paradigm (Young, 2016).

Research has shown that political satire, more specifically late-night talk shows, has emerged as a main source of political news and information in the past decade or so (Cao \& Brewer, 2008; Gottfried \& Anderson, 2014; Mitchell, Gottfried, \& Matsa, 2015). The Daily Show with Jon Stewart was considered an "alternative journalism," since it used "satire to interrogate power, parody to critique contemporary news, and dialogue to enact a model of deliberative democracy" (Baym, 2005, p. 261). The Colbert Report's Super PAC segment is often cited as an example of political satire serving as a civics lesson, even greater than news media (Hardy, Gottfried, Winneg, \& Jamieson, 2014). Recent years have seen a surge in the number of late-night talk shows, especially in the wake of the retirements of the so-called "three late-night pillars" - Jon Stewart, David Letterman, and Jay Leno - that completed in 2015 (Steinberg, 2018). More importantly, with the emergence of Donald Trump as a GOP presidential nominee and his election as the $45^{\text {th }}$ president of the United States during the 2016 presidential election, late-night talk shows have become increasingly more politically pointed, even putting on unusual 
live shows for political events, such as the 2016 presidential election, the 2018 State of the Union address, and most recently, the 2018 midterm elections, for their viewers who apparently turn to them for political news and information (Keveney, 2018; Russonello, 2018). With the pointed comments on what is ridiculous and absurd in the presence of President Trump, whose public remarks "have been marked by untruths and misleading claims," late-night talk shows are now even viewed as "the antidote to Trumpism" (Grynbaum, 2019; Maza, 2017). In the Trump era, political satirists appear to be doing a better job at covering the Trump administration than traditional journalists who cherish journalistic norms and principles to take everything seriously and try to show all sides of the story (Maza, 2017). Some scholars even call political satire the fourth estate (Kilby, 2018) or fifth estate (Basu, 2018).

Taken together, political satire informs the public by engaging them in the conversation with humor and interaction, which is perceived as a new journalistic form (Harrington, 2012). These entertaining and humorous satirical messages, therefore, are assumed to permeate more easily than traditional political messages with a serious tone, which in turn could further facilitate political participation (Jones \& Baym, 2010). Accordingly, it is timely and necessary to more systematically examine if and how this so-called "alternative journalism" and "a new journalistic form" lives up to the great promise that many qualitative and cultural media scholars hold for this media form.

With the limitations in the existing study of political satire in mind and the aim to better untangle the effect of political satire, this study proposes structural relationships between audience background orientations (i.e., Democrats, Republicans, education, alternative concepts of citizenship, hard news use), distinct forms of political satire 
viewing (i.e., political satire viewing in general, harsh satire viewing, gentle satire viewing, self-viewing, curated viewing), information processing activities (i.e., news attention, offline political discussion, online political messaging), cognitive outcomes (i.e., political knowledge, political efficacy), and political participation, online and offline, based on the O-S-R-O-R (background Orientation-Stimulus-Reasoning-outcome Orientation-Response) model of communication effects. In this study, political satire is operationalized as late-night talk shows, such as The Daily Show, Jimmy Kimmel Live, and Full Frontal with Samantha Bee.

\section{Significance of The Present Study}

This study contributes to the field of political communication in a couple of important ways. First, this study advances a new theoretical model to better untangle and explain the participatory effects of political satire in the contemporary media environment. Specifically, based on the O-S-R-O-R model of communication effects, I theorize and test structural relationships in which audience factor-driven political satire viewing increases participation both online and offline through various reasoning processes and outcome orientation variables, which existing studies suggest are worth testing. I do so by differentiating between various types of political satire viewing. An overarching conceptual model linking audience factors with political satire viewing and comparing multiple communicative behaviors and cognitive outcomes from audience factor-driven political satire viewing to political participation has not been tested. Findings suggest that it is important to examine the link between audience factors and media consumption, such that hard news use appears to be an essential prerequisite for the participatory effects of political satire viewing. In addition, reasoning variables, 
political talk and social media expression, are key mediators between political satire viewing and participation, which advances an O-S-R-R model as a better model.

Second, we know very little about the effects of exposure to different forms of late-night talk shows which are currently on the air. Existing research heavily relied on The Daily Show with Jon Stewart in rare combination with Late Show with David Letterman, The Tonight Show with Jay Leno, and The Colbert Report. With the exit of three of the satirists - Jon Stewart, David Letterman, and Jay Leno - and the remaining one - Stephen Colbert - taking on a different program, it is important to examine if and how the currently aired late-night talk shows produce democratic good to live up to the great promise that many qualitative studies of political satire argue (Basu, 2018; Baym, 2005; Faina, 2013; J. P. Jones \& Baym, 2010; Kilby, 2018). In addition, this study moves beyond the simple approach to use one or two popular shows. Instead, this study uses 11 different late-night talk shows to make a reasonably complete estimate of what programs people were watching. They include The Tonight Show Starring Jimmy Fallon, Late Show with Stephen Colbert, Jimmy Kimmel Live, Late Night with Seth Meyers, Late Late Show with James Corden, Last Call with Carson Daly, The Daily Show with Trevor Noah, Conan, Saturday Night Live, Last Week Tonight with John Oliver, and Full Frontal with Samantha Bee.

Third, the changes in the media consumption environment have been largely neglected in the study of political satire. Accordingly, little research has considered the role of social media in consumption of political satire and its impact on political outcomes. Research has shown that more and more people turn to social media for their news and information (Mitchell et al., 2015; Shearer \& Gottfried, 2017) and 
informational use of social media encourages political participation (Boulianne, 2015). With the departure of the "three late-night pillars," which completed in 2015, late-night talk shows moved online to compete for ratings (Pallotta, 2015). Today, all of the latenight talk shows have their social media presence. This study examines the role of the social media environment in political satire viewing to demonstrate the importance of differentiating between media channels (e.g., television, social media environment) in media consumption in the contemporary media environment to better explain the effects of media. Findings suggest that media channel matters in the participatory effects of poltical satire, such that watching late-night talk shows on television is less likely to encourage political participation, whereas watching the shows in the social media environment is more likely to encourage political participation by facilitating social media expression.

Fourth, this study demonstrates the importance of integrative work in media effects study, which crosses three communication subdisciplines, such as mass media, interpersonal and computer-mediated communication, to better understand the communication process in the digital era and its influence on democratic citizenship (Valkenburg, 2017). As mentioned earlier, findings suggest that reasoning processes through political talk and social media expression mediate the effects of political satire viewing on political participation. And, social media use for news and information and political expression appears to be central to democratic life.

Lastly, this study adds a methodological contribution to the study of media effects. Few studies have used latent variables in structural equation modeling (SEM). The vast majority of SEM models in the political communication study are path models 
that only use observed variables (Chan, 2016; Cho et al., 2009; Jung et al., 2011; Shah, Cho, Eveland, \& Kwak, 2005; Shah et al., 2007), which could add measurement error back into the models and thus attenuate the latent relationships. Each model in this study contains latent variables in the stimulus, reasoning, and outcome orientation steps.

\section{Design of the Present Study}

Using cross-sectional survey data obtained via Amazon's Mechanical Turk (MTurk), this study systematically examines the effects of political satire viewing on political participation. Specifically, based on the O-S-R-O-R model of communication effects, this study proposes structural relationships in which audience factors (i.e., Democrats, Republicans, education, alternative concepts of citizenship, hard news use) guide political satire viewing, and reasoning variables such as information processing activities (i.e., news attention, political talk, social media expression) and outcome orientation variables such as cognitive outcomes (i.e., political knowledge, political efficacy), channel the impact of audience factor-driven political satire viewing on participation. To better untangle the participatory effects of political satire in the contemporary media environment, this study utilizes three diffeent models to differentiate between various types of political satire viewing.

Model 1 examines if and how political satire in general mobilizes its viewers in comparison to hard news. In this model, I propose structural relationships in which audience factors (i.e., Democrats, Republicans, education, alternative concepts of citizenship) serve as background orientations; political satire viewing in general and hard news use as stimuli; news attention, political talk, and social media expression as reasoning processes; political knowledge and political efficacy as outcome orientations; 
and political participation, online and offline, as responses. Research has shown that the line between news and entertainment has been blurred (Edgerly, Vraga, Bode, Thorson, $\&$ Thorson, 2017) and more and more people, especially young audiences, are abandoning traditional news as a source of news and information in favor of political entertainment programs, mostly late-night talk shows (Cao \& Brewer, 2008; Mitchell et al., 2015). In addition, research suggests that news media are no longer a dominant source of news and information to follow in relation to civic information and citizenship norms, and rather digital media or everyday life activities can better get people informed and engaged in political activities (Bennett, Wells, \& Freelon, 2011; Thorson, 2012). This model aims to examine the extent to which political satire, the most popular political entertainment program, lives up to the great promise that these media scholars hold for the non-news media source of news and information. In order to untangle the participatory effects of political satire, this model basically compares a route through which hard news use influences offline and online political participation as mediated through information processing activities and cognitive outcomes - at least some of which are extensively supported in other studies - with a route that goes through political satire viewing instead. Previous studies on political satire also reveal links between some of the key variables - political satire viewing and news attention (Feldman \& Young, 2008), and political satire viewing and political discussion (Lee, 2012; Moy et al., 2005).

Model 2 examines if and how satire type matters in the participatory effects of political satire viewing. In this model, I propose structural relationships in which audience factors (i.e., Democrats, Republicans, education, hard news use) serve as background orientations; harsh satire viewing and gentle satire viewing as stimuli; news 
attention, political talk, and social media expression as reasoning processes; political knowledge and political efficacy as outcome orientations; and political participation, online and offline, as responses. Research suggests that late-night talk shows are not monolithic and distinct forms of satire (e.g., horatian or gentle satire, juvenalian or harsh satire) lead to different political outcomes (Boukes \& Boomgaarden, 2015; Cao \& Brewer, 2008; Hoffman \& Young, 2011; Holbert, 2005; Holbert et al., 2011; Young \& Tisinger, 2006). For example, harsh satire (e.g., The Daily Show with Jon Stewart, The Colbert Report) is likely to facilitate political participation, while gentle satire (e.g., The Tonight Show with Jay Leno, Last Show with David Letterman) is not (Cao \& Brewer, 2008; Hoffman \& Young, 2011). This model seeks to add nuance to the study of participatory effects of political satire by analyzing the influence of these two commonly used distinctive types of satire. In addition, unlike existing studies which mostly treat traditional news use and political satire viewing as distinctive phenomena simply to compare their political effects (Hoffman \& Young, 2011), this model links hard news use with political satire viewing in a single framework to provide a more holistic understanding of the underlying mechanisms between political satire viewing and participation. Research suggests that one of the necessary features of political satire is assumed knowledge of the audience (Caufield, 2008), and consumption of late-night talk shows was positively and significantly correlated with exposure to traditional news (Young \& Tisinger, 2006). This raises the possibility that the viewers of late-night talk shows might be news followers in the first place, so that they can fully appreciate the jokes with laughter. Little empirical research has examined if and how hard news use predicts political satire viewing and how the relationship affects political outcomes. 
Model 3 explores if and how media channel matters in the participatory effects of political satire. In this model, I propose structural relationships in which audience factors (i.e., Democrats, Republicans, education, hard news use) serve as background orientations; self-viewing and curated viewing as stimuli; news attention, political talk, and social media expression as reasoning processes; political knowledge and political efficacy as outcome orientations; and political participation, online and offline, as responses. Research suggests that media consumption activity of today is multifaceted and varied via the proliferating media platforms and channels (Thorson \& Wells, 2015). In the social media environment with user-friendly communication tools, people actively curate media content, by filtering, liking, and reframing the content with personal evaluations (Gil de Zúñiga et al., 2012; Hong, 2016; Mitchell, Kiley, Gottfried, \& Guskin, 2013; Park, 2015). And this socially curated media content in the social media environment is actively consumed (Domingo et al., 2008; Rosenstiel et al., 2017; Villi, 2012), which could influence political attitudes and behaviors (Bode, 2012; Bond et al., 2012; Hong, 2016). Little research, however, has examined the role of social media in political satire viewing and its influence on political outcomes. For the same reason elaborated earlier, this model also links hard news use with political satire viewing in a single framework. 


\section{Chapter 2: Theoretical Review}

\section{Political Satire}

Satire is used as a verbal tool to criticize politics and disclose violations of social norms in a biting and humorous way (Stroud \& Muddiman, 2013). Thus, the role of satire is to express social and political criticism. While news presents politics as something to learn, satire "not only offers meaningful political critiques but also encourages viewers to play with politics, to examine it, test it, and question it rather than simply consume it as information or "truth" from authoritative sources" (Gray, Jones, \& Thompson, 2009, p. 11). Through a comical play with the political, audiences can sense a greater ownership over it and feel more empowered to participate in politics. In other words, by dealing with important social and political issues in a simple, approachable, and entertaining manner, political satire provides audiences with a means for playful engagement with politics (Baym, 2005). And this is what makes political satire a potent form of political expression (Day, 2011; Young, 2016) and even "alternative journalism" (Baym, 2005, p. 259).

Political satire has been an important part of life in democracies for centuries (Young, 2016). In ancient Greek and Roman societies, playwrights used satire to challenge and criticize the power and reveal violations of social norms by political leaders and social institutions. Athenian playwright and satirist Aristophanes employed satire to reveal hypocrisy of the government, shortcomings of political leaders and the futility of war. Roman poet and satirist Juvenal used harsh, bitter satire to scorn all representatives of social deviance in Roman society, often using irony. Given the 
influence they had on elites and citizens alike, people regarded satirists as magicians with respect and fear. In contemporary society satire is perceived as an aesthetic form of expression, with no longer associated with magical power. However, the role of satire remains the same - to express social and political criticism in a playful, entertaining manner (Caufield, 2008).

Thus, political satire can be defined as a "verbal aggression in which some aspect of historical reality is exposed to ridicule." Satire is "a mode of aesthetic expression that relates to historical reality, involves at least implied norms against which a target can be exposed as ridiculous, and demands the pre-existence or creation of shared comprehension and evaluation between satirist and audience" (Fletcher, 1987, p. ix).

Characteristics. Satire has four necessary features - aggression, judgment, play and laughter - which distinguish it from other similar forms of aesthetic discourse such as "humor, comedy, social criticism, parody, burlesque, farce, and travesty" (Test, 1991). Verbal attack and judgment are the most important components of political satire. In other words, satire makes a playful, but still aggressive judgment on power (Becker, 2014), and this is what makes satire a particularly potent form of political communication (Baym, 2005). Satire also evokes laughter to diminish or derogate a subject (LaMarre, Landreville, Young, \& Gilkerson, 2014).

More recently, a fifth characteristic has been added to the four: assumed knowledge of the audience. In other words, the audience is expected to be familiar with the topic and target of the attack and judgment to fully play with the satirist and laugh as an outcome (Caufield, 2008). 
In addition to these necessary criteria for political satire, political communication scholars have also sought to categorize political satire in terms of the amount of political content (e.g., primary political, somewhat political), the level of political message (e.g., implicit, explicit) (Hmielowski et al., 2011), and the satirical tone (e.g., Horatian satire being more gentle and lighthearted, Juvenalian satire being more harsh and bitter) (Holbert et al., 2011).

Political satire is described as "a full-fledged artistic mode ('literary'), not merely a symptom of ill humor or personal spite" (Bogel, 2001, p. 1). While satire shares the central purpose of blending humor and attack (Highet, 1962; Knight, 2004) to ultimately persuade viewers, while both educating and entertaining them, the literary is not a single entity (Holbert et al., 2011; LaMarre et al., 2014).

When it comes to how political satire tries to persuade, the artistic mode largely breaks into two forms of satire: Horatian and Juvenalian (Holbert et al., 2011). Horatian satire is named after Roman poet and satirist Quitus Hoatius Flasccus. This type of satire tends to be grounded on everyday activities and present a form of self-satire with commentary on power and social norms (Highet, 1962). The Simpsons is one good example of horatian satire, since it raises questions of politics through the daily experiences of the family (Cantor, 1999; Holbert et al., 2011). In addition, the program seeks to please but not offend the viewers, but at the same time point out human pretensions and incongruities with a wry smile (Highet, 1962). Therefore, this form of satire is often considered light or gentle compared to juvenalian satire (Sanders, 1971). On the other hand, juvenalian satire, named after another Roman poet and satirist Decimus Junius Juvenalias, has been described as "savage and merciless" (Sanders, 
1971). In other words, this type of satire also seeks to point out human follies with a wry smile, but in a harsh and bitter way, compared to horatian satire. Good examples of this type of satire available in the contemporary media environment include Michael Moore's documentary style (Zimmerman, 2004) and Stephen Colbert's harsh and bitter humor he made about former President George W. Bush and his administration at the 2006 White House Correspondents Association dinner (Holbert et al., 2011).

All these examples reveal that satire is not monolithic and rarely a form of discourse with clear-cut or easily digestible meanings. It rather can be "work" and tends to require a level of sophistication that network television news rarely demands of its audiences (Caufield, 2008; Holbert et al., 2011).

Based on the literature reivew, this study defines political satire as verbal aggression with judgment, while using play to provoke laughter. It functions as a way of pointing to prejudices, injustices, immoral behavior and bad governance. Among the political satire, harsh satire is definded as political satire whose humor is harsh and bitter, mainly relying on rhetorical criticism to seek to offend and derogate the subject, while asking the audience to challenge the power. On the other hand, gentle satire is defined as political satire whose humor is light and gentle, mainly relying on punchline jokes to seek to please, but not offend the viewers, while pointing out human follies.

History of American political satire. The United States has a rich history of political satire in the forms of catroons, novels, and television shows. During the American revolution, political cartoons were used to express contempt toward the practices and policies of British soldiers for frustrated colonists. In the 1870s, Thomas Nast, a cartoonist at Harper's Weekly, contributed to the downfall of Boss Tweed, the 
leader of the corrupt Tammany Hall Democratic party political machine. In the late $19^{\text {th }}$ and early $20^{\text {th }}$ centuries, America's most well-known humorists and satirists, Mark Twain and Will Rogers, wrote stories and columns, focusing on the human foibles such as hypocrisy and inequties in the United States (Young, 2016).

With the advent of television in the $20^{\text {th }}$ century, political satire began to reach a wider audience, although the genre was able to expand its reach and cultural significance to the degree that it enjoys today only after cable television and the Internet came along (Gray et al., 2009; Young, 2016).

Satire faced resistence early in the television era. Even though social criticism was prevalent in the form of satire in the 1950s and early 1960s, the reluctance of television executives to ruffle the feathers of advertisers and cultural and political establishment with objectionalbe types of programming made its transition to the audiovisual medium not easy. Instead, it found a popular audience in print culture and on LP records. Among the examples are $M A D$ magazine and Playboy of 1950s. MAD routinely critized advertisements, films and television shows, while occasionally running social criticism. Playboy ran feature stories on socially conscious comedians such as Lenny Bruce and Mort Sahl. And through LP records, the social satire of these comedians resonated with those who wanted to negotiate their identities in postwar and political culture. The few TV programs that managed to incorporate satire into their formats in the 1960s include NBC's politically-charged “Rowan \& Martin's Laugh-In" and CBS's musically subversive "The Smothers Brothers Comedy Hour." In early 1970s, television networks started to consider to have socially relevant programming, this time, to target upscale audiences, whom advertisers wanted to have. Still, the format they chose for the 
programs is the traditional sitcom format or late-night TV programs rather than biting political satire. Sitcoms of the time, such as "All in the Family," "Good Times" and "Maude" used characters to say funny things in response to socially relevant issues rather than poltical bite. Saturday Night Live came to life with properly neutralized political satire format in the mid 1970s to appeal to mass audiences. Even news-parody programs on cable channels (e.g., Not Necessarily the News on HBO) had little political bite during this time (Gray et al., 2009).

However, things dramatically changed in the state of television comedy in the late 1980s, when FOX unveiled The Simpsons, the first kind of politically-biting television comedy program, to accompany the George H. W. Bush era, which was perceived as an extension of the Reagan years. In the form of animation, The Simpsons has touched on social issues and vices in irreverence and implicit political satire through parodies of most of the televised genres, such as news, ads, and sitcoms, to the extent that it broke television norms and even created an atmosphere in which "social satire must often be both on and about television" in a televised country (Gray et al., 2009, p. 24). The Simpsons is now perceived to be the most important program in creating "the televisual space for the satire TV boom" (Gray et al., 2009, p. 25). Through the 1990s, more cable channels emerged to broaden television talk shows by blending entertainment and serious political talk to make it attractive to mass audiences. Among them, Comedy Central has enjoyed the unique position of establishing the "hybrid entertainment-political talk show" with the introduction of "Politically Incorrect" hosted by comedian Bill Maher, which featured a panel of actors, celebrities, comedians, and politicians to discuss, both seriously and humorously, current events in politics and the media. Later, with "satirical 
treatments of politics" central to its identity, Comedy Central developed satirical programs, such as "The Daily Show," "South Park," "That's My Bush!," "Chappelle's Show," "The Colbert Report," and "Lil' Bush" (Gray et al., 2009, p. 26).

Political satire had exponential growth during the eight years of George W. Bush era. This is because his administration provided limited transparency and access while expanding presidential power (Day, 2011). More importantly, the 9/11 terrorist attacks created an environment where many of government policies went unchallenged by the mainstream media until the Iraq war in 2003. Political satirists did not miss this opportunity to fill in the critical void with deconstruction of real news stories and the government language (Day, 2011).

With the proliferation of social media, political satire has expanded its reach and impact even further, not only through traditional satirical media contents, but through user-generated contents (Day, 2011). For example, in 2012, Jon Stewart attracted the attention and fandom of thousands of young people in China through two clips satirizing North Korean leader Kim Jong-un. These clips led to an increased satirical humor targeting social problems, such as pollution, on social media in China (Young, 2016). In another example, images of "Big Bird" from Sesame Street covered social media with satirical comments, such as "HELP" and "Will Work for Food" during the 2012 presidential election season. These user-generated satirical contents were meant to criticize the negative stance of Governor Mitt Romney, then presidential candidate, on PBS funding. He had stated in the first presidential debate that he was not going to keep on funding for public broadcasting, and Big Bird eventually became a symbol of the debate (Young, Holbert, \& Jamieson, 2014). 
Contemporary political TV satire. Starting with Fox's signature animation, The Simpsons, in 1989, political TV satire has emerged in full bloom. After cable channel Comedy Central's signature late-night talk show, Politically Incorrect, moved to ABC in late 1990s, an adult animated sitcom, South Park, took over the title of Comedy Central's signature program. Unlike The Simpsons, South Park garnered its unprecedented popularity with its crude language and dark humor that satirized a variety of topics. Around the same time, another highly influential satirical show started at Comedy Central. It was The Daily Show, a news satire television program. Once Jon Stewart took over as the host of the show in 1999, the program started to gain popularity especially among young viewers (Gray et al., 2009). It was later rated as one of the top trusted sources of news about politics and government among millennials (Mitchell et al., 2015). Time magazine even named him the most trusted newscaster after Walter Cronkite in the United States based on its online poll in 2009 (Jones \& Baym, 2010). Along with its spinoff program, The Colbert Report, which ran from 2005 to 2014 and was considered a trusted news source among young males (Gottfried \& Anderson, 2014), The Daily Show has been even considered to represent a new kind of journalism, garnering prestigious journalism awards, such as Peabody Awards (Baym, 2005; Borden \& Tew, 2007). In the form of mock news, The Daily Show provides playful, but aggressive criticism and commentary on politics, media and society, while trying to make sense of the news (Basu, 2018; Jones \& Baym, 2010).

What is noticeable is, during an election season, these late-night talk shows draw great attention not only from the public, but also from political candidates and journalists alike, with their satirical comments on the campaigns and candidates in an entertaining 
manner (Baumgartner \& Morris, 2006; Brewer \& Marquardt, 2007; Young \& Tisinger, 2006). Each political debate and speech becomes the subject of these shows (Becker, 2014). Among the representative examples are The Daily Show's coverage of the 2000 presidential election campaign under the title of "Indecision 2000" and of the war in Iraq as "Mess-O-Potamia" (Brewer \& Marquardt, 2007). With more and more people tuning in to late-night talk shows for election news, these programs have even become 'must-be' venues for presidential hopefuls and political candidates to reach the public whom are otherwise unreachable (Baumgartner \& Morris, 2006). Even journalists increasingly found quotes and themes from these satire programs to support their own positions, making satirists legitimate players in serious political discourse, which can be perceived as an disruption of the traditional journalistic model (Brewer, Young, \& Morreale, 2013; Day, 2011; Jacobs \& Wild, 2013).

Research has shown that political satire, more specifically late-night talk shows, has emerged as a main source of political news and information in the past decade or so (Cao \& Brewer, 2008; Gottfried \& Anderson, 2014; Mitchell et al., 2015). The Daily Show with Jon Stewart was considered an "alternative journalism," since it used "satire to interrogate power, parody to critique contemporary news, and dialogue to enact a model of deliberative democracy" (Baym, 2005, p. 261). The Colbert Report's Super PAC segment is often cited as an example of political satire serving as a civics lesson, even greater than news media (Hardy et al., 2014). Recent years have seen a surge in the number of late-night talk shows, especially in the wake of the retirements of the so-called "three late-night pillars" - Jon Stewart, David Letterman, and Jay Leno - that completed in 2015 (Steinberg, 2018). More importantly, with the emergence of Donald Trump as a 
GOP presidential nominee and his election as the $45^{\text {th }}$ president of the United States during the 2016 presidential election, late-night talk shows have become increasingly more politically pointed, even putting on unusual live shows for political events, such as the 2016 presidential election, the 2018 State of the Union address, and most recently, the 2018 midterm elections, for their viewers who apparently turn to them for political news and information (Keveney, 2018; Russonello, 2018). With the pointed commentary on what is ridiculous and absurd in the presence of President Trump, whose public remarks "have been marked by untruths and misleading claims," late-night talk shows are now even viewed as "the antidote to Trumpism" (Grynbaum, 2019; Maza, 2017). In the Trump era, political satirists appear to be doing a better job at covering the Trump administration than traditional journalists who cherish journalistic norms and principles to take everything seriously and try to show all sides of the story (Maza, 2017). Some media scholars even call late-night talk shows the fourth estate (Kilby, 2018) or the fifth estate (Basu, 2018) to highlight these programs' potential democratic impact. Accordingly, it is timely and important to examine the democratic effects of late-night talk shows, the most popular program of political satire, in the contemporary media and political environment.

The currently aired late-night talk show programs include The Tonight Show Starring Jimmy Fallon (NBC), Late Show with Stephen Colbert (CBS), Jimmy Kimmel Live (ABC), Late Night with Seth Meyers (NBC), Late Late Show with James Corden (CBS), Last Call with Carson Daly (NBC), The Daily Show with Trevor Noah (Comedy Central), Conan (TBS), Saturday Night Live (NBC), Last Week Tonight with John Oliver (HBO), and Full Frontal with Samantha Bee (TBS). We know very little about the effects 
of exposure to these late-night talk shows currently on the air. Existing research heavily relied on The Daily Show with Jon Stewart in a rare combination with Late Show with David Letterman, The Tonight Show with Jay Leno, or The Colbert Report. Most of these satirists are off the air now. Therefore, this study operationalizes political satire viewing as watching late-night talk shows. Specifically, it measures the use of those 11 specific late-night talk shows to make a reasonably complete estimate of what programs people were watching and provide a more holistic and complete understanding of the participatory effects of political satire.

Democratic outcomes of late-night talk shows. Research on political satire has surged in recent decades (Cao \& Brewer, 2008; Young, 2016). Scholars in the fields of media studies and political communication have tested the relationships between the consumption of late-night talk shows, mostly The Daily Show, and political outcome variables, such as knowledge, persuasion, perceptions of candidates, efficacy, and participation, to assess whether it is helping or hurting democracy. And the results are mixed, indicating late-night talk shows are not associated with those various forms of citizenship for all sectors of the citizenry at all times (Holbert, 2013; Moy et al., 2005).

Qualitative and cultural studies suggest that political satire is a form of political discourse that can educate, mobilize and engage people in the political process, which ultimately fosters democratic good. This research tradition even presents late-night talk shows, mostly The Daily Show, as a new type of journalism. This is because political satire informs the public of important social and political issues in an entertaining manner, while interrogating and challenging power, criticizing current news, and engaging audiences in the process (Baym, 2005; Jones \& Baym, 2010). Using humor, the 
satirists often perform as public affairs journalists, by trying to better engage audiences with the news, make sense of the news, and ultimately increase audience participation in the political process (Basu, 2018; Faina, 2013). Content analyses of the late-night talk shows confirm many of these arguments. Brewer and Marquardt (2007) content-analyzed 52 episodes of The Daily Show and found that the program provided a substantial amount of political coverage, addressing political topics, world affairs, and the news media. These findings suggest that The Daily Show has the potential to educate its audiences about politics and world affairs, serving as a gateway to the consumption of traditional news and, at the same time, encourage them to critically evaluate the news media. Political satire is also expected to increase audience interest in politics through jokes about political candidates' personalities (Niven, Lichter, \& Amundson, 2003). Through content analyses of the jokes that Jay Leno and David Letterman made during the 2000 presidential election, Young (2004) found that the late-night talk shows tended to focus on candidates' personalities. More recently, employing content and discourse analyses, Kilby (2018) found that Last Week Tonight with John Oliver and Full Frontal with Samantha Bee use frames associated with advocacy journalism, such as solution and motivational building, to facilitate sense of participation in civic and political life.

Effects-based studies, on the other hand, present rather inconclusive findings (Holbert, 2013; Young et al., 2014). This quantitative research has tested for various democratic effects of political satire, employing experimental and survey methodologies. First, this line of research has examined the persuasive effect of political satire on audience opinion, relying mostly on experiments. It often tests if political satire fosters attitude change, examining the audience evaluations of political figures or policies within 
the context of elections. The results are quite mixed, suggesting that elements of satire and individual factors should be part of the inquiry (Baumgartner \& Morris, 2006; Moy, Xenos, \& Hess, 2006). In an experimental study, Baumgartner and Morris (2006) tested the effects of The Daily Show on the candidate evauations of young Americans and found that those who were exposed to a clip of The Daily Show critical of George W. Bush and John Kerry evaluated both candidates more negatively compared to those who were exposed to a clip of traditional TV news coverage of the candidates' shortcomings. In a survey study, Moy, Xenos, and Hess (2005) tested the effect of late-night talk shows on character evaluations of political candidates using the National Annenberg Election Survey data collected from the 2000 presidential election campaign. Using George Bush's appearance on The Late Show with David Letterman, they found that appearances mattered, such that viewers of Bush's appearance with David Letterman showed higher favorability of the presidential candidate. More specifically, they found a strong interaction between late-night talk show viewing and perceptions that Bush really cared about citizens. On the Letterman show, Bush portrayed himself as a caring individual, talking about the death penalty, terrorism, and the environment, and viewers seemed to base their evaluations of him on the basis of perceived caring. On the other hand, Vice President Al Gore's appearance on The Tonight Show with Jay Leno did not produce any priming effects. Late-night talk show viewers held significantly higher assessments of Gore than nonviewers throughout the survey period, suggesting that priming effects of late-night talk shows are stronger for lesser-known candidates than well-known candidates. In a more recent experimental study, Holbert, Hmielowski, Jain, Lather, and Morey (2011) examined how satirical message type (i.e., Juvenalian satire, Horatian 
satire, traditional opinion-editorial) and recipient ability (i.e. high political knowledge, low political knowledge) mattered in the study of political persuasion. Based on the elaboration likelihood model, they found interaction between the message types and recipient ability in relation to oucome variables, such as perceived humor, counterarguing and attitudes about Hillary Clinton's universal health care plan. Findings suggest that political satire should not be treated as monolithic: Recipient levels of knowledge interacted with the message types, such that the horatian (gentle, lighthearted) satire was likely to be most effective in the low-ability condition and least effective in the highability condition. In other words, they found higher degrees of perceived humor and lower degrees of counterarguing associated with horatian satire among the low-ability participants. On the other hand, the juvenalian (harsh, bitter) satire was likely to be most effective in the high-ability condition. The high-ability participants showed significantly lower levels of counterarguing than the high-ability participants who were exposed to the horatian or traditional conditions. More recently, employing an online experiment and a structural equation model analysis, Boukes and colleagues (2015) found the indirect effects of two different forms of political satire (i.e., gentle and harsh) on political attitudes through absorption and decreased counterarguing. For political satire in general, those who were absorbed in satire were more likely to have negative views of the satirical target consistent with the intentions of the satirist. However, the two different forms of satire appeared to work differently in terms of counterarguing. More specifically, gentle or horatian satire (i.e., addressing the topic with a gentle nature of attack) was likely to be less effective in persuasion than harsh or juvenalian satire (i.e., addressing the topic in a harsh satirical way), since the lighter form of satire requires less cognitive effort and 
evokes more humoristic pleasure. More recently, in an experimental study, Greenwood and colleagues (2016) examined the persuasive effects of John Oliver's show in a simulated Facebook environment to demonstrate that exposure to political satire in the social media environment can influence attitudes. By manipulating issue salience (Ferguson video or payday loan video) and the presence of Facebook comments accompanying the video that challenged Oliver's arguements, the researchers found a message-consistent persuasive effect of the show for both high and low salience issues. They also found that message-incongruent comments reduced the persuasive effects of the show when the video dealt with a low-salience issue for the viewer.

This line of research has also tested for the learning effect of exposure to political satire (Feldman, 2013; Hardy et al., 2014; Y. M. Kim \& Vishak, 2008; Benjamin R. Warner, Hawthorne, \& Hawthorne, 2015). Based on the by-product learning hypothesis (Baum, 2002) and gateway hypothesis (Baum, 2003b), Baum argues that entertainment or comedy associated with soft news reduces the cognitive costs associated with learning about politics in the first place. And that low-cost incidental learning leads those viewers to consume more traditional news media about those issues. This way, political entertainment programs can serve as the viewers' gateway to becoming more knowledgeable about politics, which may in turn facilitate political participation. Research suggests that political satire viewing may lead to greater attention to news. In an analysis of time trends using data collected via the National Annenberg Election Survey during the 2004 presidential primary season, Feldman and Young (2008) examined if exposure to late-night talk shows was associated with attention to the presidential campaign and found that viewers of late-night talk shows such as The 
Tonight Show with Jay Leno, The Late Show with David Letterman, and The Daily Show with Jon Stewart paid more attention to the campaign in national network and cable news than nonviewers.

The effects of political satire on political knowledge, however, are rather complicated. In general, the effects of political satire consumption on political knowledge is minimal (Holbert, 2013). To put it another way, political satire may have conditional effects on knowledge through individual factors, such as age and political interest. This is because political satire can take on various forms under the discretion of the satirist in terms of the amount of political content (e.g., primary political or somewhat political), the level of political message (e.g., implicit or explicit), and the tone of criticism (e.g., gentle or bitter) (Hmielowski et al., 2011; Holbert et al., 2011). In an experiment study, Xenos and Becker (2009) examined causal relationships between exposure to The Daily Show and political learning processes and found general support for the gateway hypothesis. Using political interest as a moderator, they found that those who were less politically interested and watched The Daily Show were more likely to pay attention to news media contents, which in turn increased their political knowledge. Based on two national telephone survey data from the Pew Research Center for the People and the Press, Cao (2008) found no significant association between late-night talk show viewing (Saturday Night Live, Politically Incorrect, The Daily Show, Late Show with David Letterman, The Tonight Show with Jay Leno) and political knowledge, but the relationship was moderated by age and education. In other words, political satire viewing can be positively related to political knowledge among less educated people, which is consistent with Baum's (2002) argument for the effect of soft news. Hardy, Gottfried, 
Winneg, and Jamieson (2014) tested if The Colbert Report can serve as a civics lesson or not. In a survey study using data collected during and after the 2012 presidential election, Hardy and colleagues examined the effects of exposure to The Colbert Report's Super PAC clips on perceived and actual knowledge of super PACs and perceptions of viewers about the role of money in politics. Findings suggest that watching the show increased both perceived and actual knowledge of Super PACs more than the news media did. Viewing The Colbert Report was also found to indirectly influence viewers' perception of money in politics. More importantly, this study highlights that learning effects come from viewing the show in general, regardless of levels of political knowledge of the viewers. In an experimental study, Kim and Vishak (2008) investigated if political satire (i.e., The Daily Show) and news media (i.e., television evening news programs) produce different patterns of political information acquisition and information processing in making political judgments on the topic of the U.S. Supreme Court Justice and Chief Justice nomination processes. Findings suggest that The Daily Show was likely to be more effective in learning factual political information than non-political contents, but it was likely to be less effective compared to the traditional news, which influenced political judgment by offering factural knowledge to the respondents. This is because those who viewed The Daily Show appeared to rely on online tally-based political information processing or overall affective impression, which is weakly correlated with recall. On the other hand, those who viewed evening news programs appeared to depend on the memory-based information processing model, which is strongly correlated with recall. These findings highlight the political knowledge gap between entertainment users and news users (Prior, 2007). Most recently, Becker and Bode (2018) examined the 
democratic effects of Last Week Tonight with John Oliver, seen "as a class of new political satire programs" along with Full Frontal with Samantha Bee, on knowledge gain and learning in the case of the net neutrality issue. Using data from an experiment conducted in January 2016, the researchers tested how similarly or differently the net neutrality coverage from Last Week Tonight vs. ABC News influenced knowledge gains, issue importance, and perceived issue difficulty, and found that exposure to the late-night talk show increased knowledge concerning the issue as much as exposure to the hard news program did, but made no significant difference in levels of perceived difficulty of the issue compared to the hard news and control groups. In terms of perception of issue importance, hard news viewers were more likely to find the issue with greater importance relative to the TV satire viewers. What is noticeable here in this line of research, however, is that even though this line of research does not quite agree upon the positive effects of late-night talk show viewing on political knowledge, it has kind of agreed on the notion that the TV satire serves as a gateway to the traditional news.

Lastly, effects-based research has examined the relationship between exposure to late-night talk shows and political participation, one of the most important elements of democratic life. Evidence suggests that the consumption of late-night talk shows instead has an indirect effect on political participation through political discussion and efficacy (Cao \& Brewer, 2008; Hoffman \& Thomson, 2009; Hoffman \& Young, 2011; Lee \& Kwak, 2014; Moy et al., 2005). Using survey data from the Pew Research Center for the People and the Press, Cao and Brewer (2008) examined if and how TV satire programs were associated with some forms of political participation. Findings suggest that latenight talk shows are not monolitic. The researchers grouped The Daily Show and 
Saturday Night Live as "political comedy shows," and Late Show with David Letterman and The Tonight Show with Jay Leno as "late-night talk shows" to examine their participatory effects and found that "political comedy shows" were likely to be positively associated with attending a campaign event and joining an organization, while "late-night talk shows" were not at all. These findings suggest that viewers of harsh satire programs like The Daily Show are more likely to participate in politics. Using national survey data, Moy et al. (2005a) examined the effects of late-night talk shows on various forms of citizenship, such as voting intent, campaign participation, and political discussion, and found that these programs had a significantly positive relationship with interpersonal political discussion. Levels of interpersonal political discussion were greater among those who were politically sophisticated than those who were politically unsophisticated. Also, these late-night programs were likely to be positively associated with campaign participation. Voting intent was likely to be greater among politically sophisticated respondents than politically unsophisticated. Unlike the previous studies that examined the direct effects of political TV satire on political participation, Hoffman and Thomson (2009) demonstrated that the effect of political TV satire on political participation is rather indirect. In a survey study with public high school students, they found that viewers of The Tonight Show or The Daily Show with Jon Stewart were more likely to increase political efficacy, which mediated the relationshp between political satire viewing and civic participation. In a survey study with university students, Hoffman and Young (2011) categorized The Daily Show and The Colbert Report as "satire or parody" and The Late Show and The Tonight Show as "late-night comedy," and examined effects of viewing those two categories of programming on political participation using political 
efficacy as a mediator. Results suggest that consumption of The Daily Show and The Colbert Report was more likely to increase political efficacy, which in turn facilitates political engagement just like traditional TV news use, while consumption of The Late Show and The Tonight Show was not associated with political efficacy and participation at all. More recently, Lee and Kwak (2014) used an online experiment to explore the mediating role of emotion in the participatory effects of political satire. Building on an OS-O-R (Orientation-Stimulus-Orientation-Response) framework, this study found that The Daily Show with Jon Stewart increased levels of political participation by triggering negative emotions toward the government bailout of big corporations. Further, this indirect mobilizing effect was stronger among more educated participants. Lee (2012) even added nuance to the study on the participatory effects of political satire using various features of political discussion (i.e., discussion frequency, online interaction, network size, heterogeneous discussion) as mediators. Building on the communication mediation model, this study employed experimental and survey methodologies to find general support for the mediating role of interpersonal political discussion in the effects of political TV satire on political participation. In the experimental study, viewers of The Daily Show with Jon Stewart expressed a greater intent to engage in frequent political discussion and online interaction, such as reading, posting, discussing, or forwarding comments or messages concerning the government bailout of big companies via webbased technologies, such as e-mail, instant messaging services, audio or video, which was, in turn, positively associated with levels of intent to participate in politics. In the survey study, the consumption of The Daily Show with Jon Stewart and The Colbert Report was significntly associated with discussion frequency, which positively predicted 
political participation. What is interesting to note here is that while both the experimental and survey studies could not find any support for the mediating role of heterogeneous discussion between the late-night talk show viewing and political participation, the survey study suggested a significant mediating role of heterogenous discussion between hard news use and political participation, and the relationship between non-likeminded discussion and political participation was contingent upon the level of education, such that highly educated respondents were more likely to participate in politics, while less educated respondents were less likely to participate in politics. Importantly, the experimental portion of the study separately examined the effects of frequently used mediating variables, such as internal efficacy, cynicism, political interest, and willingness to learn (as a proxy for political knowledge), in addition to the originally proposed mediators and found no mediating effects of those cognitive and attitudinal variables at all. However, the mediating effects of discussion frequency and online interaction were still valid.

Content, delivery and audience differences. Research suggests that not all satirical television programs are created equal (Holbert, 2005), and late-night talk shows also differ in both content and effects (Cao \& Brewer, 2008; Hoffman \& Young, 2011; Holbert et al., 2011). Specifically, The Tonight Show with Jay Leno and Late Show with David Letterman were different from The Daily Show in terms of political content, message level, and satirical tone, resulting in different political outcomes (Cao \& Brewer, 2008; Hoffman \& Young, 2011).

The most systematically studied late-night talk show program is The Daily Show with Jon Stewart. Through a textual analysis of The Daily Show coverage of the 2004 
presidential campaign, Baym (2005) found that The Daily Show uses satire to challenge and interrogate the power, criticize current news, and facilitate a model of deliberative democracy. Based on these findings, Baym (2005) argued that the program is information-rich comparable to network television news and should even further be understood as an "experiment in journalism" or "alternative journalism," since it uses techniques derived from genres of news, comedy and television talk to "revive a journalism of critical inquiry and advance a model of deliberative democracy" (p. 259). Quite a few content-analysis studies demonstrated that the program provided a substantial amount of political information to educate its viewers about politics, public policy, and world affairs (Brewer \& Marquardt, 2007; Fox, Koloen, \& Sahin, 2007). In content-wise, along with The Colbert Report, The Daily Show served as "a primer in rhetorical criticism," in which the satirist deconstructed the day's news, asking the audience to challenge the power, the media, and the current discursive environment, while offering them the tools to critically evaluate, analyze, and interpret media messages (J. P. Jones \& Baym, 2010). On the other hand, other late-night talk show programs, such as the Late Show with David Letterman and The Tonight Show with Jay Leno, tended to rely on punchline jokes, simple caricatures of political candidates, and repetitive themes (Hoffman \& Young, 2011; Young \& Tisinger, 2006). Through a content-analysis of Jay Leno's and David Letterman's jokes during the 2000 general campaign, Young (2004) found that these programs were more likely to focus on personal traits of political candidates rather than public policy. Therefore, while The Daily Show was considered an entertainment program that functions mostly as a political program, the other two, the 
Late Show and The Tonight Show, were rather considered entertainment programs that include political elements (Young \& Tisinger, 2006).

Viewers of The Daily Show were different from those of the other late-night talk shows as well. In a survey study, Young and Tisinger (2006) examined the audience characteristics of three late-night talk shows (i.e., The Daily Show, Late Show with David Letterman, The Tonight Show with Jay Leno) and found that viewers of The Daily Show were more likely to be male, younger, liberal with greater political interest and knowledge and tune in to cable news, whereas viewers of Late Show with David Letterman and The Tonight Show with Jay Leno were more likely to be younger and tune in to local news, but were not significantly associated with political sophistication, interest or ideological leaning.

Those differences in program content and audience characteristic seem to explain why political effects of late-night talk shows are mixed. Cao and Brewer (2008) found that The Daily Show with Jon Stewart was more likely to facilitate political participation, while Late Show with David Letterman and The Tonight Show with Jay Leno were not. Hoffman and Young (2011) demonstrated that The Daily Show and The Colbert Report were more likely to increase political efficacy, thereby encouraging political participation, whereas The Late Show and The Tonight Show were not associated with those political outcomes at all. Research suggests that audience characteristics and satire type can even influence the effects of late-night talk show viewing. In a survey study, Young (2004) examined the effects of Late Show with David Letterman and The Tonight Show with Jay Leno on viewers' perceptions of the political candidates and found that the effects of the jokes on candidate trait ratings were moderated by political knowledge and 
partisanship. In an experimental study, Holbert and colleagues (2011) manipulated the type of satire (i.e., horatian, juvenalian) and level of knowledge and found that horatian satire (lighthearted and gentle) was least effective or persuasive with those with high knowledge, but most effective with those with low knowledge. On the other hand, juvenalian satire (harsh and bitter) was most persuasive with those politically knowledgeable.

These findings suggest that it is important to know who is tuning in to view which late-night talk shows in the study of political satire to better explain its democratic effects. Existing research, however, has generally failed to systematically examine the link between audience characteristics, late-night talk show viewing and political outcomes.

\section{Social Media and Political Participation}

With the proliferation of social networking sites, social media have emerged as a main source of political news and information. For example, Facebook is the most common source of news about politics and government among millennials (Mitchell et al., 2015; Shearer \& Gottfried, 2017). Accordingly, social media have received great scholarly attention for their role in media consumption and its influence on democratic citizenship, and research has shown that social media use for news and information mobilizes citizens (Boulianne, 2015). In a meta-analysis of 36 studies testing the relationship between social media use and participation in civic and political life, Boulianne (2015) found that more than 80 percent of the studies showed a positive link between the two. 
These participatory effects of social media derive from a series of related attributes of the new media. First, it is often said that the interactive feature of the Internet-enabled social media, beyond temporal and geographical boundaries, plays an integral role in political outcomes (Mitchelstein \& Boczkowski, 2010). This is mainly because the interactive feature of social media allows users to express and exchange their political opinions through user-friendly communication tools for commenting, sharing, and posting (Gil de Zúñiga et al., 2012; Hong, 2016; Mitchell et al., 2013; Park, 2015). In a survey study, Gil de Zuniga, Jung, and Valenzuela (2012) examined the effects of news consumption on social networking sites on civic and political participation. Results show that social media use for news and information had a significant and positive effect on people's social capital and civic and political behaviors, both online and offline, which involve writing to a politician, attending a political rally, making a campaign contribution, subscribing to a political listserv, and signing up to volunteer for a campaign. In a survey study, Hong (2016) examined the effects of social media, such as Facebook, Plurk, and YouTube, on political efficacy within the context of the 2012 Taiwanese presidential election. Results suggest that the more the respondents watched political videos, the more they shared the videos on social media, which led to higher discussion of the issue and hence greater understanding of politics. In a survey study, Park (2015) examined the relationships between different types of social media use (i.e., information seeking, social interaction, and recreation) and distinct types of participation (i.e., online expressive, offline expressive, and offline collective participation) and found that informational motives are positively related to online and offline expressive participation, such as posting political opinions on social media, forwarding political 
messages to others through social media, and discussing the election on social media. In a telephone study conducted in Hong Kong, Chan (2016) focused on various interactive aspects of Facebook to test its effects on political behaviors. The author examined the effects of Facebook network size, connections with public political actors, use for news, and political expression on political protest and participation. Results show that Facebook network size had direct effect on political protest, while Facebook connections had direct effect on political participation. Both network size and connections with public political actors also had significant indirect effects on protest and participation through Facebook news use, expression and political efficacy.

Further, this interactivity-driven sharing culture in the social media environment can facilitate incidental learning, thereby increasing engaged citizenry (Boulianne, 2015). Social media provide users a space where they can gather news and information not only from traditional news media, but also from family and friends to share in their social networks (Dimitrova, Shehata, Strömbäck, \& Nord, 2014; Gil de Zúñiga, Copeland, \& Bimber, 2014; Park, 2015). This social sharing increases inadvertent exposure not only to political information, but to political difference to facilitate political discourse, which in turn increases political participation (Kim, 2011; Kim et al., 2013). Pew Research Center reports also support this incidental learning hypothesis: Half of Facebook users get their news from that social media platform alone, and most of the Facebook news users encounter news incidentally as by-product of their social activities (e.g., liking, commenting, sharing, laughing) and through their social network ties (DeSilver, 2014; Grieco, 2017). In other words, even if people use social media for entertainment purpose, they may stumble upon news inadvertently, while surfing the feed. And this inadvertent 
encounter with news and information would increase traditional news consumption and political discourse, thereby facilitating political outcomes (Baum, 2003b; Chan, 2016; Kim, 2011; Kim et al., 2013; Tang \& Lee, 2013). In an online survey, Kim, Chen, and Gil de Zuniga (2013) tested if and how incidental news exposure on the Internet (e.g., through search engines, SNSs, and advertisements) and relative entertainment use (i.e., preference for entertainment over news) influence online and offline political participation. The results show a significant positive relationship between incidental news exposure and online and offline participation, but a negative relationship between relative entertainment use and participation, online and offline. Further, the effect of incidental news exposure on online participation was stronger for those who consumed less entertainment online. Inadvertent exposure to news and information on social media can also facilitate political discourse among people with different points of view to facilitate political participation. In a survey study, Kim (2011) examined the relationship between social media use and exposure to political difference and found that online political messaging had the potential to expand one's political view and facilitate political discourse across partisanship through increased inadvertent cross-cutting exposure. In an experimental study, Messing and Westwood (2014) examined if and how social media influence partisan selective exposure and found that presence of social endorsment (i.e., number of recommenders) was a stornger predictor of news selection than news source cues. Further, the presence of social endorsements reduced partisan selective exposure, altering the way partisans select news contents. Indeed, partisans exposed to social endorsements were most likely to select news stories from ideologically asynchronous sources. Tang and Lee (2013) demonstrated that this heterogeneous network online has 
the potential to facilitate political participation. The authors examined the relationship between social media use and political participation among young people, focusing on diverse aspects of Facebook, such as the effects of time spent on Facebook, shared political information exposure, network size, network structural heterogeneity, and direct connection with public political actors. Results show that those with high on the network structural heterogeneity, connection with public political actors, and exposure to shared political information were more likely to participate in political activities.

Lastly, this content sharing in the form of personal endorsement on social media (Young et al., 2014) increases the level of trust in and engagement with shared content and hence facilitates political engagment (Bode, 2012; Bond et al., 2012). In other words, news and information encountered on social media platforms can be more persuasive and influential than news and information from the traditional media platforms, such as newspapers and television, since it comes from family and friends, whom they trust (Bode, 2012; Hong, 2016; Rosenstiel et al., 2017). In an experimental study, Rosenstiel and colleagues (2017) examined the elements of trust in news on social media by manipulating the source of information and found that the sharer's credibility was more important in choosing what to read compared to the credibility of media source. In other words, in the social media environment, it does not matter whether the information comes from a reliable or reputable media source or a fictional one. As long as the post is made by those whom social media users trust, the users are more likely to read, believe, share, and recommend the post. In a survey study with undergraduate students, Bode (2012) examined the effects of Facebook on political participation and found that those who were intensely engaging with his or her Facebook community were more likely to 
participate in various types of politcal behaviors, such as voting, online and offline participation. These findings suggest that personal trust in the socia media environment may increase the level of intimacy users feel and the level of engagement in which they participate in the Facebook community, which ultimately facilitates political participation. In other words, compared to media contents with more balanced perspectives, these tailored social messages through two-step or even $\mathrm{N}$-step flow in a multitude context on social media can be more effective in persuading, thereby influencing political attitudes and behaviors (Bond et al., 2012; Cacciatore, Scheufele, \& Iyengar, 2016; Hong, 2016; McQuail, 1987). In an experimental study employing 61 million Facebook users in a real-world setting, Bond and colleagues (2012) examined the social influence effects of social media networks during the U.S. congressional elections in 2010. Users were randomly assigned to a 'social message' condition, an 'informational message' condition, or a control condition. Those in the social message group were shown a statement at the top of their 'News Feed,' which encouraged the users to vote, offered a link to find local polling places, showed a clickable button saying 'I Voted,' presented a counter showing the number of Facebook users who had previously reported voting, and showed up to six randomly selected 'profile pictures' of the users' Facebook friends who had already clicked the 'I Voted' button. Those in the informational message group were shown the message, poll information, counter and button, but no pictures of friends. The control group did not receive any message at the top of their News Feed. The results show that the political mobilization messages directly influenced political selfexpression (clicking the 'I Voted' button), information seeking (clicking the polling-place link) and real-world voting behavior (matched to publicly availabe voter records) of the 
users. More importantly, the messages not only influenced the users who received the messages, but also the users' friends, and friends of their friends. Further, the effect of social transmission on real-world voting was stronger than the direct effect of the mobilization messages.

The active audience involvement in media content distribution via political expression on social media and the strong effects of the shared, personalized contents require media scholars to turn their attention to the concept of curation and its nature and process in relation to media consumption in the highly networked media landscape. Curation is hardly a new concept in the fields of journalism and mass communication. In the practice of gatekeeping, journalists select the information to publish under the influence at various levels, such as the individual (e.g., demographic profiles, role conceptions), the institutional routine (e.g., information verification, deadlines), the organizational (e.g., ownership structure), the social institutional (e.g., sources, government, advertisers), and the social system levels (e.g., cultural values) (Shoemaker \& Vos, 2009). Basically, journalistic gatekeeping is about journalists curating news by selecting from an unlimited amount of information and deciding how to frame, emphasize, place and promote the information under those influences (Thorson \& Wells, 2015). With the rise of the Internet and social media, however, construction and dissemination of news and information is no longer solely in the hands of journalists, news organizations, and opinion leaders (Park \& Kaye, 2018; Vos \& Heinderyckx, 2015), and that is what challenges the study of media effects (Thorson \& Wells, 2015). The proliferating channels and platforms through which audiences experience media contents (Thorson \& Wells, 2015; Vos \& Heinderyckx, 2015) and the unprecedented audience 
autonomy in choosing what to consume in the high-choice media environment (Prior, 2007) have democratized the curatorial process, opening up a near-limitless number of information flows, which may present the same media contents differently, leading to different media experiences and hence different media effects. As social media offer new, easy ways for people to access, select, assemble, reframe and distribute media contents, the curatorial process is now grounded on the opinions not only of the experts or professionals, but also of laymen or ordinary citizens, including family and friends (Edmundson, 2015; Hope \& Turner, 2015; Park \& Kaye, 2018). Further, research suggests that social media users are more likely to trust news and information curated by their family and friends than by news media (Rosenstiel et al., 2017). Therefore, it is important to examine the role of curation in media consumption in today's highly networked media environment and its implications for democratic citizenship. Little research has taken an approach to capture the unique nature of curated viewing in relation to democratic outcomes in the study of political satire.

Curation. Curation can be defined as "the ability to distill the most relevant information on a specific topic for a specific audience" (Valenza, Boyer, \& Curtis, 2014, p. 51) and "the ability to find, to filter, to evaluate, to annotate, to choose which sources are valuable" (Valenza et al., 2014, p. 56). Curation is also defined as behaviors of "aggregating, sharing, ranking, tagging, reposting, juxtaposing, and critiquing contents on a variety of platforms - from personal blogs to open video-sharing sites to social network profile pages" (Clark \& Aufderheide, 2009, p. 6). What these definitions basically say is that curation is a practice where individuals add their qualitative evaluations to what they 
gather and organize (Rosenbaum, 2011), and that is what makes curation different from mere distribution (Edmundson, 2015; Hope \& Turner, 2015; Krysa, 2006).

Originated from the Latin root of curate, 'curare or to care,' meaning being responsible for the care of souls (Hope \& Turner, 2015), curation has transformed in the focus, nature, and process over the past decades (Hope \& Turner, 2015; Krysa, 2006; Villi, 2012). In the contemporary world, curation has been concerned with more secular manifestations of the practice ranging from the curation of artworks in galleries and museums (Edmundson, 2015), to curation of contents in the library (Valenza et al., 2014), to curation of big data in computer science (Goble et al., 2010). More importantly, with the rise of the Internet and social media, the site for curation has been expanded to include cyberspace, and the focus of curation has been expanded as well to include processes and dynamic networked systems in addition to mere objects (Krysa, 2006). Further, the abundance of contents and the highly interactive digital media environment have allowed multiple actors to work in the curatorial process, and curation is no longer solely in the hands of professionals with knowledge and expertise (Hope \& Turner, 2015; Thorson \& Wells, 2015). Instead, the curatorial process involves the inputs of dynamic networked systems and their members, which ultimately influences the selection (Krysa, 2006; Popova, 2011). Simply put, we live in the "age of curation," where virtually every one of us can collect and display tangible and intangible things in a way that influences how others view the world (Edmundson, 2015; Van Buskirk, 2010), enjoying the socalled "democratisation of curation" (Hope \& Turner, 2015).

Journalistic curation. Curation has its deep roots in journalistic practice, and the journalism field has not been immune to all these changes made in the curatorial process. 
Journalists have long operated as curators in content production and dissemination (Shoemaker \& Vos, 2009; Snider, 1967; Thorson \& Wells, 2015; Vos \& Heinderyckx, 2015; White, 1950). Based on journalistic norms, institutional routines, and news values, journalists select issues to focus on and decide how to construct media messages (Shoemaker \& Vos, 2009). The media contents selected, produced, and disseminated later influence audience opinions, attitudes, and behaviors (Graber \& Dunaway, 2015; McCombs \& Shaw, 1972; Shoemaker \& Reese, 2014), often linked to democratic citizenship (Prior, 2007). Specifically, news use increases political knowledge and efficacy, thereby facilitating political engagement (Delli Carpini \& Keeter, 1996; Verba et al., 1995).

However, in the digital media environment, curation of news is no longer the preserve of news media or opinion leaders. Instead, audience members share the curatorial power in the news-making and news-distributing processes (Popova, 2011; Thorson \& Wells, 2015; Van Buskirk, 2010; Villi, 2012). Further, research has shown that consumption of user-distributed news and information on social media is more likely to engage the readers with the media contents than news from traditional news media (Rosenstiel et al., 2017) and hence facilitate political outcomes (Boulianne, 2015). This trend has recently led a handful of media scholars to pay attention to the concept and process of curation in relation to news consumption and distribution in the digital media environment to examine what facilitates social media engagement (Park \& Kaye, 2018; Villi, 2012) and what constitutes media effects in the contemporary networked media ecosystem (Thorson \& Wells, 2015). 
Social curation. Villi (2012) calls audience involvement in consuming and distributing news media contents in the social media environment "social curation," which can increase the circulation and consumption of various kinds of media contents online. And social curation can be practiced through "providing links to online media contents by using e-mail messages, tweeting, tagging, 'recommending' (Facebook Recommend button), '+1 ing' (Google +1 button) or by using social reader apps" (Villi, 2012, p. 615). Simply put, social curation involves gathering, aggregating, and distributing media contents in the networked environment. And the digital media environment allows people to have horizontal communication, through which they curate media contents to serve their family, friends, or acquaintances (Marshall, 2009).

It is important to note that social curation of news and information is not a new phenomenon either, since as the two-step flow model (Katz \& Lazarsfeld, 1955) indicates, people shared news and information via word-of-mouth long before the Internet came along. The difference here is that while the traditional version of social curation mainly relies on verbal description and distribution, the Internet-based social curation not only provides people unprecedented autonomy in reframing media contents and shaping information flows, but also comes with ready-to-use sharing and recommendation tools. In other words, it is much easier to share news and information in the social media environment (Hermida, Fletcher, Korell, \& Logan, 2012; Villi, 2012).

Audiences of the networked communities formed through various channels and communication tools (Marshall, 2009) consume socially curated media contents as a communal, shared social experience (Villi, 2012). Further, when audiences share or distribute the media contents, they actively reshape and reframe the contents by adding 
personal judgment and social significance (Hermida et al., 2012). And these socially curated media contents are actively consumed to the point where media companies are encouraged to practice "curation optimization" to facilitate social sharing through peerto-peer distribution (Domingo et al., 2008; Villi, 2012).

Curated flows. With the proliferating media channels and platforms in mind, Thorson and Wells (2015) examined flows of news and information in the contemporary media environment and identified five different pathways called "curated flows" through which audiences experience news. They include a) "Journalistic curation," in which journalists curated information based on their values and routines; b) "Social curation," in which individuals are influenced by their social networks; c) "Personal curation," in which individuals curate their own information environments, enjoying more autonomy than ever in selecting and shaping media contents; d) "Strategic curation," in which strategic actors, such as politicians, companies, and interest groups, curate media contents to address publics directly; and e) "Algorithmic curation," in which computer algorithms and other modes of decision-making influence the display of media contents on users' devices and platforms. Based on the curated flows framework, the authors argue that the growing supply of media sources, platforms, and channels and the proliferation of news and information have increased the number of actors who can actively select, shape, and curate media contents, and these changes in the media environment require media scholars, especially those studying media effects, to pay more attention to the question of "exposure to what." In other words, today's media experience is multifaceted and varied and it is getting more difficult to explain media effects without fully understanding who receives what messages from where and how (Lee, 2013; Thorson \& Wells, 2015). 
The extant media effects research to date has generally examined the effects of the curated flows outlined above on democratic outcomes, mostly focusing on news (Bode, 2012; Cho et al., 2009; Delli Carpini \& Keeter, 1996; Gil de Zúñiga, Molyneux, \& Zheng, 2014; Park \& Kaye, 2018; Prior, 2007; Rosenstiel et al., 2017; Shah et al., 2007; Verba et al., 1995). No study, however, has examined, yet, the political effects of political satire viewing with curation in mind.

As mentioned earlier, digital media tools make it easy for ordinary users to consume and curate news and information by aggregating, analyzing, reorganizing, reframing and sharing (Clark \& Aufderheide, 2009). As the technological innovations have tremendously transformed the media environment and media experience accordingly varies across the media channels, a handful of media scholars have started to examine the effects of different media channel use for news and information (e.g., print, television, online, social media) and found discrete democratic outcomes (Andersen, Bjarnøe, Albæk, \& De Vreese, 2016; Dimitrova et al., 2014; Moeller et al., 2014; Shah et al., 2007).

Media channel matters. Using two-wave panel surveys collected in Sweden, Dimitrova, Shehata, Strömbäck, and Nord (2014) examined whether and how various forms of digital media use influence political participation and knowledge. The different forms of digital media use included online news (national TV, Tabloids, National dailies), party web sites (left-wing party web sites, right-wing party web sites), and social media. Items for social media use included reading blogs about politics or current affairs, writing text on one's own blog about politics or current affairs, commenting on or discussing politics or current affairs on the Internet, following a politician or party on 
Twitter, Facebook, or YouTube. The results show that social media use for political purposes increased political participation along with party web sites, while online news had no effect on participation. Using a four-wave panel data collected in the Netherlands, Moeller, de Vreese, Esser, and Kunz (2014) examined the effects of TV news, newspapers, and online news sources (use of webpages of a newspaper, a TV news show, and online news only source) on internal efficacy and turnout among adolescents. The results show that newspaper use and online news use were significant predictors of efficacy, which, in turn, predicted turnout, while TV news use was not. Interestingly, when civic messaging (e.g., posting messages or videos on social media) was included in the model, the online political communication mediated the participatory effect of online news use. Using panel data, Lee, Shah, and McLeod (2013) examined the various roles communication plays in political socialization of youth and found strong online pathways to political participation such that conventional online news use (e.g., websites of mainstream news organizations), nonconventional online information (e.g., blogs) and digital media use for political expression facilitated participation, whereas traditional news use (e.g., TV news, newspaper) and face-to-face discussion were not associated with participation. More recently, Andersen, Bjarnoe, Albaek, and de Vreese (2016) examined the indirect process via which different news types (i.e., hard TV news, soft TV news, printed broadsheets, online broadsheets, printed tabloids, and online tabloids) influence online and offline political participation during non-election and election time. The results show that the indirect effects depend on media type and context, and knowledge influences political participation through political efficacy. Specifically, print 
tabloid use was generally negatively related to political participation, whereas its online version was positively associated with participation, both directly and indirectly.

These findings suggest that socially curated media consumption in the digital media environment is more likely to mobilize media consumers, whereas personally curated media consumption in the traditional media environment is less likely to, or even negatively, influence political participation.

Compared to the literature on news use and social media, little research has explored the role of social media in consumption of political satire and its implications for political outcomes. Given the growing popularity of social media as a source of news and information and the highly interactive nature of social media, it is important to examine if the social media environment offers different experiences in consumption of political satire than television. Further, this new avenue of research may help us untangle the effects of poltical satire on political participation better, moving beyond conventional cognitive and attitudinal elements, which are often included in the strict media effects paradigm. For example, Baym and Shah (2011) tracked the online circulation of a set of environmental advocacy clips first broadcast on The Daily Show and The Colbert Report and found that citizens and advocacy groups repost and shared them on numerous websites including social media platforms and online archives of information. These findings demonstrate that late-night talk shows have the potential to serve not only as informational resource, but also as affinity (e.g., collective action) and deliberative resources, and intrinsic features of social media, such as instant messaging, may mediate the effect of political satire on participation as well.

\section{Theoretical Framework}


Early media effects research adopted a simple S-R (Stimulus-Response)

framework. These studies assumed that media effects were the sole attribute of the media themselves and accordingly suggested that the media had either a strong or limited effect on individual opinions, attitudes and behaviors (Lazarsfeld, Berelson, \& Gaudet, 1948; McQuail, 1987; Sparks, 2010). The Payne Fund studies of 1920s suggested the powerful influence of movies on the behavior of children. Combined with the study on the impact of the "War of the Worlds" radio broadcast on its audience in the 1930s, these studies established widespread theories of "a legacy of fear" or "a magic bullet," suggesting that the media were dangerous and could have powerful, relatively uniform effects on the viewers (Sparks, 2010). More recently, television was thought to be a culprit for the decline of civic participation (Putnam, 1995), and televised violence was considered to cultivate a view of a "mean world" (Gerbner, Gross, Morgan, \& Signorielli, 1980). On the other hand, "The People's Choice" study introduced a new era of minimal effects in the study of media effects. The classic voting study during the 1940 presidential election suggested that media exposure is rather minimal or limited (Lazarsfeld et al., 1948).

This direct media effects approach has been criticized on the grounds that it failed to account for individual differences in motivations for and patterns of media use (Rubin, 1984, 2009) and cognitive processes that underlie between media use and its outcomes (Markus \& Zajonc, 1985). Accordingly, the focus of media effects study shifted away from the "mechanistic," "magic bullet" approach to "phenomenistic" one to consider various functions and uses of the media and audience activities in media uses and effects (Blumler, 1979; Klapper, 1963; Rubin, 2009). 
As media effects scholars began to take into account individual, social and cultural circumstances and personal-psychological processes in media uses, moving away from mainly focusing on the amount of media exposure, an O-S-O-R (background Orientation-Stimulus-Outcome orientation-Response) model was established to explain the dynamic relationships underlying media use and effects (Markus \& Zajonc, 1985; McLeod, Kosicki, \& McLeod, 1994). The uses and gratifications research has shown that individual motives condition media use and effects and information and entertainment motives are central to media selection (Rubin, 1984). Combined with viewing patterns of "habitual" or "ritualized," these motivations affect not only media consumption, but also information processing (Eveland, Shah, \& Kwak, 2003) and audience behaviors (Papacharissi \& Rubin, 2000; Rubin \& Perse, 1987). Individual factors, such as informational use of the media and political interest, influence information processing, thereby increasing political knowledge (Eveland et al., 2003) and accordingly behaviors such as political participation (Mcleod et al., 1996; Park, 2015). Therefore, individual orientations $(\mathrm{O})$ precede media use $(\mathrm{S})$, which, in turn, influences attitudes $(\mathrm{O})$, thereby changing behaviors $(\mathrm{R})$.

Communication mediation model. More recently, political communication scholars have demonstrated that political conversation largely mediates the effects of media use on political outcomes, such as civic and political participation (Cho et al., 2009; Eveland, 2001; Eveland et al., 2003; Hardy \& Scheufele, 2005; Mcleod et al., 1996; Scheufele, 2002; Shah et al., 2005, 2007). McLeod and colleagues (2001) coined the term "communication mediation model," positing that the effects of media on political outcomes are strong but largely through their effects on individual 
communication behaviors (e.g., information seeking, interpersonal communication) (Shah et al., 2005, 2007). By incorporating mass and interpersonal communication into the processes leading to participatory behaviors, this model highlights information seeking process and political conversation among citizens, online and offline, as key variables in the study of media effects on civic and political engagement (Shah et al., 2005). This model also posits that these communication variables largely channel the effects of background orientations, such as demographic, dispositional, and structural factors, on cognitive processes and behavioral responses (Sotirovic \& McLeod, 2001). Further, in the context of a political campaign, political talk, online and offline, largely mediates the effect of political media contents on political participation, since it serves as both "a source of information and a site of deliberation" (Shah et al., 2007, p. 698).

Unlike the traditional media effects approach, which understands the effects of media, mainly focusing on media consumption, not expression, this model treats both media use and political expression as sources of information and the triggers for reflection on media contents and public affairs, which, as a result, facilitate democratic engagement. This model places expression - both offline and online, written and spoken - at the center of civic and political engagement, recognizing the difference between traditional, interpersonal communication and new, online-based self-expression (Shah, 2016; Shah et al., 2005, 2007).

Cognitive mediation model. Research has shown that informational use of media facilitates information processing, which results in increased knowledge and awareness of civic and political opportunities and objectives (Eveland et al., 2003). In this cognitive mediation model, political discussion is a function of interpersonal 
communication as well as a product of the intrapersonal reflection (Cho et al., 2009; Pingree, 2007). People organize their viewpoints and positions by elaborating on news information they are exposed to before, during, or after discussion (Eveland, 2004). Therefore, political discussion is a self-reflective "consequential behavior" (Southwell \& Yzer, 2007, p. 422). This is especially true when interpersonal discussion is a part of the campaign communication process, where information is "reconsidered, elaborated, and clarified" (Cho et al., 2009, p. 74). Exposure to political information increases informational use of media and political talk, which results in greater participation (Cho et al., 2009; Shah et al., 2007).

O-S-R-O-R framework. The above-mentioned mediation models, when combined together, complement Markus and Zajonc's (1985) O-S-O-R framework to fully explain the interrelated mediating processes between media use and civic and participatory behaviors (Chan, 2016; Cho et al., 2009; Jung et al., 2011; Shah et al., 2007). The communication mediation model highlights the mediating role of interpersonal communication about politics in the effects of media messages on outcome orientations (e.g., political efficacy, political knowledge) and behavioral responses (e.g., civic and political participation) (Mcleod et al., 1996; McLeod et al., 2001; Shah et al., 2005, 2007). The cognitive mediation model focuses on the mediating role of mental reflection as part of interpersonal and intrapersonal communications in the effects of informational use of media on political learning (Eveland, 2001).

Taken together, the communication mediation model (McLeod et al., 2001; Shah et al., 2005; Sotirovic \& McLeod, 2001) and the cognitive mediation model (Eveland, 2001) extends the O-S-O-R framework to situate a new mediating step, "reasoning," 
between stimuli and outcome orientations, thereby creating the O-S-R-O-R (background Orientation-Stimulus-Reasoning-Outcome orientation-Response) framework of media effects.

The extended O-S-R-O-R framework postulates that interpersonal and intrapersonal communications constitute reasoning processes that represent deliberative processes through mental elaboration, thereby mediating the effect of news use on cognitive and behavioral political outcomes (Cho et al., 2009; Shah et al., 2007). Further, by differentiating the cognitive processes in the stimuli stage from the deliberative processes in the reasoning stage, this framework provides stronger explanatory power above and beyond traditional theories (Shah et al., 2007). Therefore, this study uses this O-S-R-O-R framework to systematically examine the participatory effects of political satire viewing.

Theoretical model. Integrating prior findings of a positive relationship between news use and political participation and existing findings of a positive association between political satire viewing and participation based on an O-S-R-O-R framework, the present study proposes overarching conceptual models in which audience factors (i.e., Democrats, Republicans, education, alternative concepts of citizenship, hard news use) guide political satire viewing, and reasoning variables, such as information processing activities (i.e., news attention, political talk, social media expression), and outcome orientation variables, such as cognitive outcomes (i.e., political knowledge, political efficacy), channel the impact of audience factor-driven political satire viewing on participation. For a note, these interrelated mediating relationships based on an O-S-R-O- 
$\mathrm{R}$ framework have been documented in the study of news use and participation (Chan, 2016; Jung et al., 2011).

\section{The first orientations: Education, partisanship, alternative concepts of}

citizenship, and hard news use. Ample research suggests that individuals select certain media among all that is available to them based on their needs and motives (Blumler \& Katz, 1974; Krcmar \& Strizhakova, 2009), and social, cultural, and environmental circumstances, along with individual factors, guide and filter media behavior and possibly influence the effects of media (Lee, 2013; Rubin, 2009). Simply put, media effects derive from "the set of structural, cultural, cognitive, and motivational characteristics the audience brings to the reception situation that affect the impact of message" (McLeod et al., 1994, p. 146).

The link between news use and political participation has been well established (Choi, 2016; Eveland \& Scheufele, 2000; Hyun \& Kim, 2015; Kim et al., 2013; Mcleod et al., 1996). However, a vast majority of these studies have overlooked which individual factors (e.g., demographics) predict such media consumption habits. In the study of political satire, there is also remarkably little understanding of how individuals' preexisting characteristics are associated with political satire viewing and how this exposure influences political behaviors (Hmielowski et al., 2011). This study, therefore, situates education, Democrats, Republicans, and alternative concepts of citizenship as the first “O” in Model 1, and education, Democrats, Republicans, and hard news use as the first "O" in Model 2 and Model 3, expecting that they will influence an individual's political satire exposure and its democratic effects. And each of these individual factors were selected for the following theoretical reasoning. 
Firstly, education. A handful of studies suggest that the effects of political satire might depend on recipient levels of political sophistication, because it requires a certain level of expertise. For example, those low in political knowledge tend to avoid political satire programs, such as The Daily Show and The Colbert Report, because they cannot understand the jokes (Young, 2013). As for the effects on persuasion, horatian satire is likely to be most effective among less politically knowledgeable people, whereas juvenalian satire is likely to be most effective among more politically knowledgeable ones (Holbert et al., 2011). In addition, education appears to moderate the relationship between late-night talk show viewing and political oucomes, such that less educated people are more likely to learn from political satire viewing (Cao, 2008), and political satire viewing is likely to mobilize those high in education more than those low in education (Lee \& Kwak, 2014). These inconsistent findings suggest that more scholarly attention needs to be paid to the role of recipient level of political sophistication. Political knowledge is one of the key cognitive outcome variables commonly used in the media effects study (Delli Carpini \& Keeter, 1996; Hardy et al., 2014; Hardy \& Scheufele, 2005; Moeller et al., 2014), and this study also uses the variable as one of the outcome orientation variables. Since research has shown that education is closely related to political knowledge and engagement (Bennett, 1995; Krause, 1997; MacKuen, 1984), this study employs education as an indicator of political sophistication.

Secondly, partisanship. Partisan selective exposure is a well-documented phenomenon in the United States. Democrats and Republicans are more likely to gravitate toward media contents that support and reinforce their pre-existing viewpoints (Stroud, 2011), which promotes political talk and political efficacy, resulting in increased 
political engagement (Choi, Warner, \& Jennings, 2018). This pro-attitudinal exposure along party lines is so strong that it even holds for nonpolitical subjects such as crime and travel (Iyengar \& Hahn, 2009). At the same time, this selective exposure to attitudeconsistent information is not intrinsically linked to selective avoidance of attitudechallenging information (Garrett, 2009; Garrett \& Stroud, 2014). As partisanship is such a salient feature of social identity, it influences the way partisans react to attitudeinconsistent satirical messages. For example, Republicans are more likely to appreciate pro-attitudinal satirical humor, in which the satirist attacks political groups or politicians who they oppose, while Democrats appreciate both pro- and counter-attitudinal satirical humor (Peifer \& Holbert, 2016). Further, partisan political satire exposure might influnece levels of internal political efficacy of the viewers based on their party affiliation, such that after watching Democrat-directed satirical humor, Republicans are more likely to have higher levels of internal political efficacy, while Democrats are more likely to have lower levels of political efficacy (Becker, 2014). While a handful of studies suggest that viewers of late-night talk shows are more likely to be liberal (Choi et al., 2018; Gottfried, Matsa, \& Barthel, 2015; Moy et al., 2005; Young \& Tisinger, 2006), little research has examined if and how party affiliation guides political satire viewing and how the relationship influences political participation.

Thirdly, alternative concepts of citizenship. An emerging line of research suggests that with the growing supply of media sources and the proliferation of political information, public perception of news use in relation to citizenship norms has changed (Bennett, 2008; Bennett et al., 2011). While the traditional concepts of citizenship posit that it is the civic duty to keep informed of public affairs by following news (McCombs 
\& Poindexter, 1983; Poindexter \& McCombs, 2001), alternative concepts of citizenship posit that good citizens should not embrace "primarily one-way consumption of managed civic information (news and political ads)" (Bennett et al., 2011, p. 840) and rather use digital media to have two-way or interactive communication to get informed and engage in political activities (Bennett et al., 2011). Said another way, activities occurring in the course of everyday life can also be considered political, from which people can learn democratic values (Thorson, 2012). Although there are theoretical reasons to expect that the dutiful communication logic (i.e., news media are still a dominant source of news and information) of the traditional concepts of citizenship increases the likelihood of engaging in various forms of political participation, it is not clear to what extent the traditional or alternative communication logic (i.e., news media are no longer a dominant source of news and information), media use, and political participation are related. In other words, despite increased research on media use and participation, the empirical connection between perception of news use in relation to citizenship norms, media use, and participation is limited. In the study of political satire, no empirical research has examined whether alternative concepts of citizenship and political satire viewing are related, and how they might work together to predict different forms of political participation. This is important especially when the lines between news and entertainment have been blurred in the contemporary media environment (Baum, 2002, 2003b), with people considering entertainment as part of news value (Edgerly et al., 2017). Further, more and more people, especially young people, turn to political entertainment programming, mostly late-night talk shows, for news and information rather than news 
media (Cao \& Brewer, 2008; Mitchell et al., 2015), which makes it worthwhile to test the link between alternative concepts of citizenship and political satire viewing.

Based on the literature review, this study defines alternative concepts of citizenship as an alternative communication logic, which argues that news media are no longer a dominant source of news and information and good citizens do not need to follow news media to be informed about public and civic affairs.

Lastly, hard news use. As increasing media choice allows content preference to guide individual's viewing behavior, scholarly debate in the fields of communication and political science has centered on if and how political entertainment programming influences political outcomes, such as knoweldge and participation. Some suggest that political entertainment programs do not provide sufficient information citizens need when making informed decisions about politics, thereby demobilizing the viewers (Prior, 2005, 2007). Others argue that such programs have the potential to facilitate political learning, especially among politically inattentive individuals, through incidental learning (i.e., incidental exposure to news and information) and gateway effects (i.e., increased consumption of news), thereby mobilizing the viewers (Baum, 2002, 2003a). The gateway hypothesis (Baum, 2003b) is one of the hot topics in the dabate on potential democratic effects of political entertainment programs (Holbert, 2013). In the case of political satire viewing, however, unlike other genres of political entertainment programs, one of the necessary features of political satire is assumed knowledge of the audience (Caufield, 2008). In other words, without prior understanding of the topic or target of the satirical attack, the audience cannot play with the satirist and laugh as an outcome. In a survey study, Young and Tisinger (2006) found that consumption of late-night talk shows 
was positively and significantly correlated with exposure to hard news (e.g., cable news, newspaper, local news). In another survey study, Hmielowski and colleagues (2011) demonstrated that liberal cable news use is a key predictor of the consumption of political TV satire. These findings raise the possibility that the viewers of late-night talk shows might be news followers in the first place, so that they can fully appreciate the jokes with laughter. Little empirical research has examined if and how hard news use predicts political satire viewing and how the relationship affects political outcomes.

Then, what is hard news? It can be described as "news coverage of breaking events involving top leaders, major issues, or significant disruption in the routine of daily life, such as an earthquake or airline disaster" (Patterson, 2000, p. 3). Information on those events is important for citizens to understand and react properly to the public or civic issues (Patterson, 2000). Thus, hard news is focused on its political and societal relevance, not on individual relevance, of events and is delivered in a reporting style characterized as straight, rational, impersonal, unemotional, thematic, or in-depth coverage (Baum, 2003b; Reinemann et al., 2012). The common topics of hard news include politics, public affairs, technology, and science (Curran, Iyengar, Brink Lund, \& Salovaara-Moring, 2009). As with soft news, however, despite common use by media scholars, there is no consensus on an operational defintion of "hard news" either (Baum, 2003b; Patterson, 2000; Reinemann et al., 2012). In response to the call for a more precise, unambiguous, theoretically fruitful and empirically useful definitions of concepts of news (Reinemann et al., 2012), this study defines hard news as news from traditional news media and operationalizes hard news use as reading or watching news from The New York Times (online and offline), The Wall Street Journal (online and offline), The 
Washington Post (online and offline), NBC Nightly News with Lester Holt (online and offline), ABC World News Tonight with David Muir (online and offline), CBS Evening News with Scott Pelley (online and offline), and PBS NewsHour (online and offline).

Stimuli: Political satire viewing in general vs. hard news use; harsh satire viewing vs. gentle satire viewing; self-viewing vs. curated viewing. Model 1 is concerned about whether political satire viewing in general operates to influence online and offline political participation the same or differently compared to hard news use through the intermediate variables (i.e., news attention, political talk, social media expression, political knowledge, political efficacy).

It has been well documented that informational use of media is closely associated with cognitive and behavioral outcomes (Prior, 2007). Those who follow news are more likely to have greater political knowledge, efficacy, and participation (Delli Carpini \& Keeter, 1996; Moy et al., 2005; Park, 2015; Verba et al., 1995).

Unlike journalists, who present politics as something to learn in one-way communication, striving for balance, fairness, and objectivity, satirists offer social and political criticism with laughter, while encouraging viewers "to play with politics, to examine it, test it, and question it" in two-way or interactive communication (Gray et al., 2009, p. 11; Stroud \& Muddiman, 2013). For example, political satire presents social and political issues in a simple, approachable, and entertaining way, while interrogating and challenging the power, criticizing news media, and engaging audiences in the process (Baym, 2005; Jones \& Baym, 2010). And research has shown that political satire has the potential to encourage political participation directly (Cao \& Brewer, 2008; Moy et al., 
2005). This study, therefore, predicts that political satire viewing will directly increase offline and online political participation.

At the same time, research demonstrates that interpersonal and intrapersonal communication largely mediates the effects of media use on civic and political participation (Eveland, 2001; Eveland et al., 2003; Mcleod et al., 1996; Shah et al., 2005, 2007; Sotirovic \& McLeod, 2001). In other words, the effects of media on political outcomes are strong but are largely mediated through their effects on communication behaviors (e.g., information seeking, interpersonal communication) (McLeod et al., 2001; Shah et al., 2005, 2007). The communication mediation model incorporates mass and interpersonal communication, online and offline, into the processes that mobilize the electorate, highlighting information seeking through news media and political communication behaviors, online and offline, as a key variable in the study of media effects on civic and political participation. (Shah et al., 2005, 2007). Further, political discussion is both an attribute of interpersonal communication and a product of intrapersonal reflection. This is because people tend to organize their thoughts and positions by elaborating on information before, during, or after discussion (Eveland, 2004), which facilitates information processing (e.g., news attention) (Eveland et al., 2003). This mediation process seems to hold for the effects of political satire viewing as well. Moy and colleagues (2005) suggest that consumption of late-night talk shows is more likely to facilitate interpersonal discussion about politics, and Lee (2012) found the significant mediating role of political discussion and online interaction (e.g., posting, discussing, forwarding) in the effects of political satire on political participation. Further, Feldman and Young (2008) found that viewers of late-night talk shows, such as The 
Tonight Show with Jay Leno and The Late Show with David Letterman as well as The Daily Show with Jon Stewart, were more likely to pay attention to the news about political campaign. This study, therefore, predicts that political satire viewing will increase news attention, political talk, and social media expression.

Research has shown that political satire viewing has the potential to increase political knowledge (Becker \& Bode, 2018; Hardy et al., 2014; Xenos \& Becker, 2009) and internal political efficacy, thereby facilitating political engagement (Hoffman \& Thomson, 2009; Hoffman \& Young, 2011). This study, therefore, predicts that political satire viewing will increase political knowledge and political efficacy.

Model 2 explores whether harsh satire viewing operates to influence online and offline political participation the same or differently through the intermediate variables (i.e., news attention, political talk, social media expression, political knowledge, political efficacy) compared to gentle satire viewing. Research on the effects of political satire suggests that late-night talk shows are not monolithic and this leads to different democratic outcomes (Holbert, 2005; Holbert et al., 2011). For example, The Tonight Show with Jay Leno and Last Show with David Letterman were different from The Daily Show with Jon Stewart in terms of political content, message level, and satirical tone, which led to different political effects (Hoffman \& Young, 2011; Jones \& Baym, 2010; Young \& Tisinger, 2006). While The Daily Show and The Colbert Report were consistently found to be associated with political outcomes, such as internal efficacy and participation, The Tonight Show with Jay Leno and Last Show with David Letterman were not (Cao \& Brewer, 2008; Hoffman \& Young, 2011). In addition, a handful of experimental studies demonstrate that distinct forms of satire (i.e., horatian or gentle 
satire, juvenalian or harsh satire) can exert different persuasive effects. Holbert and colleagues (2011) found that horatian satire was more effective in persuading participants with lower levels of knowledge, while juvenalian satire was more effective in persuading participants with higher levels of knowledge. Boukes and colleagues (2015) showed that horatian or gentle satire was less persuasive than juvenalian or harsh satire. These findings suggest that late-night talk shows should not be treated as monolithic. Since horatian satire and juvenalian satire are two important and distinct types of satire (Holbert et al., 2011), this study seeks to add nuance to the study of participatory effects of political satire by analyzing the influence of horatian satire in comparison to juvenalian satire. Research suggests that harsh satire is likely to facilitate political participation, while gentle satire is not (Cao \& Brewer, 2008; Hoffman \& Young, 2011). This study, therefore, predicts that harsh satire viewing will increase offline and online political participation, while gentle satire viewing will not.

At the same time, as elaborated earlier, the effects of media on political outcomes are largely mediated through deliberative reasoning processes, such as information seeking and interpersonal communication (Mcleod et al., 1996; Shah et al., 2005, 2007; Sotirovic \& McLeod, 2001). This mediation process seems to hold for the effects of political satire viewing as well. Consumption of late-night talk shows is more likely to facilitate political expression, online and offline, which in turn increases political engagement (Lee, 2012; Moy et al., 2005). Research also suggests that consumption of late-night talk shows leads to greater news attention (Feldman \& Young, 2008). This study, therefore, predicts that both harsh and gentle satire viewing will increase news attention, political talk, and social media expression. 
Research suggests that consumption of harsh satire, such as The Daily Show, The Colbert Report, and John Oliver's Last Week Tonight, is more likely to increase political knowledge (Becker \& Bode, 2018; Hardy et al., 2014) and political efficacy, thereby increasing political participation, while consumption of gentle satire, such as The Late Show with David Letterman and The Tonight Show with Jay Leno, is not (Hoffman \& Young, 2011). This study, therefore, predicts that harsh satire viewing will increase political knowledge and political efficacy, while gentle satire will not.

Model 3 explores whether curated viewing of political satire operates to influence online and offline political participation the same or differently through the intermediate variables (i.e., news attention, political talk, social media expression, political knowledge, political efficacy) compared to self-viewing of political satire. Thorson and Wells (2015) assert that media consumption activity of today is mutlifaceted and varied via the proliferating media platforms and channels, listing five different groups of actors journalistic, social, personal, strategic, and algorithmic - that are actively curating media content flows. This categorization implies that consumption of these differently curated flows of information may result in different political outcomes. For example, social curation occurs on social media platforms, where the audience experiences communal, shared, and networked media contents, whereas personal curation occurs in his or her own information environment, where the audience experiences personalized and individualized media contents solely selected based on his or her own motivational use of the contents (Jenkins, 2006; Thorson \& Wells, 2015; Villi, 2012). In fact, existing research on various forms of media use for news and information and democratic citizenship has shown that media channel matters in news consumption and its impact on 
democratic outcomes (Andersen et al., 2016; Dimitrova et al., 2014; Moeller et al., 2014; Shah et al., 2007). The findings suggest that use of newspaper and online news increases political efficacy, thereby promoting turnout, while use of TV news is not (Moeller et al., 2014). Print tabloid use is more likely to be negatively associated with political participation, whereas online tabloid use is more likely to be positively associated with participation, both directly and indirectly (Andersen et al., 2016). Shah and colleagues (2007) also found more positive participatory effects of online news use rather than traditional media use. When social media use comes into play, however, online news use appears to lose its participatory effect. Dimitrova and colleagues (2014) found that social media use for political purposes (e.g., reading blogs about politics, commenting and discussing politics) increased political participation, whereas online news use had no effect at all. These findings - online news use appears to exert greater participatory effects than traditional news use, and informational use of social media appears to exert greater participatory effects than online news use - call for a more systematic attention to the role of media channel in media consumption and its influence on democratic outcomes in today's highly interactive, networked media environment.

This study, therefore, seeks to examine the role of the social media environment in political satire viewing and its influence on participation. Since research suggests that socially curated media consumption in the digital media environment is more likely to energize users (Bode, 2012; Bond et al., 2012; Dimitrova et al., 2014), and personally curated media consumption via traditional media platforms is more likely to demobilize users (Andersen et al., 2016), this study divides political satire viewing into two distinct forms: self-viewing and curated viewing. Self-viewing is defined as a media consumption 
activity that is directed, driven, and guided by one's motivation and operationalized as watching late-night talk shows on television. On the other hand, curated viewing is defined as a media consumption activity that is directed, driven, and guided by others' comments or recommendations and operationalized as watching late-night talk shows on social media platforms or through others' recommendations. This study, therefore, predicts that curated viewing of political satire will increase offline and online political participation, while self-viewing will decrease offline and online political participation.

As elaborated earlier, the effects of media on political outcomes are strong but are largely mediated through deliberative reasoning processes, such as information seeking and interpersonal communication (Mcleod et al., 1996; Shah et al., 2005, 2007; Sotirovic \& McLeod, 2001). This mediation process seems to hold for the effects of political satire viewing as well. Consumption of late-night talk shows is more likely to facilitate political expression, online and offline, which in turn increases political engagement (Lee, 2012; Moy et al., 2005). Research also suggests that consumption of late-night talk shows leads to greater news attention (Feldman \& Young, 2008). This study, therefore, predicts that both curated viewing and self-viewing will increase news attention, political talk, and social media expression. At the same time, socially curated media contents in the networked media environment are more likely to be consumed than media contents from traditional media platforms, since it comes from whom the users trust, such as family and friends (Bode, 2012; Rosenstiel et al., 2017; Villi, 2012). The high level of trust and intimacy users assign to the socially curated media messages may be more effective in increasing attention to news and facilitating political discourse on the topics or issues covered in the programs. This study, therefore, predicts that curated viewing will have a 
greater effect on news attention, political talk, and social media expression than selfviewing.

Existing literature on political satire has shown that consumption of political satire itself has the potential to increase political knowledge (Becker \& Bode, 2018; Hardy et al., 2014) and political efficacy, thereby increasing political participation (Hoffman \& Thomson, 2009). This study, therefore, predicts that both curated viewing and self-viewing will increase political knowledge and political efficacy. At the same time, research suggests that consumption of socially curated media contents in the networked media environment increases incidental exposure to political information and hence improves one's knowledge of political issues, thereby facilitating participation in political and civic life (Boulianne, 2015; DeSilver, 2014; Grieco, 2017; Kim et al., 2013). Also, the exposure to socially curated media contents enhances one's confidence in understanding politics, thereby increasing political participation (Chan, 2016; Hong, 2016). This study, therefore, predicts that curated viewing will have a greater effect on political knowledge and political efficacy than self-viewing.

\section{Reasoning: News attention, political talk, and social media expression.}

Contemporary communication scholars have demonstrated that political discussion, online and offline, is a key mediator of the effects of media use on civic and political participation, highlighting its deliberative nature (Cho et al., 2009; McLeod et al., 2001;

Shah, 2016; Shah et al., 2005, 2007). This is because expressed ideas do not often exist intact in the expresser's mind before he or she expresses them. Rather, the expresser undergoes complex mental processes, through which the expresser engages in intrapersonal reasoning and cognitive articulation to clarify and organize his or her 
thoughts and ideas (Pingree, 2007). Unlike the two-step flow model (E. Katz \& Lazarsfeld, 1955), which paid first attention to the role of interpersonal communication to argue for minimal direct effects of media, contemporary communication scholars have taken into consideration the mediating role of interpersonal communication to advocate strong effects of media (Jung et al., 2011).

This line of research has shown that political discussion increases cognitive political outcomes, such as political knowledge and efficacy, thereby facilitating political participation (Hardy \& Scheufele, 2005; Jung et al., 2011; McLeod et al., 2001). For example, media consumption provides a variety of topics for political conversation (Delli Carpini \& Williams, 1994), which highlights common issues and opportunities for political participation. Through this deliberative process, people elaborate on their thoughts and ideas of the issues and topics, while seeking information and paying attention to news to form their opinions (Cho et al., 2009; Eveland, 2004; Eveland et al., 2003; Mcleod, Scheufele, \& Moy, 1999; Shah et al., 2007). In other words, those who engage in political discussion are more likely to pay attention to news to process the information more carefully and thoroughly and present argumentations that are more reasoned. This deliberative reasoning process, in turn, increases cognitive outcomes, such as political knowledge and efficacy, thereby facilitating political participation (McLeod et al., 2001; Shah et al., 2007). This mediation process seems to hold for the effects of political satire viewing as well. Research suggests that consumption of late-night talk shows is likely to facilitate political talk, online and offline, thereby mobilizing voters (Lee, 2012; Moy et al., 2005). This study, therefore, predicts that news attention, political talk, and social media expression will increase political knowledge and political efficacy. 
Research also suggests that news consumption and political discussion, online and offline, have direct effects on political participation (Chan, 2016; Jung et al., 2011; Shah et al., 2005, 2007). This study, therefore, predicts that news attention, political talk, and social media expression will increase online and offline political participation.

The differentiation of online communication behaviors (e.g., online messaging, social media expression) from offline communication behaviors (e.g., political talk) in the study of media effects is important, since the Internet provides a distinct conversational space (Price \& Cappella, 2002; Shah et al., 2005). The Internet allows individuals to share their political perspectives and concerns with others via "interactive messaging technologies such as e-mail, instant messaging, electronic bulletin boards, online chats, and feedback loops to news organizations and politicians" (Shah et al., 2005, p. 536). The self-paced and asynchronous features of the Internet may even promote deeper selfreflection (Cho et al., 2009; Shah, 2016). Further, the written form of expression online, especially on social media, often includes verbal and visual elements along with links to associated contents (Shah, 2016) and lacks social presence, which may facilitate more goal-oriented, extremely open conversation than face-to-face interpersonal discussion (Berger, 2013), thereby facilitating participatory behaviors (Gil de Zúñiga, Copeland, et al., 2014; Valenzuela, 2013).

Research has shown that Internet users are more likely to read news and engage in political activities (Katz \& Rice, 2002). Within the context of the 2000 presidential campaign, Price and Cappella (2012) examined if online discussion is more likely to engage the public with political issues. Having participants engage in real-time political discussions online during the presidential campaign, this study found that with all other 
things being equal, those who participated in online political discussion were more likely to engage in political and civic activities. In a two-wave panel survey study to propose a citizen communication mediation model, Shah, Cho, Eveland, \& Kwak (2005) examined the role of the Internet not only as a political information source, but as a public expression space and found its communicative potential. The results show that traditional media's influence is strong in shaping civic participation, but indirectly through political discussion, interactive civic messaging (e.g., using the Internet as a resource and a forum), and reasoning about civic affairs. In other words, citizen communication, both online and offline, plays a key role between information use and participation, but online communication is more likely to facilitate the mediation process, since it allows users to post messages and images to distribute instantly, globally, at minimal cost. In a similar study, this time, to propose a campaign communication mediation model, Shah and colleagues (2007) examined how exposure to political ads influences civic and political participation through the communicative variables. The findings suggest that interpersonal discussion and online messaging largely mediated the effects of media messages on participation, but the role of online political messaging was even greater than interpersonal communication.

With the proliferating social media platforms, social media have emerged not only as a main source of political news and information (Mitchell et al., 2015; Shearer \& Gottfried, 2017), but also as a major venue for political expression (Cho, Ahmed, Keum, Choi, \& Lee, 2018). By allowing users to easily create or customize messages to share with sizable audiences beyond temporal and geographical boundaries (Mitchelstein \& Boczkowski, 2010; Valkenburg, 2017), social media broadened the scope of political 
expression and opened up the democratic benefit of political expression to a broader range of people (Cho et al., 2018).

It is only in recent years that communication scholars have turned their attention to participatory effects of political expression on social media on the expresser, and findings suggest that social media expression has a significant, positive effect on political participation (Pingree, 2007; Shah, 2016; Valkenburg, 2017). Using a two-wave panel data, Gil de Zuniga and colleagues (2014) examined the role of social media in political expression and its influence on participation. This study defined social media expression as “people's use of social network sites to express themselves politically in a variety of ways" (i.e., "posting personal experiences related to politics or campaigning," "friending a political advocate or politician," "posting or sharing thoughts about politics," "posting or sharing photos, videos, or audio files about politics," and "forwarding someone else's political commentary to other people"). Findings suggest that informational use of social media has direct effects on offline participation and social media expression mediates the effects of social media news use on participation, both online and offline. Using survey data collected in Chile, Valenzuela (2013) examined the link between various forms of social media use (e.g., information, political expression, activism) and protest behavior. This study conceptualized social media expression as "using social media to express political opinions," such as using social network sites for expressing opinions on political issues and using social media to spread information about certain issues. Findings suggest that those who use social media for political expression and activism are more likely to participate in political protest, but those who use social media for news are not. More recently, using survey data collected in South Korea, Park and Kaye (2018) examined the 
role of social media use in news curation through commenting, reconstructing, and sharing and its influence on political knowledge, internal political efficacy, and online and offline political participation. Calling the social media use for news curation "curatorial news use" and measuring it by asking respondents how often they "posted political news together with their own comments about the news," "combined related political news and posted it on social media," and "posted a summary of political news for others to read," during a recent campaign, this study found that political expression on social media has significant, positive effects on those three indicators of democratic citizenship. Drawing on the literature on partisan reinforcement, Cho and colleagues (2018) found a moderating role of social media expression in reinforcing partisan opinion. The effects of party affiliation on opinions about political issues grew stronger as the respondents engaged more in political expression on social media, such as posting links to political or social stories, posting one's comments on political or social issues, and reposting or liking others' posts.

An emerging line of research even suggests that social media expression outpaces conventional interpersonal communication as a driver of democratic citizenship (Lee, Shah, \& McLeod, 2013; Valkenburg, 2017). Using panel data, Lee and colleagues (2013) examined the various roles communication plays in political socialization of youth and found strong online pathways to political participation, such that conventional online news use (e.g., websites of mainstream news organizations), nonconventional online information (e.g., blogs) and digital media use for political expression facilitated participation, whereas traditional news use (e.g., TV news, newspaper) and face-to-face discussion were not associated with participation. Research also suggests that the rise of 
social media both as a main source of news and information and as a major venue for political expression has tremendously contributed to a surge in grassroots participation. User-friendly social media tools allow ordinary citizens to easily express their opinions more openly and freely, while forming a more active and significant relationship with policy makers (Gil de Zuniga, 2016). This study, therefore, examines the effects of social media expression in comparison to conventional political talk. The extant research on social media use and political behavior outlined above demonstrates that social media expression can be defined and measured in multiple different ways. Research on political satire suggests that consumption of political satire leads to greater news attention (Feldman \& Young, 2008) and political discussion (Moy et al., 2005), thereby mobilizing its viewers (Lee, 2012). In the social media environment, paying attention to news and expressing one's political opinions can happen simultaneously. This study, therefore, defines social media expression as expressing one's political opinions on social media through commenting on political events, posting or sharing videos or articles about political events. Little research on political satire has examined the role of social media in news attention and political expression.

\section{The second orientations: Political knowledge and political efficacy. The} second set of orientations consists of political knowledge and political efficacy.

Political knowledge is a critical component of democratic citizenship. Wellinformed citizens are more likely to pay attention to politics and, as a result, get more engaged in various forms of political participation, while committed to democratic principles. And those democratic principles must be first understood to follow and act upon in a meaningful way (Delli Carpini \& Keeter, 1996). John Stuart Mill referred to the 
cultivation of understanding as "learning the grounds of one's own opinions" (Mill, 1872, p. 21). In other words, it is a fundamental tenet in democracy that citizens should have a free and easy access to political information to get informed and exchange the informed opinions with each other to make sound opinions about what is proper and just in a democratic society (Delli Carpini \& Keeter, 1996).

Empirical research provides substantial evidence of such a positive relationship between media use, political knowledge, and participation (Chaffee, Zhao, \& Leshner, 1994; Eveland \& Scheufele, 2000; Prior, 2007). Employing a model comparison approach, Eveland, Hayes, Shah, and Kwak (2005) examined the various assumptions of causality (i.e., unidirectional or reciprocal) presented in research on communication and political knowledge and found that knowledge about politics depends on communication, both mass and interpersonal. Political knowledge has also been linked to political participation (Chaffee et al., 1994; Prior, 2007; Verba et al., 1995). This study, therefore, predicts that political knowledge will increase online and offline political participation.

Political efficacy is defined as "the feeling that individual political action does have, or can have, an impact upon the political process, i.e., that it is worthwhile to perform one's civic duties." It is also defined as "the feeling that political and social change is possible, and that the individual citizen can play a part in bringing about this change" (Campbell, Gurin, \& Miller, 1954, p. 187). Accordingly, in political behavior research, political efficacy has been one of the most important psychological constructs that are closely associated with participation in politics (Cohen, Vigoda, \& Samorly, 2001; Morrell, 2003). 
The cognitive construct has two dimensions: internal and external efficacy (Balch, 1974). Internal political efficacy relates to one's feeling that he or she is capable of understanding and influencing politics, and external political efficacy relates to one's perception that government institutions and officials are responsive to the needs and demands of citizens (Hoffman \& Thomson, 2009; Niemi, Craig, \& Mattei, 991). While media use has been associated with both internal and external efficacy (Hansen \& Pedersen, 2014), which predicts political participation (Pollock, 1983), research also suggests that internal political efficacy is more closely related to psychological involvement with politics, resulting in greater civic and political participation (Choi et al., 2018; Gil de Zúñiga et al., 2012). The study of political satire also seems to support this positive link between internal efficacy and participatory behaviors. Those who watch late-night talk shows were more likely to feel confident about their understanding of politics, thereby participating more in politics (Baumgartner \& Morris, 2006; Hoffman \& Thomson, 2009, 2009; Hoffman \& Young, 2011). This study, therefore, predicts that internal political efficacy will increase online and offline political participation.

Response: Online and offline political participation. Political participation is a multidimensional concept. Existing literature has defined it in broad categories, such as 'active vs. passive,' 'conventional vs. unconventional,' 'symbolic vs. instrumental,' and 'expressive vs. collective,' and there is still no generally accepted definition (Conge, 1988; Conway, 2000; Park, 2015). As the political system has evolved, the criteria for political participation have also expanded from focusing on politics-oriented activities, such as voting and political donation, to working in civic affairs, such as attending local forums. These changes have made the boundaries between political participation and 
civic participation blurry (McLeod, 2001). Further, the Internet has added a new layer of complexity to this already challenging task of conceptualizing and measuring participation (Gibson \& Cantijoch, 2013).

Even though there is no universally accepted definition of political participation, most of the commonly-used definitions limit themselves to activities by which private citizens influence government or policy-making processes, somewhat broadly or narrowly (Cohen et al., 2001). Verba and Nie (1972) defined the participatory behaviors as "those activities by private citizens that are more or less directly aimed at influencing the selection of governmental personnel and/or the actions they take" (Verba \& Nie, 1972, p. 2). Verba, Nie, and Kim (1978) further limited the activities to "legal" ones, excluding violence. More recently, Verba, Schlozman, and Brady (1995) referred to political participation as "activity that has the intent or effect of influencing government action - either directly by affecting the making or implementation of public policy or indirectly by influencing the selection of people who make those policies" (Verba et al., 1995, p. 38).

The present study focuses on political participation that involves activities to influence government and the policy-making processes, and accordingly adopts Verba et al.'s (1995) broad definition. Further, unlike the other definitions, this chosen one is broad enough to incorporate online political channels, such as sending a political message via e-mail (Gil de Zúñiga et al., 2012).

In addition, this study considers online forms of participation distinct from offline forms of participation. The differentiation of political participation online from political participation offline is important for the following reasons: First, there is 
disparity in the cost and time between online and offline activities (Jung et al., 2011; Park, 2015). For example, online activities, such as contacting officials via e-mail and participating in online public forums, cost less compared to activities in offline settings (Jung et al., 2011). Second, research has shown that the Internet can encourage those lacking civic skills or less politically active in offline settings to participate in politics (Wang \& Shi, 2018). And this can be why policy makers should pay attention to the needs of those most active online in addition to those most active in conventional forms of politics (Best \& Krueger, 2005; Gibson, Lusoli, \& Ward, 2005). Lastly, citizens are more in control of their participatory actions online than offline, and this online participation may translate into offline forms of participation (Chan, 2016), such as voting. In a survey study, Jung et al. (2011) differentiated online participation from conventional, offline participation and found that communication activities (i.e., offline interpersonal political discussion and online political messaging) and outcome orientation variables (i.e., political knowledge and political efficacy) accounted for nearly half of the variance in online participation, while explaining 20 percent of the variance in traditional, offline participation.

\section{Modeling mediated relationships between political satire viewing and}

political participation. This study examines the effects of political satire viewing on political participation by explicating the roles of information processing activities (i.e., news attention, political talk, social media expression) and cognitive outcomes (i.e., political knowledge, political efficacy) in mediating the effects.

Based on the O-S-R-O-R framework, this study proposes structural relationships in which audience factors (i.e., education, Democrats, Republicans, alternative concepts 
of citizenship, hard news use) serve as background orientations; political satire viewing (i.e., political satire viewing in general vs. hard news use; harsh satire viewing vs. gentle satire viewing; self-viewing vs. curated viewing) as stimuli; news attention, political talk, and social media expression as reasoning processes; political knowledge and political efficacy as outcome orientations; and political participation, online and offline, as responses. In this two-step mediation model, audience factors guide political satire viewing, and audience factor-driven political satire viewing facilitates information processing activities, such as news attention, political talk, and social media expression. These deliberative, reasoning processes, in turn, enhance political knowledge and efficacy, which mediate the effects of political satire viewing on political participation, both online and offline. 


\section{Chapter 3: Research Hypotheses}

This chapter organizes research hypotheses guiding this study. Based on the O-SR-O-R framework, this study examines the effects of political satire viewing on political participation by proposing structural relationships in which audience factors (i.e., Democrats, Republicans, education, alternative concepts of citizenship, hard news use) serve as background orientations; various forms of political satire viewing (i.e. political satire viewing in general vs. hard news use; harsh satire viewing vs. gentle satire viewing; self-viewing vs. curated viewing) as stimuli; news attention, political talk, and social media expression as reasoning processes; political knowledge and political efficacy as outcome orientations; and political participation, online and offline, as responses in three different models (i.e., Model 1, Model 2, Model 3). Specifically, this study explicates the roles of information processing activities (i.e., news attention, political talk, social media expression) and cognitive outcomes (i.e., political knowledge, political efficacy) in mediating the effects of political satire on participation.

All three models contain the same reasoning processes (i.e., news attention, political talk, social media expression), outcome orientations (i.e., political knowledge, political efficacy), and responses (offline and online political participation). However, they use different sets of stimuli and background orientation variables depending on the focus of the inquiry for a more systematic examination of the participatory effects of political satire viewing.

\section{Model 1}


This model basically compares a route through which hard news use influences offline and online political participation as mediated through information processing activities or reasoning processes (i.e., news attention, political talk, social media expression) and cognitive outcomes or outcome orientation variables (i.e., political knowledge, political efficacy) - at least some of which are extensively supported in other studies - with a route that goes through political satire viewing instead.

Partisans tend to expose themselves to likeminded political media (Stroud, 2011). Republicans gravitate toward pro-Republican, right-leaning messages (e.g., Fox News, conservative talk radio, conservative political blogs), and Democrats lean toward proDemocrat, left-leaning messages (e.g., MSNBC, political comedy, liberal political blogs). Since this study does not use any of those partisan media, I propose the following hypotheses:

H1a: Democrats will not be significantly associated with hard news use. H1b: Republicans will not be significantly associated with hard news use. Research suggests that liberals and Democrats are more likely to watch late-night talk shows (Choi et al., 2018; Gottfried et al., 2015; Moy et al., 2005; Young \& Tisinger, 2006). At the same time, no research suggests that conservatives and Republicans actively avoid late-night talk shows. Therefore, I propose the following hypotheses:

H1c: Democrats will be positively associated with political satire viewing. H1d: Republicans will not be significantly associated with political satire viewing.

Education has long been linked to greater use of hard news (Lee \& Chyi, 2014; Poindexter \& McCombs, 2001). Research on political satire suggests that recipient level 
of political sophistication is a key predictor of political satire viewing (Caufield, 2008). Therefore, I propose the following hypotheses:

H1e: Education will be positively associated with hard news use.

H1f: Education will be positively associated with politcal satire viewing.

While traditional concepts of citizenship embrace the dutiful communication logic, which posits that good citizens should use traditional news media to follow public affairs (McCombs \& Poindexter, 1983; Poindexter \& McCombs, 2001), alternative concepts of citizenship embrace the alternative communication logic, which posits that good citizens should not embrace "primarily one-way consumption of managed civic information (news and political ads)" (Bennett et al., 2011, p. 840). In other words, alternative concepts of citizenship argue that activities occurring in the course of everyday life, including interactive communication in the digital media environment, can also be considered political, from which people can learn democratic values (Bennett et al., 2011; Thorson, 2012). Research suggests that more and more people get their news and information from political entertainment programs, mostly late-night talk shows, rather than news media (Cao \& Brewer, 2008; Mitchell et al., 2015). At the same time, the lines between news and entertainment have been blurred in the contemporary media environment (Baum, 2002, 2003b), with people considering entertainment as part of news value (Edgerly et al., 2017). Therefore, I propose the following hypotheses:

H1g: Alternative concepts of citizenship will be negatively associated with hard news use.

H1h: Alternative concepts of citizenship will be positively associated with political satire viewing. 
The link between informational use of media and political participation has been well documented (Mcleod et al., 1996; Prior, 2007). Research also suggests that political satire has the potential to directly influence political participation (Cao \& Brewer, 2008; Moy et al., 2005). Therefore, I propose the following hypothesis:

H2a: Hard news use and political satire viewing will be positively associated with offline and online political participation.

At the same time, the effects of media on political outcomes are strong but are largely mediated through their effects on communication behaviors (e.g., information seeking, interpersonal communication) (McLeod et al., 2001; Shah et al., 2005, 2007). For example, media consumption provides a variety of topics for political conversation (Delli Carpini \& Williams, 1994), which highlights common issues and opportunities for political participation. Through this deliberative process, people elaborate on their thoughts and ideas of the issues and topics, while seeking information and paying attention to news to form their opinions (Cho et al., 2009; Eveland, 2004; Eveland et al., 2003; Mcleod et al., 1999; Shah et al., 2007). In other words, those who engage in political discussion are more likely to pay attention to news to process the information more carefully and thoroughly and present argumentations that are more reasoned (McLeod et al., 2001; Shah et al., 2007).

This process seems to hold for the effects of political satire viewing as well. Moy and colleagues (2005) suggested that consumption of late-night talk shows is more likely to facilitate interpersonal discussion about politics. Further, Lee (2012) found the significant mediating role of political discussion and online interaction (e.g., posting, discussing, forwarding) in the effects of political satire viewing on political participation. 
Research also suggests that consumption of late-night talk shows leads to greater news attention (Feldman \& Young, 2008). Therefore, I propose the following hypothesis:

H2b: Hard news use and political satire viewing will be positively associated with news attention, political talk, and social media expression.

The link between news use and political knowledge and efficacy has been well documented (Jung et al., 2011; Prior, 2007). Research also suggests that political satire viewing has the potential to increase political knowledge (Becker, 2014; Becker \& Bode, 2018) and internal political efficacy (Hoffman \& Thomson, 2009). Therefore, I propose the following hypothesis:

H2c: Hard news use and political satire viewing will be positively associated with political knowledge and political efficacy.

News use increases political knowledge and efficacy (Chan, 2016; Jung et al., 2011; Prior, 2007). Research also suggests that news attention is a better predictor of political learning (Chaffee \& Schleuder, 1986; Martinelli \& Chaffee, 1995; McLeod \& McDonald, 1985). In addition, research has shown that political discussion, a deliberative reasoning process, increases cognitive political outcomes, such as political knowledge and efficacy, thereby facilitating political participation (Hardy \& Scheufele, 2005; Jung et al., 2011; McLeod et al., 2001). This mediation process seems to hold for the effects of political satire viewing as well. Political discussion and online interaction (e.g., posting, discussing, forwarding) appear to significantly mediate the effects of political satire viewing on political participation (Lee, 2012). Therefore, I propose the following hypothesis: 
H3a: News attention, political talk, and social media expression will be positively associated with political knowledge and political efficacy.

Much of the research on news attention has been devoted to its influence on political learning (Chaffee \& Schleuder, 1986; Martinelli \& Chaffee, 1995; McLeod \& McDonald, 1985), such that news attention increases political learning, through which it is expected to translate into political behaviors (Martinelli \& Chaffee, 1995). Research also suggests that news attention has a direct effect on participation. Shah and colleagues $(2005,2007)$ examined the effect of hard news use on civic and political participation by combining measures of exposure and attention to hard news contents by medium (e.g., newspaper hard news use, television hard news use) and found that newspaper hard news use increased participation. Further, an emerging line of research suggests that the highchoice media environment offers various ways of processing news and information (e.g., posting, endorsing, or reading news), and different news consumption activities yield different democratic outcomes (Choi, 2016; Hyun \& Kim, 2015). While news posting was significantly, positively associated with political participation, news reading was not significantly associated with participation (Choi, 2016). The communication mediation model (Cho et al., 2009; Shah et al., 2005, 2007) and the cognitive mediation model (Eveland, 2001, 2004) suggest that news attention and political discussion, online and offline, are part of information processing, which mobilizes citizens. Therefore, I propose the following hypothesis:

H3b: News attention, political talk, and social media expression will be positively associated with online and offline political participation. 
Research provides substantial evidence of the mediating role of political knowledge and political efficacy in the effects of informational use of media on political participation (Chan, 2016; Hoffman \& Young, 2011; Hong, 2016; Jung et al., 2011; McLeod et al., 2001; Prior, 2007). Also, research suggests that political satire viewing is positively associated with political efficacy, thereby facilitating political behaviors (J. Baumgartner \& Morris, 2006; Hoffman \& Thomson, 2009, 2009; Hoffman \& Young, 2011). Therefore, I propose the following hypothesis:

H4: Political knowledge and political efficacy will be positively associated with online and offline political participation.

Modeling mediated relationships. Most of the earlier hypotheses imply both direct and indirect effects of political satire viewing and hard news use on political participation, online and offline. Political satire viewing, hard news use, news attention, political talk, social media expression, political knowledge, and political efficacy are expected to have direct effects on political participation, online and offline.

The O-S-R-O-R model hypothesizes indirect effects in which the information processing activities (i.e., news attention, political talk, social media expression) and cognitive outcomes (i.e., political knowledge, political efficacy) mediate the effects of informational use of media on political behaviors. Therefore, I propose the following hypothesis:

H5a: Hard news use and political satire viewing will increase online and offline political participation as mediated through news attention, political talk, or social media expression, and political knowledge or political efficacy. 
Qualitative and cultural studies have long argued for democratic good of political satire, calling this media form an "alternative journalism" or a "new journalistic form" (Baym, 2005; Harrington, 2012). Therefore, I propose the following hypothesis:

H5b: The mediating process of hard news use affecting online and offline political participation will be similar to the mediating process of political satire viewing affecting online and offline political participation.

[Figure 1 here]

\section{Model 2}

The central question in this model is whether harsh satire viewing operates to influence online and offline political participation the same or differently through information processing activities (i.e., news attention, political talk, social media expression) and cognitive outcomes (i.e., political knowledge, political efficacy) compared to gentle satire viewing.

Democrats and higher education have been shown to be associted with greater use of political satire (Gottfried \& Anderson, 2014; Gottfried et al., 2015). Therefore, I propose the following hypotheses:

H1a: Democrats will be positively associated with harsh and gentle satire viewing.

H1b: Education will be positively associated with harsh and gentle satire viewing.

While liberals and Democrats are more likely to watch late-night talk shows (Choi et al., 2018; Gottfried et al., 2015; Moy et al., 2005; Young \& Tisinger, 2006), no research suggests that conservatives and Republicans actively avoid late-night talk shows. Therefore, I propose the following hypothesis: 
H1c: Republicans will not be significantly associated with harsh and gentle satire viewing.

Assumed knowledge of the audience about the topic covered in the show is one of the necessary features of political satire (Caufield, 2008; Niven et al., 2003). Also, news use predicts consumption of late-night talk shows (Hmielowski et al., 2011; Young \& Tisinger, 2006). Thus, viewers of both harsh and gentle satire are expected to follow hard news in the first place to understand the satirical messages Therefore, I propose the following hypothesis:

H1d: Hard news use will be positively associated with harsh and gentle satire viewing.

Research suggests that harsh satire viewing is likely to be associated with political participation, while gentle satire viewing is not (Cao \& Brewer, 2008; Hoffman \& Young, 2011). Therefore, I propose the following hypotheses:

$\mathrm{H} 2 \mathrm{a}$ : Harsh satire viewing will be positively associated with online and offline political participation.

$\mathrm{H} 2 \mathrm{~b}$ : Gentle satire viewing will not be significantly associated with online and offline political participation.

At the same time, the effects of media on political outcomes are strong but are largely mediated through their effects on communication behaviors (e.g., information seeking, interpersonal communication) (McLeod et al., 2001; Shah et al., 2005, 2007). This process seems to hold for the effects of political satire viewing as well. Moy and colleagues (2005) suggested that consumption of late-night talk shows is more likely to facilitate interpersonal discussion about politics, and Lee (2012) found significant 
mediating roles of political discussion and online interaction (e.g., posting, discussing, forwarding) in the effects of political satire viewing on political participation. Research also suggests that consumption of late-night talk shows leads to greater news attention (Feldman \& Young, 2008). Even though the two different types of satire use different satirical tones, they are expected to share the same goal, which is to educate and entertain viewers by making jokes about news, government and politics (Holbert et al., 2011). Therefore, I propose the following hypothesis:

H2c: Harsh and gentle satire viewing will be positively associated with news attention, political talk, and social media expression.

Research suggests that harsh satire viewing is likely to increase political knowledge and political efficacy, while gentle satire viewing is not (Becker \& Bode, 2018; Hardy et al., 2014; Hoffman \& Young, 2011). Therefore, I propose the following hypotheses:

H2d: Harsh satire viewing will be positively associated with political knowledge and political efficacy.

H2e: Gentle satire viewing will not be significantly associated with political knowledge and political efficacy.

News use increases political knowledge and efficacy (Chan, 2016; Jung et al., 2011; Prior, 2007). Research also suggests that news attention is a better predictor of political learning (Chaffee \& Schleuder, 1986; Martinelli \& Chaffee, 1995; McLeod \& McDonald, 1985). In addition, research has shown that political discussion, a deliberative reasoning process, increases cognitive political outcomes, such as political knowledge and efficacy, thereby facilitating political participation (Hardy \& Scheufele, 2005; Jung 
et al., 2011; McLeod et al., 2001). This mediation process seems to hold for the effects of political satire viewing as well. Political discussion and online interaction (e.g., posting, discussing, forwarding) appear to significantly mediate the effects of political satire viewing on political participation (Lee, 2012). Therefore, I propose the following hypothesis:

H3a: News attention, political talk, and social media expression will be positively associated with political knowledge and political efficacy.

Much of the research on news attention has been devoted to its influence on political learning (Chaffee \& Schleuder, 1986; Martinelli \& Chaffee, 1995; McLeod \& McDonald, 1985), such that news attention increases political learning, through which it is expected to translate into political behaviors (Martinelli \& Chaffee, 1995). Research also suggests that news attention has a direct effect on participation. Shah and colleagues $(2005,2007)$ examined the effect of hard news use on civic and political participation by combining measures of exposure and attention to hard news contents by medium (e.g., newspaper hard news use, television hard news use) and found that newspaper hard news use increased participation. Further, an emerging line of research suggests that the highchoice media environment offers various ways of processing news and information (e.g., posting, endorsing, or reading news), and different news consumption activities yield different democratic outcomes (Choi, 2016; Hyun \& Kim, 2015). While news posting was significantly, positively associated with political participation, news reading was not significantly associated with participation (Choi, 2016). The communication mediation model (Cho et al., 2009; Shah et al., 2005, 2007) and the cognitive mediation model (Eveland, 2001, 2004) suggest that news attention and political discussion, online and 
offline, are part of information processing, which mobilizes citizens. Therefore, I propose the following hypothesis:

H3b: News attention, political talk, and social media expression will be positively associated with online and offline political participation.

Research provides substantial evidence of the mediating role of political knowledge and political efficacy in the effects of informational use of media on political participation (Chan, 2016; Hoffman \& Young, 2011, 2011; Hong, 2016; Jung et al., 2011; McLeod et al., 2001; Prior, 2007). Therefore, I propose the following hypothesis:

H4: Political knowledge and political efficacy will be positively associated with online and offline political participation.

Modeling mediated relationships. Most of the earlier hypotheses imply both direct and indirect effects of harsh and gentle satire viewing on political participation, online and offline. Harsh satire viewing, gentle satire viewing, news attention, political talk, social media expression, political knowledge, and political efficacy are expected to have direct effects on political participation, online and offline.

The O-S-R-O-R model hypothesizes indirect effects in which the information processing activities (i.e., news attention, political talk, social media expression) and cognitive outcomes (i.e., political knowledge, political efficacy) mediate the effects of informational use of media on political behaviors. Therefore, I propose the following hypothesis:

H5: Harsh and gentle satire viewing will increase online and offline political participation as mediated through news attention, political talk, or social media expression, and political knowledge or political efficacy. 
[Figure 3 here]

\section{Model 3}

The central question in this model is whether self-viewing of political satire operates to influence online and offline political participation the same or differently through information processing activities (i.e., news attention, political talk, social media expression) and cognitive outcomes (i.e., political knowledge, political efficacy) compared to curated viewing of political satire.

Democrats and higher education have been shown to be associted with greater use of political satire (Gottfried \& Anderson, 2014; Gottfried et al., 2015). Therefore, I propose the following hypotheses:

H1a: Democrats will be positively associated with self-viewing and curated viewing of politcal satire.

H1b: Education will be positively associated with self-viewing and curated viewing of politcal satire.

While liberals and Democrats are more likely to watch late-night talk shows (Choi et al., 2018; Gottfried et al., 2015; Moy et al., 2005; Young \& Tisinger, 2006), no research suggests that conservatives and Republicans actively avoid late-night talk shows. Therefore, I propose the following hypothesis:

H1c: Republicans will not be significantly associated with self-viewing and curated viewing of political satire.

Assumed knowledge of the audience about the topic covered in the show is one of the necessary features of political satire (Caufield, 2008; Niven et al., 2003). Also, news use predicts consumption of late-night talk shows (Hmielowski et al., 2011; Young \& 
Tisinger, 2006). Thus, those who watch late-night talk shows on television or in the social media environment are expected to follow hard news in the first place to understand the satirical messages. Therefore, I propose the following hypothesis:

H1d: Hard news use will be positively associated with self-viewing and curated viewing of political satire.

Research suggests that socially curated media consumption in the networked media environment is likely to mobilize voters, while personally curated media consumption is not or is even negatively associated with political participation (Andersen et al., 2016; Dimitrova et al., 2014; Moeller et al., 2014). Self-viewing of political satire belongs to personally curated media consumption based on one's motivation. On the other hand, curated viewing of political satire belongs to socially curated media consumption based on increased motivation to watch the program as it is recommended by others in the social media environment. Therefore, I propose the following hypotheses:

H2a: Curated viewing of political satire will be positively associated with online and offline political participation.

$\mathrm{H} 2 \mathrm{~b}$ : Self-viewing of political satire will be negatively associated with online and offline political participation.

At the same time, the effects of media on political outcomes are strong but are largely mediated through their effects on communication behaviors (e.g., information seeking, interpersonal communication) (McLeod et al., 2001; Shah et al., 2005, 2007). This process seems to hold for the effects of political satire viewing as well. Moy and colleagues (2005) suggested that consumption of late-night talk shows is more likely to 
facilitate interpersonal discussion about politics. Further, Lee (2012) found that political discussion and online interaction (e.g., posting, discussing, forwarding) mediate the effects of political satire viewing on political participation. Research also suggests that consumption of late-night talk shows leads to greater news attention (Feldman \& Young, 2008). Therefore, I propose the following hypothesis:

H2c: Self-viewing and curated viewing of political satire will be positively associated with news attention, political talk, and social media expression.

Socially curated media contents in the networked media environment are more likely to be consumed compared to media contents curated by news media, since they come from whom users trust, such as family and friends (Bode, 2012; Rosenstiel et al., 2017; Villi, 2012). This high level of trust and intimacy users assign to the socially curated media messages may be more effective in increasing attention to news and facilitating political discourse, online and offline, on the topics or issues presented in the show. Therefore, I propose the following hypothesis:

H2d: Curated viewing of political satire will have a greater effect on news attention, political talk, and social media expression than self-viewing of political satire.

Existing literature on political satire has shown that consumption of political satire itself is likely to increase political knowledge and political efficacy, thereby facilitating political participation (Becker \& Bode, 2018; Hardy et al., 2014; Hoffman \& Thomson, 2009). Therefore, I propose the following hypothesis:

H2e: Self-viewing and curated viewing of political satire will be positively associated with political knowledge and political efficacy. 
At the same time, research suggests that consumption of socially curated media consumption in the networked media environment increases incidental exposure to political information and hence improves one's knowledge of political affairs, thereby facilitating participation in political and civic life (Boulianne, 2015; DeSilver, 2014; Grieco, 2017; Kim et al., 2013). Also, the exposure to the socially curated media contents enhances one's confidence in understanding politics, thereby increasing political participation (Chan, 2016; Hong, 2016). Therefore, I propose the following hypothesis:

H2f: Curated viewing of political satire will have a greater effect on political knowledge and political efficacy than self-viewing of political satire.

News use increases political knowledge and efficacy (Chan, 2016; Jung et al., 2011; Prior, 2007). Research also suggests that news attention is a better predictor of political learning (Chaffee \& Schleuder, 1986; Martinelli \& Chaffee, 1995; McLeod \& McDonald, 1985). In addition, research has shown that political discussion, a deliberative reasoning process, increases cognitive political outcomes, such as political knowledge and efficacy, thereby facilitating political participation (Hardy \& Scheufele, 2005; Jung et al., 2011; McLeod et al., 2001). This mediation process seems to hold for the effects of political satire viewing as well. Political discussion and online interaction (e.g., posting, discussing, forwarding) appear to significantly mediate the effects of political satire viewing on political participation (Lee, 2012). Therefore, I propose the following hypothesis:

H3a: News attention, political talk, and social media expression will be positively associated with political knowledge and political efficacy. 
Much of the research on news attention has been devoted to its influence on political learning (Chaffee \& Schleuder, 1986; Martinelli \& Chaffee, 1995; McLeod \& McDonald, 1985), such that news attention increases political learning, through which it is expected to translate into political behaviors (Martinelli \& Chaffee, 1995). Research also suggests that news attention has a direct effect on participation. Shah and colleagues $(2005,2007)$ examined the effect of hard news use on civic and political participation by combining measures of exposure and attention to hard news contents by medium (e.g., newspaper hard news use, television hard news use) and found that newspaper hard news use increased participation. Further, an emerging line of research suggests that the highchoice media environment offers various ways of processing news and information (e.g., posting, endorsing, or reading news), and different news consumption activities yield different democratic outcomes (Choi, 2016; Hyun \& Kim, 2015). While news posting was significantly, positively associated with political participation, news reading was not significantly associated with participation (Choi, 2016). The communication mediation model (Cho et al., 2009; Shah et al., 2005, 2007) and the cognitive mediation model (Eveland, 2001, 2004) suggest that news attention and political discussion, online and offline, are part of information processing, which mobilizes citizens. Therefore, I propose the following hypothesis:

H3b: News attention, political talk, and social media expression will be positively associated with online and offline political participation.

Research provides substantial evidence of the mediating role of political knowledge and political efficacy in the effects of informational use of media on political 
participation (Chan, 2016; Hoffman \& Young, 2011; Hong, 2016; Jung et al., 2011;

McLeod et al., 2001; Prior, 2007). Therefore, I propose the following hypothesis:

H4: Political knowledge and political efficacy will be positively associated with online and offline political participation.

Modeling mediated relationships. Most of the earlier hypotheses imply both direct and indirect effects of self-viewing and curated viewing of political satire on political participation, online and offline. Self-viewing, curated viewing, news attention, political talk, social media expression, political knowledge, and political efficacy are expected to have direct effects on political participation, online and offline.

The O-S-R-O-R model hypothesizes indirect effects in which the information processing activities (i.e., news attention, political talk, social media expression) and cognitive outcomes (i.e., political knowledge, political efficacy) mediate the effects of informational use of media on political behaviors. Therefore, I propose the following hypothesis:

H5a: Self-viewing and curated viewing of political satire will increase online and offline political participation as mediated through news attention, political talk, or social media expression, and political knowledge or political efficacy.

At the same time, given that socially curated media consumption in the networked media environment is more likely to mobilize its viewers, while personally curated media consumption is not or is even negatively associated with political participation (Andersen et al., 2016; Dimitrova et al., 2014; Moeller et al., 2014), it is expected that consumption of socially curated late-night talk show segments would be more effective in facilitating 
political participation than consumption of personally curated late-night talk show segments. Therefore, I propose the following hypothesis:

H5b: Curated viewing of political satire will have a greater effect on online and offline political participation as mediated through news attention, political talk, or social media expression, and political knowledge or political efficacy than self-viewing of political satire.

[Figure 5 here] 


\section{Chapter 4: Research Method}

Based on the O-S-R-O-R framework, this study examines the effects of political satire viewing on participation by proposing structural relationships in which audience factors (i.e., Democrats, Republicans, education, alternative concepts of citizenship, hard news use) serve as background orientations; distinct forms of political satire viewing (i.e. political satire viewing in general vs. hard news use, harsh satire viewing vs. gentle satire viewing, self-viewing vs. curated viewing) as stimuli; news attention, political talk, and social media expression as reasoning processes; political knowledge and political efficacy as outcome orientations; and political participation, online and offline, as responses in three different models (i.e., Model 1, Model 2, Model 3). Simply put, this study examines the roles of information processing activities (i.e., news attention, political talk, social media expression) and cognitive outcomes (i.e., political knowledge, political efficacy) in mediating the effects of political satire viewing on participation.

All three models contain the same reasoning processes (i.e., news attention, political talk, social media expression), outcome orientations (i.e., political knowledge, political efficacy), and responses (offline and online political participation). However, each model uses a different set of stimuli (i.e. political satire viewing in general vs. hard news use; harsh satire viewing vs. gentle satire viewing; self-viewing vs. curated viewing) depending on the focus of the inquiry. Model 1 includes a total of 573 participants who watched or did not watch late-night talk shows. Since Model 1 compares the route through which hard news use influences political participation as mediated through information processing activities and cognitive outcomes to the route that goes 
through political satire viewing instead, this model has Democrats, Republicans, education, and alternative concepts of citizenship as background orientation variables. Model 2 and Model 3 include a total of 315 participants who watched late-night talk shows. Since these models examine the link between hard news use and different types of political satire viewing and its fluence on participation as mediated through the same information processing activities and cognitive outcomes, they have Democrats, Republicans, education, and hard news use as background orientation variables instead.

I used parcels of items for some of the latent variables (i.e., hard news, political satire, harsh satire, gentle satire, curated viewing of political satire, political talk). Parceling is an analytic tool to bring the manifest information into the latent space and optimize the representation of the latent variable (Little, Rhemtulla, Gibson, \& Schoemann, 2013). Parcels are "aggregate-level [indicators] comprised of the sum (or average) of two or more items, responses, or behaviors" (Little, Cunningham, Shahar, \& Widaman, 2002, p. 152). Parceling reduces parameter estimates, improves identification of the latent variable, and increases measurement reliability (Kline, 2011; Little et al., 2002). Employing a balancing approach, I made the parceling decisions based on loadings (Little et al., 2002, 2013). Specifically, I used the three items with the highest loadings to anchor the three parcels first. I paired the highest loaded item from the anchor items with the lowest loaded item. The next highest item and next lowest item were paired to form the second parcel. The third highest and third lowest were paired in the third parcel. This basic procedure continued by placing lower loaded items with higher loaded parcels.

\section{Procedure}


A survey questionnaire was created using Qualtrics. Subjects $(N=573)$ were recruited via Amazon's Mechanical Turk (MTurk) and completed this survey with a payment of $\$ 1.00$. I set the location such that only people living in the United States could participate. In order to achieve high quality data collections with MTurk (Lowry, D’Arcy, Hammer, \& Moody, 2016), respondents had at least a 90\% approval rating. All data were collected on February 1, 2017. The expected time of survey completion was 30 minutes to one hour, and the mean elapsed time was 17 minutes and the median elapsed time was 15 minutes. After screening out participants who (a) had missing data, (b) spent less than 7 minutes to complete the survey, or (c) was 80 years old or older, it resulted in a total of 573 participants in the analysis. Research suggests that MTurk respondents are not quite different from those on other survey platforms (Huff \& Tingley, 2015), and the data obtained via MTurk are at least as reliable as those obtained through conventional methods (Buhrmester, Kwang, \& Gosling, 2011; Steelman, Hammer, \& Limayem, 2014). MTurk is also considered to be more representative of the general population (Lowry et al., 2016).

Once participants agreed to participate, they were presented with questions about their general media use, late-night talk show viewing, perception of news and citizenship, news attention, political talk, social media expression, political participation, political efficacy, and political knowledge, followed by demographic questions.

\section{Model 1}

Overview. Model 1 examines if and how political satire mobilizes its viewers in the place of or in addition to hard news. This model proposes structural relationships in which audience factors (i.e., Democrats, Republicans, education, alternative concepts of 
citizenship) serve as background orientations; political satire viewing in general and hard news use as stimuli; news attention, political talk, and social media expression as reasoning processes; political knowledge and political efficacy as outcome orientations; and political participation, online and offline, as responses.

Participants. Respondents ranged in age from 18 to $74(M=37.25, S D=11.91)$. A slight majority self-identified as female $(N=308,54 \%)$, and most were white $(N=$ $441,77 \%)$ compared to African American $(N=45,8 \%)$, Asian $(N=30,5 \%)$, or Hispanic/Latinx $(N=23,4 \%)$. Many reported having completed a bachelor's degree $(N=$ $214,37 \%)$ or a postgraduate degree $(N=93,16 \%)$. Consistent with the national trend of party identification, respondents were more likely to identify as Democrat or Democrat leaning $(N=259,45 \%)$ than Republican or Republican leaning $(N=157,27 \%)$. Twentyseven percent of the respondents identified as independent $(N=155)$. Two participants opted not to provide their age, gender, education level and partisanship.

\section{Measures.}

Education. This variable was created as an indicator variable by coding 1 if the respondent has a college degree or beyond and 0 if not (68\% College degree or beyond).

Alternative Concepts of Citizenship. Participants responded to two items on a 1

to 7 agreement scale $(1=$ strongly disagree and $7=$ strongly agree $)$ : "News is a dominant source of political information and a good citizen should follow news to be informed of public and civic affairs (reversed)" and "Citizens should be informed about public and civic affairs by following news media (reversed)" ( $M=2.50, S D=1.17, r=.619 * *)$.

Hard News Use. Use of specific traditional news media was measured.

Participants were asked how many days in the past week (0-7) they read or watched (a) 
The printed version of The New York Times; (b) The New York Times online; (c) The printed version of The Wall Street Journal; (d) The Wall Street Journal online; (e) The printed version of The Washington Post; (f) The Washington Post online; (g) NBC Nightly News with Lester Holt on television; (h) NBC Nightly News with Lester Holt online; (i) ABC World News Tonight with David Muir on television; (j) ABC World News Tonight with David Muir online; (k) CBS Evening News with Scott Pelley on television; (1) CBS Evening News with Scott Pelley online; (m) PBS NewsHour on television; and (n) PBS NewsHour online $(M=76, S D=.99, \alpha=.90)$.

Political Satire Viewing. To achieve a reasonably complete estimate of what programs respondents were watching, use of specific programs was measured. Participants were asked on a 5-point scale $(0=$ never and $4=$ a great deal $)$ how often they tended to watch the following late-night talk shows during the past 12 months: (a) The Tonight Show Starring Jimmy Fallon; (b) Late Show with Stephen Colbert; (c) Jimmy Kimmel Live; (d) Late Night with Seth Meyers; (e) Late Late Show with James Corden; (f) Last Call with Carson Daly; (g) The Daily Show with Trevor Noah; (h) Conan; (i) Saturday Night Live; (j) Last Week Tonight with John Oliver; and (k) Full Frontal with Samantha Bee $(M=.71, S D=.81, \alpha=.91)$.

News Attention. Participants were asked to respond, on a 7-point scale $(1=$ very little attention and $7=$ very close attention), to three items borrowed from Shah and colleagues (2007). I asked how much attention in the past week they paid to (a) “newspaper stories about state and national politics?”; (b) “television news stories about 
state and national politics?"; and (c) “online news stories about state and national politics?" $(M=4.59, S D=1.50, \alpha=.61)$.

Political Talk. Participants were asked to respond to 11 items borrowed from Jung and colleagues (2011) on a 5-point scale $(0=$ never and $4=$ a great deal $)$ I asked respondents how often during the past 12 months they talked about politics with (a) "friends and family"; (b) "coworkers and acquaintances"; (c) "strangers"; (d) "people who agree with me"; (e) "people who disagree with me"; (f) "people who are more knowledgeable about politics than I am"; (g) "people who are less knowledgeable about politics than I am"; (h) "people outside my family who do not share my ethnicity, socioeconomic status, or gender"; (i) "people who back up their arguments with evidence"; (j) "people who are unreasonable and illogical when stating their point of view"; and (k) "people who propose alternatives or policies for problem solving" $(M=$ $1.88, S D=.69, \alpha=.87)$.

Social Media Expression. Participants were asked to respond to three items adapted from Jung and colleagues (2011) on a 5-point scale $(0=$ never and $4=$ a great deal). I asked respondents how often during the past 12 months they did (a) "post or share comments or opinions about current political events and public affairs on social media (e.g., Facebook, Twitter, YouTube)?”; (b) "post or share videos about current political events and public affairs on social media (e.g., Facebook, Twitter, YouTube)?"; and (c) "post or share articles about current political events and public affairs on social media (e.g., Facebook, Twitter, YouTube)?” $(M=1.31, S D=1.22, \alpha=.93)$. 
Political Knowledge. Participants were asked to answer the following 11 questions regarding the biographies and issue positions of presidential candidates and civic knowledge adapted from Young (2004): (a) "Which of these served as a Secretary of State?"; (b) "Which of these was born in New York City and graduated from New York Military Academy?"; (c) "Who says global warming and climate change are a hoax?"; (d) "Who cast doubt on Russia's hacking role and praised Russian President Vladimir Putin during the presidential campaign?"; (e) "Who initiated the vote recount efforts in Michigan, Wisconsin, and Pennsylvania after the presidential election?”; (f) "Which political party has a majority in the U.S. House of Representatives?"; (g) "Whose responsibility is it to nominate judges to the Federal Courts?"; (h) "How much of a majority is needed for the U.S. Senate and House to override a presidential veto?"; (i) "What job is currently held by Paul Ryan?"; (j) "Who has the final responsibility to decide if a law is constitutional or not?"; and (k) "In which institution does a presidential candidate have to get a majority votes to win the election?" Respondents were given 15 seconds to answer each question. Correct answers were coded as 1 and then were summed to create an overall knowledge score, with a score of 11 representing those most knowledgeable and 0 the least $(M=8.57, S D=2.14, \alpha=.70)$.

Political Efficacy. Participants responded to three items borrowed from Park (2015) on a 1 to 7 agreement scale $(1=$ strongly disagree and $7=$ strongly agree $)$ : (a) "I consider myself to be well qualified to participate in politics"; (b) "I feel that I have a pretty good understanding of the important political issues facing our country"; and (c) "I think that I am as much informed about politics and government as most people" $(M=$ $5.22, S D=1.20, \alpha=.86)$. 
Offline Political Participation. Participants were asked to respond to 10 items adapted from Jung and colleagues (2011) on a yes/no basis. I asked if, during the past 12 months, they did: (a) "speak to a public official in person?"; (b) “call or send a letter to an elected public official?"; (c) "participate in any demonstrations, protests, or marches?"; (d) "attend a political meeting, rally, or speech?"; (e) "encourage someone to vote?"; (f) "wear a campaign button or T-shirt?"; (g) "display a campaign bumper sticker or yard sign?"; (h) "work for a political party or candidate?"; (i) "get involved in political action groups, political clubs, or party committees?"; and (j) "participate in groups that took any local action for social or political reform?" Each participation was coded as 1 and then was summed to create an overall offline participation score, with a score of 10 representing those most politically active offline and 0 the least $(M=1.93, S D=2.20, \alpha$ $=.82)$.

Online Political Participation. Participants were asked to respond to five items adapted from Jung and colleagues (2011) on a yes/no basis. I asked if, during the past 12 months, they did: (a) "send e-mails to politicians?"; (b) “visit a campaign or candidate advocacy website?”; (c) “make contributions to a political campaign online?”; (d) "subscribe to a political listserv?"; and (e) "sign up online to volunteer for the activities of political parties?" Each participation was coded as 1 and then was summed to create an overall online participation score, with a score of 5 representing those most politically active online and 0 the least $(M=1.04, S D=1.29, \alpha=.71)$.

Control Variables. Age, gender, race and political interest were included as covariates. Age was measured with a single item asking respondents of their age $(M=$ 
$37.25, S D=11.91)$. Gender was measured with one item asking participants their biological sex (54\% Female). Race was measured by asking respondents their race. They were instructed to select all that apply. I coded participants who selected "White" only as White (77\% White). Political interest was assessed by asking participants how much interested they are in (a) "the presidential election"; (b) "elections for officials in your state"; and (c) "political news (non-election related)." Response options ranged from not at all interested (0) to extremely interested (4). Scores of the three items were averaged $(M=2.65, S D=.92, \alpha=.82)$.

\section{Model 2}

Overview. Model 2 is concerned about whether and how similarly or differently harsh satire viewing and gentle satire viewing influence political participation. This model proposes structural relationships in which audience factors (i.e., Democrats, Republicans, education, hard news use) serve as background orientations; harsh satire viewing and gentle satire viewing as stimuli; news attention, political talk, and social media expression as reasoning processes; political knowledge and political efficacy as outcome orientations; and political participation, online and offline, as responses.

Participants. This model includes the responses of 315 participants who answered they watched late-night talk shows. Respondents ranged in age from 19 to 72 $(M=36.37, S D=11.71)$. A slight majority identified as female $(N=169,54 \%)$, and most were white $(N=242,77 \%)$ compared to African American $(N=25,8 \%)$, Asian $(N=21$, $7 \%)$, or Hispanic/Latinx $(N=12,4 \%)$. Many reported having completed a bachelor's degree $(N=106,34 \%)$ or a postgraduate degree $(N=54,17 \%)$. Consistent with the national trend of party identification, respondents were more likely to identify as 
Democrat or Democrat leaning $(N=160,51 \%)$ than Republican or Republican leaning $(N$ $=73,23 \%)$. Twenty-six percent of the respondents identified as independent $(N=81)$. One participant did not provide his or her age, race, gender, education level, and partisanship.

Measures. In Model 2, I used two distinct types of satire: harsh satire and gentle satire. Research has shown that satirical television programs are not created equal and satirical message type matters in the persuasive effects of political satire (Holbert et al., 2011). The Tonight Show with Jay Leno and Late Show with David Letterman are different from The Daily Show in terms of political content, message level and satirical tone, which results in different effects on political outcomes (Cao \& Brewer, 2008; Hoffman \& Young, 2011). I ran a factor analysis to identify these two distinct types of satire (see Table 1). I used Late Show with Stephen Colbert as an anchor for the harsh satire group since Holbert et al. (2011) described Stephen Colbert's harsh and bitter humor as a good example of harsh or juvenalian satire.

Education. This variable was created as an indicator variable by coding 1 if the respondent has a college degree or beyond and 0 if not (70\% College degree or beyond). Hard News Use. Participants were asked how many days in the past week (0-7) they read or watched (a) The printed version of The New York Times; (b) The New York Times online; (c) The printed version of The Wall Street Journal; (d) The Wall Street Journal online; (e) The printed version of The Washington Post; (f) The Washington Post online; (g) NBC Nightly News with Lester Holt on television; (h) NBC Nightly News with Lester Holt online; (i) ABC World News Tonight with David Muir on television; (j) ABC World News Tonight with David Muir online; (k) CBS Evening News with Scott Pelley on 
television; (1) CBS Evening News with Scott Pelley online; (m) PBS NewsHour on television; and (n) PBS NewsHour online. Responses were averaged to create an overall hard news use score $(M=.97, S D=1.13, \alpha=.91)$.

Harsh Satire Viewing. Participants were asked on a 5-point scale ( $0=$ never and 4=a great deal) how often they tended to watch the following late-night talk shows during the past 12 months: (a) "Late Show with Stephen Colbert"; (b) "The Daily Show with Trevor Noah"; (c) "Last Week Tonight with John Oliver"; and (d) "Full Frontal with Samantha Bee" $(M=1.25, S D=.97, \alpha=.73)$.

Gentle Satire Viewing. Participants were asked on a 5-point scale $(0=n e v e r$ and $4=a$ great deal ) how often they tended to watch the following late-night talk shows during the past 12 months: (a) "The Tonight Show Starring Jimmy Fallon”; (b) “Jimmy Kimmel Live"; (c) "Late Night with Seth Meyers"; (d) "Late Late Show with James Corden"; (e) "Last Call with Carson Daly"; (f) "Conan"; and (g) "Saturday Night Live" $(M=1.31, S D=.73, \alpha=.78)$.

News Attention. Participants were asked to respond, on a 7-point scale $(1=$ very little attention and $7=$ very close attention), to three items borrowed from Shah and colleagues (2007). I asked how much attention in the past week they paid to (a) "newspaper stories about state and national politics?"; (b) "television news stories about state and national politics?"; and (c) "online news stories about state and national politics?” $(M=4.84, S D=1.40, \alpha=.62)$. 
Political Talk. Participants were asked to respond to 11 items borrowed from Jung and colleagues (2011) on a 5-point scale $(0=$ never and $4=$ a great deal $)$. I asked respondents how often during the past 12 months they talked about politics with (a) "friends and family"; (b) "coworkers and acquaintances"; (c) "strangers"; (d) "people who agree with me"; (e) "people who disagree with me"; (f) "people who are more knowledgeable about politics than I am"; (g) "people who are less knowledgeable about politics than I am"; (h) "people outside my family who do not share my ethnicity, socioeconomic status, or gender”; (i) “people who back up their arguments with evidence"; (j) "people who are unreasonable and illogical when stating their point of view"; and (k) "people who propose alternatives or policies for problem solving" $(M=$ $1.94, S D=.69, \alpha=.87)$.

Social Media Expression. Participants were asked to respond to three items adapted from Jung and colleagues (2011) on a 5-point scale $(0=$ never and $4=$ a great deal). I asked respondents how often during the past 12 months they did (a) "post or share comments or opinions about current political events and public affairs on social media (e.g., Facebook, Twitter, YouTube)?”; (b) "post or share videos about current political events and public affairs on social media (e.g., Facebook, Twitter, YouTube)?”; and (c) "post or share articles about current political events and public affairs on social media (e.g., Facebook, Twitter, YouTube)?” $(M=1.39, S D=1.22, \alpha=.93)$.

Political Knowledge. Participants were asked to answer the following 11 questions regarding the biographies and issue positions of presidential candidates and civic knowledge adapted from Young (2004): (a) "Which of these served as a Secretary 
of State?"; (b) "Which of these was born in New York City and graduated from New York Military Academy?”; (c) "Who says global warming and climate change are a hoax?”; (d) "Who cast doubt on Russia's hacking role and praised Russian President Vladimir Putin during the presidential campaign?"; (e) “Who initiated the vote recount efforts in Michigan, Wisconsin, and Pennsylvania after the presidential election?”; (f) "Which political party has a majority in the U.S. House of Representatives?"; (g) "Whose responsibility is it to nominate judges to the Federal Courts?"; (h) "How much of a majority is needed for the U.S. Senate and House to override a presidential veto?”; (i) "What job is currently held by Paul Ryan?"; (j) "Who has the final responsibility to decide if a law is constitutional or not?"; and (k) "In which institution does a presidential candidate have to get a majority votes to win the election?" Correct answers were coded as 1 and then were summed to create an overall knowledge score, with a score of 11 representing those most knowledgeable and 0 the least $(M=8.43, S D=2.15, \alpha=.68)$.

Political Efficacy. Participants responded to three items borrowed from Park (2015) on a 1 to 7 agreement scale ( $1=$ strongly disagree and $7=$ strongly agree): (a) "I consider myself to be well qualified to participate in politics"; (b) "I feel that I have a pretty good understanding of the important political issues facing our country"; and (c) "I think that I am as much informed about politics and government as most people" $(M=$ $5.21, S D=1.16, \alpha=.83)$.

Offline Political Participation. Participants were asked to respond to 10 items adapted from Jung and colleagues (2011) on a yes/no basis. I asked if, during the past 12 months, they did: (a) "speak to a public official in person?"; (b) “call or send a letter to an 
elected public official?"; (c) "participate in any demonstrations, protests, or marches?"; (d) "attend a political meeting, rally, or speech?"; (e) “encourage someone to vote?”; (f) “wear a campaign button or T-shirt?”; (g) “display a campaign bumper sticker or yard sign?”; (h) “work for a political party or candidate?"; (i) "get involved in political action groups, political clubs, or party committees?"; and (j) "participate in groups that took any local action for social or political reform?" Each participation was coded as 1 and then was summed to create an overall offline participation score, with a score of 10 representing those most politically active offline and 0 the least $(M=2.24, S D=2.37, \alpha$ $=.83)$.

Online Political Participation. Participants were asked to respond to five items adapted from Jung and colleagues (2011) on a yes/no basis. I asked if, during the past 12 months, they did: (a) "send e-mails to politicians?"; (b) “visit a campaign or candidate advocacy website?”; (c) "make contributions to a political campaign online?”; (d) "subscribe to a political listserv?"; and (e) "sign up online to volunteer for the activities of political parties?" Each participation was coded as 1 and then was summed to create an overall online participation score, with a score of 5 representing those most politically active online and 0 the least $(M=1.14, S D=1.34, \alpha=.71)$.

Control Variables. Age, gender, race and political interest were included as covariates. Age was measured with a single item asking respondents of their age $(M=$ 36.37, $S D=11.71)$. Gender was measured with one item asking participants their biological sex (54\% Female). Race was measured by asking respondents their race. They were instructed to select all that apply. I coded participants who selected "White" only as 
White (77\% White). Political interest was assessed by asking participants how much interested they are in (a) "the presidential election"; (b) "elections for officials in your state"; and (c) "political news (non-election related)." Response options ranged from not at all interested (0) to extremely interested (4). Scores of the three items were averaged $(M=2.74, S D=.87, \alpha=.81)$.

\section{Model 3}

Overview. Model 3 is concerned about whether and how similarly or differently self-viewing and curated viewing of political satire influence political participation. This model proposes structural relationships in which audience factors (i.e., Democrats, Republicans, education, hard news use) serve as background orientations; self-viewing and curated viewing as stimuli; news attention, political talk, and social media expression as reasoning processes; political knowledge and political efficacy as outcome orientations; and political participation, online and offline, as responses.

\section{Participants. Same as Model 2.}

Measures. In Model 3, I used two distinct types of political satire viewing: selfviewing and curated viewing. Research has shown that the networked media environment provides different meida experiences than the traditional media environment, thereby resulting in different democratic outcomes (Andersen et al., 2016; Dimitrova et al., 2014; Moeller et al., 2014). People actively curate media contents on social media, by filtering, reshaping, and reframing the contents with personal evaluations and social significance (Hermida et al., 2012). And the socially curated media contents are actively consumed (Domingo et al., 2008; Rosenstiel et al., 2017; Villi, 2012), which influences political attitudes and behaviors (Bode, 2012; Bond et al., 2012; Hong, 2016). Therefore, self- 
viewing is defined as a media consumption activity that is directed, driven, and guided by one's motivation and operationalized as watching late-night talk shows on television. On the other hand, curated viewing is defined as a media consumption activity that is directed, driven, and guided by others' comments or recommendations in the digital media environment and operationalized as watching late-night talk shows on social media platforms or via the digital media environment through others' comments or recommendations.

Education. Same as Model 2.

Hard News Use. Same as Model 2.

Self-viewing of Political Satire. Participants were asked to respond to the following one item on a 5-point scale $(0=$ never and $4=$ a great deal): "About how often during the past 12 months did you watch late-night talk shows on television (live or recorded)?" $(M=2.30, S D=1.20)$.

Curated Viewing of Political Satire. Participants were asked on a 5-point scale (0 $=$ never and $4=a$ great deal) that about how often during the past 12 months they watched late-night talk shows (a) "on Facebook"; (b) “on Twitter”; (c) “on YouTube”; (d) "after hearing about it via email"; (e) "after hearing about it via instant messaging"; and (f) "when you were guided to them by news sources like the Wall Street Journal, ABC news, and your local newspapers, or other news media online (e.g., Politico, Huffington Post $) "(M=1.14, S D=.73, \alpha=.74)$.

News Attention. Same as Model 2.

Political Talk. Same as Model 2.

Social Media Expression. Same as Model 2. 
Political Knowledge. Same as Model 2.

Political Efficacy. Same as Model 2.

Offline Political Participation. Same as Model 2.

Online Political Participation. Same as Model 2.

Control Variables. Same as Model 2. 


\section{Chapter 5: Results}

\section{Analysis 1}

Preliminary correlation analyses showed positive correlations between hard news use and all the key variables included in the analyses except for Republicans, alternative concepts of citizenship, and political knowledge. It was negatively associated with political knowledge. Political satire viewing was positively associated with all the key variables except for Republicans, alternative concepts of citizenship, political knowledge and political efficacy. It was negatively associated with Republicans, alternative concepts of citizenship, and political knowledge. Both online and offline political participation was positively associated with all the key variables included in the analyses except for alternative concepts of citizenship and Republicans (see Table 2). For a note, hard news use was positively associated with political satire viewing $(r=.466, p<.001)$. Hard news use was positively associated with both offline $(r=.312, p<.001)$ and online political participation $(r=.207, p<.001)$. Political satire viewing was positively associated with both offline $(r=.263, p<.001)$ and online political participation $(r=.125, p<.01)$.

All the hypotheses were tested in structural equation modeling (SEM) using Lavaan (Rosseel, 2012) for the R ecosystem. The analysis included seven latent variables (alternative concepts of citizenship, hard news use, political satire viewing, news attention, political talk, social media expression, and political efficacy) and three manifest variables (political knowledge, offline political participation, and online political participation) as well as dummy variables, including Democrats, Republicans, and education. Little, Rhemtulla, Gibson and Schoemann (2013) contend that over-identified 
latent variables should be parceled to make sure all variables are just-identified,

containing only three indicators. In accordance with this recommendation, hard news use was parceled by averaging the sixth, eighth, ninth, tenth, and thirteenth indicators; first, second, fourth, fifth, and fourteenth indicators; and third, seventh, eleventh, and twelfth indicators. Political satire viewing was parceled by averaging the first, third, seventh, and eleventh indicators; the fourth, fifth, sixth, and ninth indicators; and the second, eighth, and tenth indicators. Political talk was parceled by averaging the first, second, fifth, and tenth indicators; the third, sixth, seventh, and eleventh indicators; and the fourth, eighth, and ninth indicators. ${ }^{1}$ I also allowed the two stimuli (i.e., hard news use and political satire viewing) and the three reasoning variables (i.e., news attention, political talk, and social media expression) to covary respectively in their affiliated steps to resemble reallife media consumption and communication. For the same reason, the two outcome orientation variables (i.e., political knowledge, political efficacy) were allowed to covary as well.

A two-step procedure recommended by Kline (2016) was adopted in which a measurement model was fit to confirm the factor structure of the latent variables first, and then a structural model was fit to evaluate the hypothesized paths.

\footnotetext{
${ }^{1}$ Fitting the model without parceling the items in the hard news use, political satire viewing, and political talk resulted in substantially worse model fit, $\chi 2(1014)=3178.679$, $p<.001, \mathrm{RMSEA}=.061(.059-063), \mathrm{CFI}=.812, \mathrm{NNFI} / \mathrm{TLI}=.800, \mathrm{SRMR}=.075$. Employing a balancing approach, I made the parceling decisions based on loadings such that three items with the highest loadings were identified first to anchor the three parcels and paired with lower loaded items to form each parcel (Little, Cunningham, Shahar, \& Widaman, 2002; Little, Rhemtulla, Gibson, \& Schoemann, 2013). The parceling resolved misfit, $\chi 2(150)=346.961, p<.001$, RMSEA $=.048(.041-.054), \mathrm{CFI}=.967, \mathrm{NNFI} / \mathrm{TLI}$ $=.958, \mathrm{SRMR}=.040$.
} 
All direct effects were generated using MLR, a robust Maximum Likelihood estimation in Lavaan for R. MLR is well known to correct for non-normality-induced biases in the standard errors and more accurately capture the appropriate amount of misfit in the model (Finney \& DiStefano, 2006; Rosseel, n.d.; Satorra \& Bentler, 2010). All mediated hypotheses were tested by examining the confidence interval of the product of the direct paths to determine whether it crossed zero (Preacher \& Hayes, 2008). The measurement model achieved adequate fit, $\chi 2(150)=346.961, p<.001$, RMSEA $=.048$ $(.041-054), \mathrm{CFI}=.967, \mathrm{NNFI} / \mathrm{TLI}=.958, \mathrm{SRMR}=.040$. A structural model was then fit to evaluate the hypothesized paths. In addition to the theoretical variables, dummy variables were included to indicate whether participants had identified themselves as Republicans or Democrats and whether they had obtained college degrees or beyond. Each theoretical variable was also regressed on control variables for age, gender $(1=$ female), race $(1=$ White $)$, and political interest. The structural model fit was adequate, $\chi 2(287)=706.177, p<.001, \mathrm{RMSEA}=.051(.046-.055), \mathrm{CFI}=.942, \mathrm{NNFI} / \mathrm{TLI}=.916$, SRMR $=.063$. The final path model is presented in Figure 2. Direct effects are presented in Table 3. Significant indirect effects are presented in Table 4.

[Figure 2 here]

[Table 3 here]

[Table 4 here]

H1 predicted that being Democrat, being higher educated, or alternative concepts of citizenship would be associated with greater use of political satire. At the same time, it was also predicted that being higher educated would be positively associated with hard news use, but alternative concepts of citizenship would be negatively associated with 
hard news use. Meanwhile, I hypothesized that Democrats and Republicans would not be associated with hard news use and Republicans would not be associated with political satire viewing either. As illustrated in Figure 2 and recorded in Table 3, the results are generally consistent with the hypotheses. As predicted, Democrats were more likely to watch late-night talk shows but were not significantly associated with hard news use. Republicans were not significantly associated with both hard news use and political satire viewing. Highly educated participants were more likely to consume both late-night talk shows and hard news. However, inconsistent with the hypotheses, alternative concepts of citizenship were not significantly associated with either hard news use or political satire viewing.

$\mathrm{H} 2$ predicted that both hard news use and political satire viewing would be associated with greater political participation, both online and offline, greater news attention, greater political expression, both online and offline, higher political knowledge, and greater political efficacy. The results presented in Table 3 are partially consistent with these hypotheses. For hard news use, every one-unit increase in hard news use was associated with a corresponding .151-point increase in news attention, .162-point increase in political talk, .287-point increase in social media expression, .379-point increase in offline participation, and .201-point increase in online participation. However, inconsistent with the hypotheses, hard news use was negatively associated with political knowledge, such that every one-point increase in hard news use was associated with a corresponding .714-point decrease in political knowledge. Also, hard news use was not significantly associated with political efficacy. For political satire viewing, inconsistent with the hypotheses, I found no significant direct association between political satire 
viewing and the reasoning, outcome orientation, and response variables except for political efficacy. Contrary to the prediction, the direct association between political satire viewing and political efficacy was negative, such that every one-unit increase in political satire viewing was associated with a corresponding .150-point decrease in political efficacy.

$\mathrm{H} 3$ predicted that news attention and online and offline political expression would be associated with higher political knowledge, greater political efficacy, and greater political participation, both online and offline. The results presented in Table 3 are generally consistent with the hypotheses. News attention was positively associated with political efficacy, such that, for each one-unit increase in news attention, political efficacy increased by .250 points. Political talk was positively associated with offline and online political participation, such that, for each one-unit increase in political talk, offline participation increased by .305 points and online participation by .123 points. Social media expression was also positively associated with political participation, both offline and online, such that, for each one-unit increase in social media expression, offline participation increased by .390 points and online participation by .239 points. However, inconsistent with the hypotheses, news attention was not significantly associated with political knowledge and offline and online participation. Political talk was not significantly related to political knowledge and political efficacy. Social media expression was not significantly associated with political efficacy, but negatively associated with political knowledge, such that every one-unit increase in social media expression was associated with a corresponding .189-point decrease in political knowledge. 
$\mathrm{H} 4$ predicted that greater political knowledge and efficacy would be associated with greater political engagement, online and offline. The results were partially consistent with these hypotheses. Every one-unit increase in political knowledge was associated with a .079-point increase in online participation, but not with offline participation. Political efficacy was not significantly associated with both offline and online participation.

H5 predicted that both hard news use and political satire viewing would increase news attention, political talk, and social media expression, and, as a result, engender political knowledge and efficacy, thereby increasing online and offline participation. Also, it was predicted that both hard news use and political satire viewing would influence online and offline political participation through similar mediating processes. As illustrated in Figure 2 and recorded in Table 3, these hypotheses were not supported. Political satire viewing appears not to have any effect on participation, both directly and indirectly. On the other hand, hard news use appears to have positive effects on participation, both directly and indirectly, but the proposed O-S-R-O-R model was not supported. What is noticeable here, however, is that an O-S-R-R model emerged as a better model to explain the participatory effects of hard news use in the contemporary media environment. As documented in Table 4, there were significant indirect associations between hard news use and political participation, online and offline, through political talk and social media expression. Specifically, among highly educated people, those who consume hard news are more likely to participate in politics, both online and offline, by engaging more in both conventional and nonconventional political expression. 


\section{Analysis 2}

Preliminary correlation analyses showed positive correlations between harsh satire viewing and all the key variables included in the analyses except for Republicans. It was negatively associated with Republicans. Gentle satire viewing was positively associated with all the key variables except for Republicans, Democrats, education, political knowledge, political efficacy, and online political participation. It was negatively associated with political knowledge. Offline political participation was positively associated with all the key variables included in the analyses except for Republicans, Democrats, and political knowledge. Online political participation was positively associated with all the key variables included in the analyses except for Republicans and gentle satire viewing (see Table 5). For a note, harsh satire viewing was positively associated with gentle satire viewing $(r=.290, p<.001)$. Harsh satire viewing was positively associated with both offline $(r=.318, p<.001)$ and online political participation $(r=.270, p<.001)$. Gentle satire viewing was positively associated with offline political participation $(r=.170, p<.01)$.

As in Analysis 1, all the hypotheses were tested in structural equation modeling (SEM) using Lavaan (Rosseel, 2012) for the R ecosystem. The analysis included six latent variables (harsh satire viewing, gentle satire viewing, news attention, political talk, social media expression, and political efficacy) and four manifest variables (hard news use, political knowledge, offline political participation, and online political participation) as well as dummy variables, including Democrats, Republicans, and education. Overidentified latent variables were parceled. Harsh satire viewing was parceled by averaging the first and fourth indicators. Gentle satire viewing was parceled by averaging the first 
and third indicators; the second, fifth and seventh indicators; and the fourth and sixth indicators. Political talk was parceled by averaging the first, second, and eighth indicators; the third, fifth, sixth, and tenth indicators; and the fourth, seventh, and ninth, and eleventh indicators. ${ }^{2}$ I also allowed the two stimuli (i.e., harsh satire viewing and gentle satire viewing), the three reasoning variables (i.e., news attention, political talk, and social media expression), and the two outcome orientation variables (i.e., political knowledge, political efficacy) to covary.

The two-step procedure recommended by Kline (2016) was adopted. The measurement model achieved adequate fit, $\chi 2(120)=197.107, p<.001$, RMSEA $=.045$ $(.034-056), \mathrm{CFI}=.966, \mathrm{NNFI} / \mathrm{TLI}=.957, \mathrm{SRMR}=.044$. A structural model was then fit to evaluate the hypothesized paths. In addition to the theoretical variables, dummy variables were included to indicate whether participants had identified themselves as Republicans or Democrats and whether they had obtained college degrees or beyond. Each theoretical variable was also regressed on control variables for age, gender $(1=$ female), race $(1=$ White $)$, and political interest. The structural model fit was adequate, $\chi 2(252)=398.920, p<.001, \mathrm{RMSEA}=.043(.036-.050), \mathrm{CFI}=.952, \mathrm{NNFI} / \mathrm{TLI}=.928$, SRMR $=.043$. The final path model is presented in Figure 4. Direct effects are presented in Table 6. Significant indirect effects are presented in Table 7.

\footnotetext{
${ }^{2}$ Fitting the model without parceling the items in harsh satire viewing, gentle satire viewing, and political talk resulted in substantially worse model fit, $\chi 2(419)=862.932, p$ $<.001, \mathrm{RMSEA}=.058(.053-063), \mathrm{CFI}=.872, \mathrm{NNFI} / \mathrm{TLI}=.858, \mathrm{SRMR}=.064$. Employing a balancing approach, I made the parceling decisions based on loadings such that three items with the highest loadings were identified first to anchor the three parcels and paired with lower loaded items to form each parcel (Little et al., 2002, 2013). The parceling resolved misfit, $\chi 2(120)=197.107, p<.001, \mathrm{RMSEA}=.045(.034-.056), \mathrm{CFI}$ $=.966, \mathrm{NNFI} / \mathrm{TLI}=.957, \mathrm{SRMR}=.044$.
} 
[Figure 4 here]

[Table 6 here]

[Table 7 here]

H1 predicted that being Democrat, being higher educated, or hard news use would be associated with greater use of both harsh and gentle satire. At the same time, it was also predicted that Republicans would not be significantly associated with both harsh and gentle satire viewing. As illustrated in Figure 4 and recorded in Table 6, the results are partially consistent with the hypotheses. Those who consume hard news were more likely to watch both types of satire. Democrats were more likely to watch harsh satire, but not significantly associated with gentle satire viewing. Education was not significantly associated with either type of satire. However, inconsistent with the hypotheses, Republicans were associated with both types of satire, but in different ways. Specifically, Republicans were more likely to consume gentle satire, but, at the same time, more likely to avoid harsh satire.

$\mathrm{H} 2$ predicted that harsh satire viewing would be positively associated with political knowledge and efficacy, and offline and online participation, while gentle satire viewing would not be significantly associated with the cognitive outcome and participation variables. It was also predicted that both harsh and gentle satire viewing would be associated with greater news attention, political talk and social media expression. The results presented in Table 6 are generally consistent with these hypotheses. For harsh satire viewing, every one-unit increase was associated with a corresponding .279-point increase in political knowledge, .377-point increase in offline political participation, and .181-point increase in online political participation. Harsh 
satire viewing was not significantly associated with news attention, political talk, social media expression, and political efficacy. For gentle satire viewing, every one-unit increase was associated with a corresponding .194-point increase in political talk. As predicted, gentle satire viewing was not significantly associated with political efficacy and offline participation. However, inconsistent with the hypotheses, gentle satire viewing was negatively associated with political knowledge and online participation. Specifically, consumption of gentle satire was associated with a .289-point decrease in political knowledge and a .378-point decrease in online participation. Gentle satire viewing was not significantly associated with news attention and social media expression. H3 predicted that news attention, political talk, and social media expression would be associated with higher political knowledge, greater political efficacy, and greater political participation, both online and offline. The results presented in Table 6 are partially consistent with the hypotheses. News attention was positively associated with political efficacy, such that, for each one-unit increase in news attention, political efficacy increased by .373 points. Political talk was positively associated with offline and online political participation, such that, for each one-unit increase in political talk, offline participation increased by .325 points and online participation by .210 points. Social media expression was also positively associated with both types of political participation, such that, for each one-unit increase in social media expression, offline participation increased by .545 points and online participation by .362 points. However, inconsistent with the hypotheses, news attention was not significantly associated with political knowledge and both offline and online participation. Political talk was not significantly related to political knowledge and political efficacy. Social media expression was not 
significantly associated with political efficacy either, but was negatively associated with political knowledge, such that every one-unit increase in social media expression was associated with a corresponding .196-point decrease in knowledge.

$\mathrm{H} 4$ predicted that greater political knowledge and efficacy would be associated with greater political engagement, online and offline. The results were not consistent with these hypotheses. These cognitive outcome variables were not significantly associated with offline and online participation.

$\mathrm{H} 5$ predicted that both harsh and gentle satire viewing would increase news attention, political talk, and social media expression, and, as a result, engender political knowledge and efficacy, thereby increasing both online and offline participation. As illustrated in Figure 4 and recorded in Table 6, this hypothesis was not supported. In other words, the proposed O-S-R-O-R model was not supported. What is noticeable here, however, is that an O-S-R-R model emerged as a better model to explain the participatory effects of gentle satire viewing. As documented in Table 7, there was a significant, but weak indirect association between gentle satire viewing and online political participation through political talk. Specifically, among hard news users, those who watch gentle satire are more likely to participate in politics online by engaging more in political talk.

\section{Analysis 3}

Preliminary correlation analyses showed positive correlations between selfviewing and all the key variables included in the analyses except for Republicans, education, political interest, social media expression, political knowledge, political efficacy, offline and online political participation. Curated viewing was positively associated with all the key variables except for Republicans, Democrats, education, and 
political efficacy. It was negatively associated with political knowledge. Offline political participation was positively associated with all the key variables included in the analyses except for Republicans, Democrats, self-viewing, and political knowledge. Online political participation was positively associated with all the key variables included in the analyses except for Republicans and self-viewing (see Table 8). For a note, self-viewing was positively associated with curated viewing $(r=.131, p<.05)$. Curated viewing was positively associated with both offline $(r=.279, p<.001)$ and online political participation $(r=.217, p<.001)$. Self-viewing was not significantly correlated with both offline and online participation.

As in Analysis 2, all the hypotheses were tested in structural equation modeling (SEM) using Lavaan (Rosseel, 2012) for the R ecosystem. The analysis included six latent variables (self-viewing of political satire, curated viewing of political satire, news attention, political talk, social media expression, and political efficacy) and four manifest variables (hard news use, political knowledge, offline political participation, and online political participation) as well as dummy variables, including Democrats, Republicans, and education. Over-identified latent variables were parceled. Curated viewing of political satire was parceled by averaging the first and seventh indicators; the third and eighth indicators; and the fifth and sixth indicators. Political talk was parceled by averaging the first, second, and eighth indicators; the third, fifth, sixth, and tenth indicators; and the fourth, seventh, ninth, and eleventh indicators. ${ }^{3}$ I also allowed the two

${ }^{3}$ Fitting the model without parceling the items in curated viewing of political satire and political talk resulted in substantially worse model fit, $\chi 2(310)=777.329, p<.001$, RMSEA $=.069(.063-075), \mathrm{CFI}=.851, \mathrm{NNFI} / \mathrm{TLI}=.832, \mathrm{SRMR}=.069$. Employing a balancing approach, I made the parceling decisions based on loadings such that three items with the highest loadings were identified first to anchor the three parcels and paired 
stimuli (i.e., self-viewing of political satire and curated viewing of political satire), the three reasoning variables (i.e., news attention, political talk, and social media expression), and the two outcome orientation variables (i.e., political knowledge, political efficacy) to covary.

The analysis followed the same two-step procedure as in Analysis 2. The measurement model achieved adequate fit, $\chi 2(90)=208.944, p<.001$, RMSEA $=.065$ $(.054-076), \mathrm{CFI}=.943, \mathrm{NNFI} / \mathrm{TLI}=.924, \mathrm{SRMR}=.049$. The structural model fit was adequate, $\chi 2(200)=371.765, p<.001$, RMSEA $=.052(.045-.060)$, CFI $=.939$, $\mathrm{NNFI/TLI}=.901, \mathrm{SRMR}=.043$. The final path model is presented in Figure 6. Direct effects are presented in Table 9. Significant indirect effects are presented in Table 10.

[Figure 6 here]

[Table 9 here]

[Table 10 here]

H1 predicted that being Democrat, being higher educated, or hard news use would be associated with greater use of both self-viewing and curated viewing of political satire. At the same time, it was also predicted that Republicans would not be significantly associated with both types of political satire viewing. As illustrated in Figure 6 and recorded in Table 9, the results are generally consistent with the hypotheses. Consistent with the hypotheses, Republicans were not significantly associated with both selfviewing and curated viewing of political satire. Those who consume hard news were more likely to practice both types of satire viewing. Democrats were more likely to watch

with lower loaded items to form each parcel (Little et al., 2002, 2013). The parceling resolved misfit, $\chi 2(90)=208.944, p<.001$, RMSEA $=.065(.054-.076)$, CFI $=.943$, $\mathrm{NNFI} / \mathrm{TLI}=.924, \mathrm{SRMR}=.049$. 
late-night talk shows on television. However, inconsistent with the hypotheses, education was not significantly associated with either type of political satire viewing, and Democrats were not significantly associated with curated viewing of political satire.

$\mathrm{H} 2$ predicted that curated viewing of political satire would be positively associated with offline and online political participation, while self-viewing of political satire would be negatively associated with both types of participation. It was also predicted that both self-viewing and curated viewing of political satire would be associated with greater news attention, political talk, social media expression, political knowledge and efficacy. The results presented in Table 9 are partially consistent with these hypotheses. For self-viewing of political satire, as predicted, every one-unit increase was associated with a corresponding .122-point increase in political talk and a .188-point decrease in online political participation, respectively. However, inconsistent with the hypotheses, self-viewing was not significantly associated with news attention, social media expression, political knowledge, political efficacy, and offline political participation. For curated viewing of political satire, consistent with the hypotheses, every one-unit increase was associated with a corresponding .264-point increase in political talk and .538-point increase in social media expression, respectively. However, inconsistent with the hypotheses, curated viewing was not significantly associated with news attention, political knowledge, political efficacy, and participation, both online and offline.

$\mathrm{H} 3$ predicted that news attention, political talk, and social media expression would be associated with higher political knowledge, greater political efficacy, and greater political participation, both online and offline. The results presented in Table 9 
are partially consistent with the hypotheses. As predicted, news attention was positively associated with political efficacy, such that, for each one-unit increase in news attention, political efficacy increased by .401 points. Political talk was positively associated with offline and online political participation, such that, for each one-unit increase in political talk, offline participation increased by .352 points and online participation by .175 points. Social media expression was also positively associated with both types of political participation, such that, for each one-unit increase in social media expression, offline participation increased by .487 points and online participation by .310 points. However, inconsistent with the hypotheses, news attention was not significantly associated with political knowledge and both offline and online participation. Political talk and social media expression were not significantly related to political knowledge and political efficacy.

H4 predicted that greater political knowledge and efficacy would be associated with greater political engagement, online and offline. The results were partially consistent with these hypotheses. Political knowledge was associated with online participation, such that, for each one-unit increase in political knowledge, online participation increased by .111 points. However, inconsistent with the hypotheses, political knowledge was not significantly associated with offline participation. Political efficacy was not significantly related to both offline and online participation.

H5 predicted that both self-viewing and curated viewing of political satire would increase news attention, political talk, and social media expression, and, as a result, engender political knowledge and efficacy, thereby increasing both online and offline participation. It was also predicted that curated viewing would have a greater effect on 
offline and online participation as mediated through these reasoning and outcome orientation variables than self-viewing. As illustrated in Figure 6 and recorded in Table 9, these hypotheses were not supported. In other words, the proposed O-S-R-O-R model was not supported. What is noticeable here, however, is that an O-S-R-R model emerged as a better model to explain the participatory effects of curated viewing of political satire. As documented in Table 10, there was a significant indirect association between curated viewing and political participation, both online and offline, through social media expression. Specifically, among hard news users, those who watch late-night talk shows through others' comments or recommendations in the digital media environment are more likely to participate in politics, both online and offline, by engaging more in political expression on social media. 


\section{Chapter 6: General Discussion}

This study systematically examined the mobilizing effects of political satire viewing by accounting for audience characteristics, various types of political satire viewing, discrete channels of media, various contemporary communicative behaviors, and possible cognitive outcomes to explicate the underlying mechanisms between political satire viewing and political participation. Unlike the existing research, which generally focuses on the relationships between political satire viewing and one or two political outcomes (Cao \& Brewer, 2008; Hardy et al., 2014; Hoffman \& Thomson, 2009; Hoffman \& Young, 2011; Holbert, 2013; Moy et al., 2005), treating political satire as monolithic (Holbert et al., 2011), which is only accessible via television (Young, 2016; Young et al., 2014), this study proposed structural relationships in which audience factors (e.g., Democrats, Republicans, education, alternative concepts of citizenship) serve as background orientations; various forms of political satire viewing (i.e., political satire viewing in general vs. hard news use; harsh satire viewing vs. gentle satire viewing; selfviewing vs. curated viewing of political satire) as stimuli; news attention, political talk, and social media expression as reasoning processes; political knowledge and political efficacy as outcome orientations; and political participation, online and offline, as responses, based on the O-S-R-O-R model of communication effects. More importantly, this study examined, for the first time, the role of social media in political satire viewing and its influence on participation. The results suggest that political satire can be used for democratic good in addition to, not in the place of, hard news, and an O-S-R-R model of communication effects is a better model to explain the participatory effects of political 
satire viewing than the O-S-R-O-R model. Specifically, hard news use appears to be an essential prerequisite for the participatory effects of political satire viewing, and partisanship is a key predictor of political satire viewing, such that Democrats are more likely to watch late-night talk shows. Satire type matters, such that harsh satire viewing has a direct, positive effect on participation, while gentle satire viewing has a direct, negative effect on participation. However, among hard news users, those who consume gentle satire and actively engage in political talk are more likely to participate in the political process, which proposes an O-S-R-R model. Most importantly, media channel matters, such that those who watch late-night talk shows on television are less likely to participate in politics, whereas those who watch late-night talk shows in the social media environment are more likely to participate in politics by engaging more in political expression on social media, which also proposes an O-S-R-R model as a better model to explain the effects of political satire viewing on participation. It is worth noting that the proposed O-S-R-O-R model was not supported for the participatory effects of hard news use either. The results suggest that political expression, conventional and nonconventional, is a key mediator between hard news use and participation in the contemporary media environment.

Consistent with research on political satire (Choi et al., 2018; Gottfried \& Anderson, 2014; Gottfried et al., 2015), Democrats were more likely to watch late-night talk shows. What is noticeable here is that Republicans were not significantly associated with political satire viewing in general, but when satire type was accounted for, Republicans are more likely to avoid harsh satire, but more likely to watch gentle satire. These findings suggest that Republicans tune in to late-night talk shows mainly focusing 
on light, gentle punchline jokes, but, at the same time, actively avoid late-night talk shows mainly focusing on harsh, rhetorical criticism, which challenges their pre-existing viewpoints. More importantly, hard news use appears to be an essential prerequisite for the participatory effects of political satire viewing, regardless of types of satire and viewing. As Young and Tisinger (2006) did, these findings challenge the popular and scholarly assumption that people tune in to these late-night talk shows for news and information instead of hard news. Specifically, as Caufield (2008) suggests, political satire viewers appeared to follow traditional news media to be familiar with the topic or target of the satirical attack, so that they could fully play with the satirist and laugh as an outcome. These findings lend strong support to the argument that it is imperative to understand who tunes in to these programs to place any effects in their proper context (Hmielowski et al., 2011). Simply put, people watch these programs in addition to, not in the place of, traditional news. Those who do not follow traditional news are not likley to consume these programs, and even though they do, they are not likely to be mobilized due to the lack of knowledge to fully understand the context. Meanwhile, education was not a key predictor of political satire viewing.

In addition, it is worth noting that as hypothesized, partisans were not strongly associated with traditional news use. At the same time, Democrats were strongly associated with political satire viewing in general, while Republicans were not. These findings lend strong support to the partisan selective exposure theory that Democrats and Republicans are more likely to gravitate toward media contents that support and reinforce their pre-existing viewpoints, such as Fox News, conservative talk radio, and conservatve political blogs for Republicans, and MSNBC, political comedy, and liberal political blogs 
for Democrats (Choi et al., 2018; Stroud, 2011). Still, little research has examined the role of political satire in partisan media use and its influence on democratic citizenship. Future research is warranted about the role poltical satire plays in partisan media use and its influence on democratic outcomes.

Audience factor-driven political satire viewing directly and indirectly influenced political participation, depending on how the respondents consumed late-night talk shows. And these results explain why existing studies have produced such mixed findings (Holbert, 2013). For direct associations, political satire viewing in general did not have any effect on participation. However, when types of satire and media channel were accounted for, some direct effects emerged. Specifically, consumption of harsh satire, such as Late Show with Stephen Colbert and The Daily Show with Trevor Noah, was positively associated with online and offline participation, while consumption of gentle satire, such as The Tonight Show Starring Jimmy Fallon and Jimmy Kimmel Live, was negatively associated with online participation. These findings support some of the existing literature suggesting that late-night talk shows are not monolithic (Holbert et al., 2011), and harsh satire programs like The Daily Show with Jon Stewart and The Colbert Report are entertainment programs that function as a political program with mobilizing power, while gentle satire programs like The Late Show with David Letterman and Tonight Show with Jay Leno are entertainment programs that simply include political elements (Cao \& Brewer, 2008; Jones \& Baym, 2010; Young \& Tisinger, 2006), which is not quite conducive to participation. When media channel was controlled, self-viewing had a strong negative association with online participation. In other words, those who watch late-night talk shows on television were less likely to participate in politics. 
For indirect associations, the proposed O-S-R-O-R framework was not supported in all three models. However, an O-S-R-R model emerged as a better model to explain the effects of political satire viewing on participation. Again, political satire viewing in general had no indirect effect on participation. When satire type and media channel were taken into account, political talk and social media expression emerged as key mediators between political satire viewing and participation. Specifically, among hard news users, those who consume gentle satire were more likely to engage in converntional political expression, thereby participating in politics online. Given that gentle satire viewing was found to have a direct, negative effect on online participation, political talk here appears to work as a moderator as well. In other words, among those gentle satire consumers, those who actively engage in political talk are more likely to participate in the political process, while those who do not engage in the conventional political expression are less likely to participate in the political process. In addition, among hard news users, those who watch late-night talk shows in the social media environment were more likely to engage in political expression on social media, thereby participating in politics, both online and offline. These findings lend strong support to the communication mediation model which posits that political discussion is a key mediator of the effects of media on participation (Cho et al., 2009; McLeod et al., 2001; Shah et al., 2005, 2007; Sotirovic \& McLeod, 2001). Especially, the indirect positive effects of gentle satire viewing on online participation highlight the effect of political expression on democratic citizenship, such that political expression could mobilize voters who are otherwise politically inactive. Inconsistent with research on news use and participation (Chan, 2016; Jung et al., 2011), the O-S-R-O-R framework for the effects of hard news use on participation was 
not supported. Instead, political talk and social media expression appear to be key mediators between hard news use and participation, both online and offline, presenting an O-S-R-R model as a better framework to explain the participatory effects of hard news use. These findings suggest that political expression, conventional and nonconventional, outpaces political knowledge and efficacy as a key mediator between informational use of media and participation in the contemporary media environment. In addition, hard news use was even negatively associated with political knowledge. Future research is warranted in order to determine if the normative implications of traditional media use for democratic outcomes (Delli Carpini \& Keeter, 1996; Gil de Zúñiga et al., 2012; Prior, 2007) should be revisited and refined in the contemporary media environment.

Consistent with research on the effects of political satire on political knowledge (Becker \& Bode, 2018; Hardy et al., 2014), there seems to be learning effects of exposure to political satire, but it depended on satire type. Consumption of harsh satire, such as Late Show with Stephen Colbert and Last Week Tonight with John Oliver, was positively associated with political knowledge, whereas consumption of gentle satire, such as Jimmy Kimmel Live and Late Late Show with James Corden, was negatively associated with political learning. However, the working mechanism seems to be different from what the existing literature has largely suggested, such as the by-product learning hypothesis (Baum, 2002) and gateway hypothesis (Baum, 2003b; Feldman \& Young, 2008). Specifically, inconsistent with these existing studies, I found no significant association between any form of late-night talk show viewing and news attention. Given that political satire viewers are more likely to be hard news consumers in the first place, the null association between political satire viewing and news attention seems to be a matter of 
course. Instead, the learning effects of harsh satire appear to come from its mode of mocking the news to deliver humor and, at the same time, to make sense of the news. In the high-choice media environment, it is impossible to consume all the news and information available and make sense of what is happening in the world (Basu, 2018; Prior, 2007). And in this fast-paced world with the "media torrent," which is increasingly polarized based on partisanship and ideology, people easily misunderstand and forget news (Basu, 2018; Gitlin, 2001; Gunter, 1987; Poundstone, 2016; Stroud, 2011). However, harsh satire programs "give the news a memory" by using news archive footage, providing historical context to news items, and explaining how certain events develop over time (Basu, 2018). Basically, as John Oliver, the host of "Last Week Tonight," once admitted, these TV satirical shows serve as "an amplifier" to bring attention to substantial news stories by breaking them down into comedy, building on the news stories that journalism organizations have already built (Moran, 2019; Variety, 2018). At the same time, unlike gentle satire programs which mostly rely on light punchline jokes (Hoffman \& Young, 2011; Young \& Tisinger, 2006), harsh satire programs provide scathing criticism on politics, the government and the media, while asking the audience to challenge the power and the media (Jones \& Baym, 2010). Simply put, with its humorous, but pointed critique on the power and the media, harsh satire itself serves to complement the role of news by making the news so memorable, which in turn leads to higher political knowledge even among hard news consumers. These findings suggest that political satire, especially harsh satire, remains to be an integral part of democracy and has the potential to increase the sense of civic duty. This mode of mocking news with in-depth analysis also seems to explain why simple exposure to hard 
news is negatively associated with political knowledge, which is inconsistent with existing research on the learning effects of news use (Delli Carpini \& Keeter, 1996; Jung et al., 2011; Prior, 2007). Again, future research is warranted in order to determine if the well-established link between traditional news use and political learning should be revisited.

These TV satire programs appear to facilitate political expression, conventional and nonconventional, through which the viewers elaborate on their thoughts and ideas of the issues and topics by seeking information from others or the news media, thereby more actively participating in politics (Pingree, 2007; Shah, 2016). What is noticeable here is that media channel and satire type appear to shape both media experience and political expression, thereby influcing political behaviors. Specifically, those who watch late-night talk shows on television were more likely to engage in conventional, face-to-face political expression, which failed to channel the impact of self-viewing of political satire on participation, whereas those who watch these programs in the social media environment were more likely to engage in nonconventional political expression on social media, which successfully mediated the effects of curated viewing of political satire on participation. These findings highlight the role of social curation, such as posting, sharing, liking, commenting on and even reframing media contents with personal evaluations in the social media environment, both in media consumption and interpersonal communication, which influences political behaviors. It is important to note that curated vieiwng of politcal satire also led to greater political talk, but the conventional political expression appeared not to be a key mediator between curated viewing and participation. These findings suggest that social media use for both news and 
information and political expression can be particularly mobilizing due to the high "traversability" (Brundidge, 2010a, 2010b) between social media use for political information and social media use for poltical expression. In addition, gentle satire viewing led to greater political talk, thereby increasing online participation. This significant indirect association between gentle satire viewing and online participation through political talk only is a bit puzzling, though. This may be due to a lack of precision in measurement. In other words, I did not differentiate between media channels when questioning about consumption of harsh and gentle satire. Future research should examine the role of media channel in consumption of harsh and gentle satire as well to better explain its role in the participatory effects of political satire.

It is worth noting that given that partisanship appears to be a key predictor of latenight talk show viewing, future research is warranted in order to determine the nature of political expression in the context of the participatory effects of political saire. The wellestablished communication mediation model treats both media consumption and political expression as sources of information and triggers for reflection on media contents and public affairs, which facilitate democratic engagement (Shah, 2016). However, the focus of much of the existing work integrating mass and interpersonal communication has been placed on traditional news media and political discussion in general, with considerably less attention given to the rise of opposing viewpoints based on partisanship and ideology in both mass and interpersonal communication environments (Mutz, 2006; Shah et al., 2017). In addition, it has been documented that social media allow for greater social sorting based on political predispositions and solidify network homogeneity through selfreinforcing political expression (Cho et al., 2018; Shah et al., 2017). Research on partisan 
selective exposure has shown existence of homophily in both mass and interpersonal communication (Stroud \& Collier, 2018). Further, partisan media use directly and indirectly influence participation (Stroud, 2011; Wojcieszak et al., 2016), and political expression, online and offline, mediates or moderates the effects of partisan media use on participation (Brundidge, Garrett, Rojas, \& Gil de Zúñiga, 2014). More importantly, research concerning partisan discussion networks and participation suggests that different communicative behaviors (e.g., homophilous, non-homophilous) may result in different participatory behaviors (Knoke, 1990; Mutz, 2006; Scheufele, Nisbet, Brossard, \& Nisbet, 2004). This line of research is important since there is a growing concern about whether participation without understanding diverse viewpoints is democratically desirable (Mutz, 2006; Stroud \& Collier, 2018). Since research suggests that the number of people who identify themselves as political independents has been growing for the past couple of years (Jones, 2018), it would be also meaningful to examine how these voters consume political satire and how it influences their political attitudes and behaviors.

It is worth reiterating the different effects of self-viewing and curated viewing of political satire on participation. As illuminated in Figure 6, consumption of socially curated late-night talk shows was more likely to facilitate political expression on social media, thereby increasing political participation, both online and offline. On the other hand, consumption of personally curated late-night talk shows was more likely to depress participation online. These findings support the emerging argument that examining curated flows of information matters in the study of media effects in the contemporary media environment. In other words, it is important to be able to answer the "exposure to what" question to better explain the effects of media (Thorson \& Wells, 2015). Therefore, 
future research should use an experiment to determine whether the participatory effect of curated viewing comes from exposure to the video, comments accompanying the video, or both in the social media environment to verify and contextualize my findings. Greenwood and colleagues (2016) demonstrated that Facebook comments accompanying the video could influence the persuasive effect of the show, such that messageincongruent comments reduced the persuasive effect of the show for low salience issues. Since my findings suggest that political satire is a partisan media and political satire viewers are most likely to be hard news consumers in the first place, future experimental studies should also take into account those audience factors to place any effects in their proper context.

Consistent with existing research on social media and political outcomes (Chan, 2016; Park, 2015), the highly interactive feature of the networked media environment appears to play an integral role in facilitating political outcomes, such that the social media environment allows users to express their political opinions more easily and instantly via user-friendly communication tools and this active process of interactive reasoning was more likely to engender political outcomes. These findings lend strong support to the existing research that personal endorsement and personal trust play an important role in media consumption and its influence on democratic outcomes in the networked media environment, which no news media appear to match (Bode, 2012; Bond et al., 2012; Rosenstiel et al., 2017).

Lastly, in terms of participation, respondents were likely to participate in politics online slightly more than offline. This lends support to the argument that the Internet has the potential to expand the opportunities for political participation with reduced time, 
cost, and effort, thereby increasing not only the number of politically active citizens, but also the frequency of political activities (Brundidge, 2010b; Brundidge et al., 2014; Jung et al., 2011).

\section{Theoretical Implications}

My study expands the body of research on political satire, in particular, and media effects, in general, in a couple of important ways.

First, my study advances a new theoretical model, an O-S-R-R model, to better explain the effects of political satire viewing on participation. Speficically, my study proposed structural relationships in which audience factor-driven political satire viewing leads to greater reasoning processes and cognitive outcomes, which in turn promotes participation. It did so by differentiating between various forms of political satire viewing, using 11 different late-night talk shows that are currently on the air. We know very little about the political effects of exposure to the contemporary late-night talk shows, since existing studies heavily relied on The Daily Show with Jon Stewart in a rare combination with The Tonight Show with Jay Leno, Late Show with David Letterman, and The Colbert Report. Most of the satirists are off the air now. The findings suggest that participatory effects of political satire viewing appear to be both direct and indirect, depending on the type or viewing of satire, and the indirect effects of political satire viewing on participation are mediated through reasoning processes, such as political talk and social media expression.

The overarching conceptual models help us illuminate various potential pathways leading to participation. Most importantly, the findings demonstrate how important it is to know who tunes in to view these TV satire programs in the first place to place any effects 
in their proper context (Hmielowski et al., 2011). Audience characteristics are often missing in the study of media effects (Rubin, 2009). The evidence provided here illustrates that those who consume political satire are more likely to be traditional news users in the first place. This makes sense, because these programs critique the news, but, at the same time, attempt to make sense of the news by mocking the news (Basu, 2018), and without enough knowledge of the event being discussed in the programs, it would be hard to fully grasp and enjoy the satirical messages (Caufield, 2008). These findings also challenge popular and scholarly assumptions that political satire can substitute for news (Baym, 2005) and more people are turning to these programs for news and information rather than news media (Cao \& Brewer, 2008; Mitchell et al., 2015). The evidence provided here suggests that those who consume these TV satire programs are news followers and these programs complement the role of news by brining attention to important news items through humor and critique.

Second, my study demonstrates that media channel matters in the study of political satire as well. Consistent with the findings in the extant research on news use and participation (Andersen et al., 2016; Moeller et al., 2014), self-viewing or watching late-night talk shows on television is more likely to depress participation, whereas curated viewing or watching late-night talk shows in the social media environment is more likely to increase participation by encouraging viewers to express themselves politically on social media. With the proliferating media platforms and channels, a handful of scholars have recently called for a new theoretical approach to the study of political satire, moving away from the strict media effects paradigm (Young, 2016; Young et al., 2014). In response to this call, this study examined the role of the social 
media environment in political satire viewing and its influence on participation. The findings suggest that the highly interactive characteristic of the social media environment in the forms of commenting, posting, and sharing with personal evaluations plays a significant role not only in media consumption, but in interpersonal communication, which influences poltical behaviors. These findings also highlight the importance of research on "social curation" in media studies. Consistent with research on social media and political participation (Bode, 2012; Bond et al., 2012) and as demonstrated in the case of Facebook data scandal (Cadwalladr \& Graham-Harrison, 2018; Kelly, 2018; Rosenberg \& Dance, 2018), socially curated media contents in the networked media environment are more likely to be influential and persuasive as the sharer's credibility is more important in choosing what to consume in the networked media environment compared to the credibility of news media (Rosenstiel et al., 2017). In other words, media consumpition is highly converged with interpersonal communication (Domingo et al., 2008; Villi, 2012), and it is getting more difficult to explain the effects of media without fully understanding who receives what messages from where and how (Lee, 2013; Thorson \& Wells, 2015).

Last but not least, my findings add strong support to the call for a more integrative research that crosses three communication subdisciplines - mass media, interpersonal and computer-mediated communication - (Valkenburg, 2017) to better understand the communication process in the digital era and its implications for democratic citizenship. By differentiating nonconventional, social media-based media consumption and political expression from conventional, offline media consumption and political expression, my study suggests that media channel shapes both media experience and political expression, 
and social media use for media consumption and political expresson can be a key driver of democratic citizenship, even outpacing traditional media channels and conventional political expression.

\section{Methodological Implications}

All the hypotheses in this study were tested in structural equation modeling (SEM) using latent variables. SEM is well known to allow for the simultaneous estimation of all variable relationships, elimination of measurement error and estimation of the latent variables from indicators (Kline, 2011). Few studies in political communication, however, have used latent variables in SEM. The vast majority of SEM models are path models based on the techniques of path analysis, a special case of SEM (Chan, 2016; Cho et al., 2009; Jung et al., 2011; Shah et al., 2005, 2007), which is concerned about the effects only among observed variables (Kline, 2011). Unlike path analyses which assume that all variables are measured without error, the conceptual models in this study used latent variables to estimate as much latent relationships as possible by accounting for measurement error.

\section{Practical Implications}

The significant effect of curated viewing of political satire on participation through social media expression demonstrates what makes media contents spreadable and persuasive in the networked media environment. Sharing is central to the way people experience news and media contents in the era of social media (Hermida et al., 2012), and socially curated and shared media contents are actively consumed (Domingo et al., 2008; Rosenstiel et al., 2017; Villi, 2012), which, in turn, influences political attitudes and behaviors (Bode, 2012; Bond et al., 2012; Hong, 2016). My study demonstrates that 
media consumption is highly converged with interpersonal communication in the digital media environment, and the media industry should pay more attention to the role of peerto-peer communication in the digital media environment in finding ways not only to distribute important news and information more effectively and widely, but to counter the spread of fake news and disinformation to prevent uninformed or underinformed voters from being easily manipulated in this constantly changing media environment.

\section{Limitations and Future Research}

As with any study, mine has important limitations.

First, this study is based on cross-sectional survey data. Although I hypothesized causal relationships in my models, my data cannot verify the causal direction. In addition, Shah and colleagues (2017) suggest that the digital media environment requires media scholars to reconsider effects processes combining mass and interpersonal communication, treating political expression and participation as both cause and effect in reciprocal relationships with news media. Future research should use panel data to test the diverse causal paths hypothesized in this study.

Second, my measures are not perfect. In particular, there is a lot of room for improvement on how to measure hard news use and harsh and gentle satire viewing. As for hard news use, I measured simple exposure to traditional news media, such as The New York Times, The Washington Post, and The Wall Street Journal. In doing so, I might have added measurement errors, since those newspapers obviously contain both hard and soft news contents. How to measure news consumption has been highly disputed, primarily due to the difficulty of obtaining accurate self-reports and the lack of consensus about how it should be defined and measured (Chaffee \& Schleuder, 1986; Martinelli \& 
Chaffee, 1995; Prior, 2005, 2007; Reinemann et al., 2012). The same critique can be made on the measures of harsh and gentle satire viewing as well. I measured exposure to each of the 11 late-night talk shows and simply used Late Show with Stephen Colbert as an anchor of the harsh satire group to find these two distinct types of political satire.

Given that the late-night talk shows are different from one another in terms of the amount of political content, the level of political message, and the satirical tone, which lead to different political outcomes (Cao \& Brewer, 2008; Hmielowski et al., 2011; Hoffman \& Young, 2011; Holbert et al., 2011), measuring simple exposure to each of the programs itself without taking into account those differences in detail might have added measurement errors as well. For example, although Saturday Night Live has a satirical segment called "Weekend Update," it loaded very poorly on both factors of harsh and gentle satire. In other words, if I had asked respondents about their exposure to the specific segment, the factor loading might have been different. These reflections highlight the importance of being able to answer the "exposure to what" question in the study of media effect (Lee, 2013; Thorson \& Wells, 2015). Therefore, future research should use more precise conceptual and operational definitions of hard news use and harsh and gentle satire viewing to increase the validity and reliability of the results.

Third, political knowledge and political efficacy did not mediate the effects of political satire viewing on participation. This suggests that other mechanisms may contribute to the relationship between political satire viewing and participation, and issue understanding, emotions, and attitude strength (Cho et al., 2018; Lee \& Kwak, 2014; Wojcieszak et al., 2016) seem to be the most likley candidates for the outcome orientation variable in the context of political satire viewing. Lee and Kwak (2014) found 
negative emotions appeared to be a key mediator between political satire viewing and participation. In addition, my findings lend strong support to the partisan selective exposure theory (Stroud, 2011), such that Democrats are more likely to gravitate toward harsh satire programs since they support and reinforce their pre-existing viewpoints, while Republicans are more likely to avoid harsh satire programs since they challenge their political attitudes and, at the same time, gravitate toward gentle satire programs since these programs heavily rely on punchline jokes that are considered less effective in persuasion and more effective in evoking humoristic pleasure (Boukes \& Boomgaarden, 2015). Research on partisan selective exposure has shown the existence of homophily in both mass and interpersonal communication (Stroud \& Collier, 2018), and partisan selective exposure is more likely to promote homophilous political expression, which strengthens one's partisan views (Cho et al., 2018). Wojcieszak and colleagues (2016) recently found that issue understanding, anger, positive emotions, and attitude strength all mediated the relationship between partisan selective exposure and intended participation. Therefore, it is reasonable to expect that issue understanding, emotions, and attitude strength may work better to channel the impact of political satire viewing on participation. Future studies should expand beyond political attitude variables to determine if the O-S-R-O-R model works with the above-mentioned cognitive outcomes in explaining the participatory effects of political satire viewing.

Fourth, unlike the existing studies on the learning effects of political satire (Becker \& Bode, 2018; Hardy et al., 2014; Kim \& Vishak, 2008), my knowledge questions covered a broad set of issues than a specific issue. Most of them are about the names of public officials and political process. Future research should use a more refined 
measure of political knowledge to determine if political satire has significant effects on political learning.

Lastly, it has been known that Amazon's Mechanical Turk (MTurk) respondents are highly experienced and tend to answer questions pretty fast (Lowry et al., 2016). Future research should use other survey methods to confirm and replicate my findings. 


\section{References}

Andersen, K., Bjarnøe, C., Albæk, E., \& De Vreese, C. H. (2016). How News Type Matters: Indirect Effects of Media Use on Political Participation Through Knowledge and Efficacy. Journal of Media Psychology, 28(3), 111-122. https://doi.org/10.1027/1864-1105/a000201

Balch, G. I. (1974). Multiple Indicators in Survey Research: The Concept "Sense of Political Efficacy." Political Methodology, 1(2), 1-43.

Basu, L. (2018). News Satire: Giving the News a Memory. 17.

Baum, M. A. (2002). Sex, lies, and war: How soft news brings foreign policy to the inattentive public. American Political Science Review, 96(01), 91-109.

Baum, M. A. (2003a). Soft News and Political Knowledge: Evidence of Absence or Absence of Evidence? Political Communication, 20(2), 173-190. https://doi.org/10.1080/10584600390211181

Baum, M. A. (2003b). Soft news goes to war: public opinion and American foreign policy in the new media age. Princeton, N.J: Princeton University Press.

Baumgartner, J., \& Morris, J. S. (2006). The Daily Show Effect: Candidate Evaluations, Efficacy, and American Youth. American Politics Research, 34(3), 341-367. https://doi.org/10.1177/1532673X05280074

Baym, G. (2005). The Daily Show: Discursive Integration and the Reinvention of Political Journalism. Political Communication, 22(3), 259-276. https://doi.org/10.1080/10584600591006492 
Becker, A. B. (2014). Playing With Politics: Online Political Parody, Affinity for Political Humor, Anxiety Reduction, and Implications for Political Efficacy. Mass Communication and Society, 17(3), 424-445. https://doi.org/10.1080/15205436.2014.891134

Becker, A. B., \& Bode, L. (2018). Satire as a source for learning? The differential impact of news versus satire exposure on net neutrality knowledge gain. Information, Communication \& Society, 21(4), 612-625. https://doi.org/10.1080/1369118X.2017.1301517

Bennett, S. E. (1995). Comparing Americans’ Political Information in 1988 and 1992. The Journal of Politics, 57(2), 521-532. https://doi.org/10.2307/2960321

Bennett, W. L. (2008). Changing citizenship in the digital age. In W. L. Bennett (Ed.), Civic life online: learning how digital media can engage youth (pp. 1-24). Cambridge, Mass: MIT Press.

Bennett, W. L., Wells, C., \& Freelon, D. (2011). Communicating Civic Engagement: Contrasting Models of Citizenship in the Youth Web Sphere. Journal of Communication, 61(5), 835-856. https://doi.org/10.1111/j.14602466.2011.01588.x

Best, S. J., \& Krueger, B. S. (2005). Analyzing the Representativeness of Internet Political Participation Author(s): Samuel J. Best and Brian S. Krueger Reviewed work(s): Political Behavior, 27(2), 183-216.

Blumler, J. G. (1979). The role of theory in uses and gratifications studies. Communication Research, 6(1), 9-36. 
Blumler, J. G., \& Katz, E. (Eds.). (1974). The Uses of mass communications: current perspectives on gratifications research. Beverly Hills: Sage Publications.

Bode, L. (2012). Facebooking It to the Polls: A Study in Online Social Networking and Political Behavior. Journal of Information Technology \& Politics, 9(4), 352-369. https://doi.org/10.1080/19331681.2012.709045

Bogel, F. V. (2001). The difference satire makes: rhetoric and reading from Jonson to Byron. Ithaca: Cornell University Press.

Bond, R. M., Fariss, C. J., Jones, J. J., Kramer, A. D. I., Marlow, C., Settle, J. E., \& Fowler, J. H. (2012). A 61-million-person experiment in social influence and political mobilization. Nature, 489(7415), 295-298. https://doi.org/10.1038/nature11421

Borden, S. L., \& Tew, C. (2007). The Role of Journalist and the Performance of Journalism: Ethical Lessons From "Fake” News (Seriously). Journal of Mass Media Ethics, 22(4), 300-314. https://doi.org/10.1080/08900520701583586

Boukes, M., \& Boomgaarden, H. G. (2015). Soft news with hard consequences? Introducing a nuanced measure of soft versus hard news exposure and its relationship with political cynicism. Communication Research, 42(5), 701-731.

Boulianne, S. (2015). Social media use and participation: a meta-analysis of current research. Information, Communication \& Society, 18(5), 524-538. https://doi.org/10.1080/1369118X.2015.1008542

Brewer, P. R., \& Marquardt, E. (2007). Mock news and democracy: analyzing The Daily Show. Atlantic Journal of Communication, 15(4), 249-267. 
Brewer, P. R., Young, D. G., \& Morreale, M. (2013). The Impact of Real News about “Fake News": Intertextual Processes and Political Satire. International Journal of Public Opinion Research, 25(3), 323-343. https://doi.org/10.1093/ijpor/edt015

Brundidge, J. (2010a). Political Discussion and News use in the Contemporary Public Sphere: The "Accessibility" and "Traversability" of the Internet. Javnost - The Public, 17(2), 63-81. https://doi.org/10.1080/13183222.2010.11009031

Brundidge, J. (2010b). Toward a Theory of Citizen Interface with Political Discussion and News in the Contemporary Public Sphere. 23.

Brundidge, J., Garrett, R. K., Rojas, H., \& Gil de Zúñiga, H. (2014). Political Participation and Ideological News Online: "Differential Gains" and "Differential Losses" in a Presidential Election Cycle. Mass Communication and Society, 17(4), 464-486. https://doi.org/10.1080/15205436.2013.821492

Buhrmester, M., Kwang, T., \& Gosling, S. D. (2011). Amazon's Mechanical Turk: A New Source of Inexpensive, Yet High-Quality, Data? Perspectives on Psychological Science, 6(1), 3-5. https://doi.org/10.1177/1745691610393980

Cacciatore, M. A., Scheufele, D. A., \& Iyengar, S. (2016). The End of Framing as we Know it ... and the Future of Media Effects. Mass Communication and Society, 19(1), 7-23. https://doi.org/10.1080/15205436.2015.1068811

Cadwalladr, C., \& Graham-Harrison, E. (2018, March 19). Facebook and Cambridge Analytica face mounting pressure over data scandal. The Guardian. Retrieved from http://www.theguardian.com/news/2018/mar/18/cambridge-analytica-andfacebook-accused-of-misleading-mps-over-data-breach 
Campbell, A., Gurin, G., \& Miller, W. E. (1954). The voter decides. Evanston, IL: Row, Peterson and Company.

Cantor, P. A. (1999). The Simpsons: Atomistic Politics and the Nuclear Family. Political Theory, 27(6), 734-749. https://doi.org/10.1177/0090591799027006002

Cao, X. (2008). Political Comedy Shows and Knowledge About Primary Campaigns: The Moderating Effects of Age and Education. Mass Communication and Society, 11(1), 43-61. https://doi.org/10.1080/15205430701585028

Cao, X., \& Brewer, P. R. (2008). Political comedy shows and public participation in politics. International Journal of Public Opinion Research, 20(1), 90-99.

Caufield, R. P. (2008). The influence of "infoenterpropagainment" : exploring the power of political satire as a distinct form of political humor. In J. C. Baumgartner \& J. S. Morris (Eds.), Laughing matters: humor and American politics in the media age (pp. 3-20). New York: Routledge.

Chaffee, S. H., \& Schleuder, J. (1986). Measurement and Effects of Attention to Media News. Human Communication Research, 13(1), 76-107. https://doi.org/10.1111/j.1468-2958.1986.tb00096.x

Chaffee, S. H., Zhao, X., \& Leshner, G. (1994). Political Knowledge and the Campaign Media of 1992. Communication Research, 21(3), 305-324. https://doi.org/10.1177/009365094021003004

Chan, M. (2016). Social Network Sites and Political Engagement: Exploring the Impact of Facebook Connections and Uses on Political Protest and Participation. Mass Communication and Society, 19(4), 430-451.

https://doi.org/10.1080/15205436.2016.1161803 
Cho, J., Ahmed, S., Keum, H., Choi, Y. J., \& Lee, J. H. (2018). Influencing Myself: SelfReinforcement Through Online Political Expression. Communication Research, 45(1), 83-111. https://doi.org/10.1177/0093650216644020

Cho, J., Shah, D. V., McLeod, J. M., McLeod, D. M., Scholl, R. M., \& Gotlieb, M. R. (2009). Campaigns, Reflection, and Deliberation: Advancing an O-S-R-O-R Model of Communication Effects. Communication Theory, 19(1), 66-88. https://doi.org/10.1111/j.1468-2885.2008.01333.x

Choi, H., Warner, B. R., \& Jennings, F. J. (2018). What mobilizes partisans? Exploring the underlying pathways between partisan media and political participation. In B. R. Warner, D. G. Bystrom, M. S. McKinney, \& M. C. Banwart (Eds.), An unprecedented election: media, communication, and the electorate in the 2016 campaign. Santa Barbara, California: Praeger, an imprint of ABC-CLIO, LLC.

Choi, J. (2016). Differential Use, Differential Effects: Investigating the Roles of Different Modes of News Use in Promoting Political Participation: Differential Use, Differential Effects. Journal of Computer-Mediated Communication, 21(6), 436450. https://doi.org/10.1111/jcc4.12176

Clark, J., \& Aufderheide, P. (2009). Public Media 2.0: Dynamic, Engaged Publics. Cohen, A., Vigoda, E., \& Samorly, A. (2001). Analysis of the Mediating Effect of Personal-Psychological Variables on the Relationship Between Socioeconomic Status and Political Participation: A Structural Equations Framework. Political Psychology, 22(4), 727-757. https://doi.org/10.1111/0162-895X.00260

Conge, P. J. (1988). Review: The Concept of Political Participation: Toward a Definition. Comparative Politics, 20(2), 241-249. https://doi.org/10.2307/421669 
Conway, M. M. (2000). Political participation in the United States (3rd ed). Washington, D.C: CQ Press.

Curran, J., Iyengar, S., Brink Lund, A., \& Salovaara-Moring, I. (2009). Media System, Public Knowledge and Democracy: A Comparative Study. European Journal of Communication, 24(1), 5-26. https://doi.org/10.1177/0267323108098943

Day, A. (2011). Satire and dissent: interventions in contemporary political debate. Bloomington: Indiana University Press.

Delli Carpini, M. X. (2004). Mediating democratic engagement: The impact of communications on citizens' involvement in political and civic life. In L. L. Kaid (Ed.), Handbook of political communication research (pp. 395-434). Mahwah, N.J: Lawrence Erlbaum Associates.

Delli Carpini, M. X., \& Keeter, S. (1996). What Americans know about politics and why it matters. New Haven: Yale University Press.

Delli Carpini, M. X., \& Williams, B. A. (1994). Methods, Metaphors, and Media Research: The Uses of Television in Political Conversation. Communication Research, 21(6), 782-812. https://doi.org/10.1177/009365094021006007

DeSilver, D. (2014). Facebook is a news source for many, but only incidentally. Retrieved from http://www.pewresearch.org/fact-tank/2014/02/04/facebook-is-anews-source-for-many-but-only-incidentally/

Dimitrova, D. V., Shehata, A., Strömbäck, J., \& Nord, L. W. (2014). The Effects of Digital Media on Political Knowledge and Participation in Election Campaigns: Evidence From Panel Data. Communication Research, 41(1), 95-118. https://doi.org/10.1177/0093650211426004 
Domingo, D., Quandt, T., Heinonen, A., Paulussen, S., Singer, J. B., \& Vujnovic, M. (2008). Participatory journalism practices in the media and beyond: An international comparative study of initiatives in online newspapers. Journalism Practice, 2(3), 326-342. https://doi.org/10.1080/17512780802281065

Edgerly, S., Vraga, E. K., Bode, L., Thorson, K., \& Thorson, E. (2017). New Media, New Relationship to Participation? A Closer Look at Youth News Repertoires and Political Participation. Journalism \& Mass Communication Quarterly, 107769901770692. https://doi.org/10.1177/1077699017706928

Edmundson, A. (2015). Curating in the Postdigital Age. M/C Journal, 18(4). Retrieved from http://journal.media-culture.org.au/index.php/mcjournal/article/view/1016

Eveland, W. P. (2001). The Cognitive Mediation Model of Learning From the News: Evidence From Nonelection, Off-Year Election, and Presidential Election Contexts. Communication Research, 28(5), 571-601. https://doi.org/10.1177/009365001028005001

Eveland, W. P. (2004). The Effect of Political Discussion in Producing Informed Citizens: The Roles of Information, Motivation, and Elaboration. Political Communication, 21(2), 177-193. https://doi.org/10.1080/10584600490443877

Eveland, W. P., \& Scheufele, D. A. (2000). Connecting News Media Use with Gaps in Knowledge and Participation. Political Communication, 17(3), 215-237. https://doi.org/10.1080/105846000414250

Eveland, W. P., Shah, D. V., \& Kwak, N. (2003). Assessing Causality in the Cognitive Mediation Model: A Panel Study of Motivations, Information Processing, and 
Learning During Campaign 2000. Communication Research, 30(4), 359-386. https://doi.org/10.1177/0093650203253369

Faina, J. (2013). Public journalism is a joke: The case for Jon Stewart and Stephen Colbert. Journalism: Theory, Practice \& Criticism, 14(4), 541-555. https://doi.org/10.1177/1464884912448899

Feldman, L. (2013). Learning about Politics From The Daily Show: The Role of Viewer Orientation and Processing Motivations. Mass Communication and Society, 16(4), 586-607. https://doi.org/10.1080/15205436.2012.735742

Feldman, L., \& Young, D. G. (2008). Late-Night Comedy as a Gateway to Traditional News: An Analysis of Time Trends in News Attention Among Late-Night Comedy Viewers During the 2004 Presidential Primaries. Political Communication, 25(4), 401-422. https://doi.org/10.1080/10584600802427013

Finney, S. J., \& DiStefano, C. (2006). Non-normal and categorical data in structural equation modeling. In G. R. Hancock \& R. O. Mueller (Eds.), Structural equation modeling: a second course (pp. 269-314). Greenwich, Conn: Information Age Publishing.

Fletcher, M. D. (1987). Contemporary political satire: narrative strategies in the postmodern context. Lanham, MD: University Press of America.

Fox, J. R., Koloen, G., \& Sahin, V. (2007). No joke: A comparison of substance in the Daily Show with Presidential Election Campaign. Journal of Broadcasting \& Electronic Media, 51(2), 213-227. 
Garrett, R. K. (2009). Echo chambers online?: Politically motivated selective exposure among Internet news users. Journal of Computer-Mediated Communication, 14(2), 265-285. https://doi.org/10.1111/j.1083-6101.2009.01440.x

Garrett, R. K., \& Stroud, N. J. (2014). Partisan Paths to Exposure Diversity: Differences in Pro- and Counterattitudinal News Consumption. Journal of Communication, 64(4), 680-701. https://doi.org/10.1111/jcom.12105

Gerbner, G., Gross, L., Morgan, M., \& Signorielli, N. (1980). The “Mainstreaming” of America: Violence Profile No. 11. Journal of Communication, 30(3), 10-29. https://doi.org/10.1111/j.1460-2466.1980.tb01987.x

Gibson, R., \& Cantijoch, M. (2013). Conceptualizing and Measuring Participation in the Age of the Internet: Is Online Political Engagement Really Different to Offline? The Journal of Politics, 75(3), 701-716.

https://doi.org/10.1017/S0022381613000431

Gibson, R., Lusoli, W., \& Ward, S. (2005). Online Participation in the UK: Testing a 'Contextualised' Model of Internet Effects <sup/>. The British Journal of Politics and International Relations, 7(4), 561-583. https://doi.org/10.1111/j.1467856x.2005.00209.x

Gil de Zúñiga, H., Copeland, L., \& Bimber, B. (2014). Political consumerism: Civic engagement and the social media connection. New Media \& Society, 16(3), 488506. https://doi.org/10.1177/1461444813487960

Gil de Zúñiga, H., Jung, N., \& Valenzuela, S. (2012). Social Media Use for News and Individuals' Social Capital, Civic Engagement and Political Participation. Journal 
of Computer-Mediated Communication, 17(3), 319-336.

https://doi.org/10.1111/j.1083-6101.2012.01574.x

Gil de Zúñiga, H., Molyneux, L., \& Zheng, P. (2014). Social Media, Political Expression, and Political Participation: Panel Analysis of Lagged and Concurrent Relationships. Journal of Communication, 64(4), 612-634. https://doi.org/10.1111/jcom.12103

Gitlin, T. (2001). Media unlimited: how the torrent of images and sounds overwhelms our lives (1st ed). New York: Metropolitan Books.

Goble, C. A., Bhagat, J., Aleksejevs, S., Cruickshank, D., Michaelides, D., Newman, D., ... De Roure, D. (2010). myExperiment: a repository and social network for the sharing of bioinformatics workflows. Nucleic Acids Research, 38(suppl_2), W677-W682. https://doi.org/10.1093/nar/gkq429

Gottfried, J., \& Anderson, M. (2014). For some, the satiric 'Colbert Report' is a trusted source of political news. Retrieved from Pew Research Center website: http://www.pewresearch.org/fact-tank/2014/12/12/for-some-the-satiric-colbertreport-is-a-trusted-source-of-political-news/

Gottfried, J., Matsa, K. E., \& Barthel, M. (2015). As Jon Stewart steps down, 5 facts about The Daily Show. Retrieved from http://www.pewresearch.org/fact$\operatorname{tank/2015/08/06/5-facts-daily-show/~}$

Graber, D. A., \& Dunaway, J. (2015). Mass media and American politics (Ninth Edition). Los Angeles: Washington, DC: Sage; CQ Press. 
Gray, J., Jones, J. P., \& Thompson, E. (2009). Satire TV: politics and comedy in the postnetwork era. Retrieved from http://public.eblib.com/choice/publicfullrecord.aspx?p=2081711

Greenwood, M. M., Sorenson, M. E., \& Warner, B. R. (2016). Ferguson on Facebook: Political persuasion in a new era of media effects. Computers in Human Behavior, 57, 1-10. https://doi.org/10.1016/j.chb.2015.12.003

Grieco, E. (2017). More Americans are turning to multiple social media sites for news. Retrieved from http://www.pewresearch.org/fact-tank/2017/11/02/moreamericans-are-turning-to-multiple-social-media-sites-for-news/

Gross, K. (2008). Framing Persuasive Appeals: Episodic and Thematic Framing, Emotional Response, and Policy Opinion. Political Psychology, 29(2), 169-192. https://doi.org/10.1111/j.1467-9221.2008.00622.x

Grynbaum, M. M. (2019, January 8). Anchors Scramble to Fact-Check Trump After Prime-Time Address - The New York Times. Retrieved from https://www.nytimes.com/2019/01/08/business/media/networks-trumpaddress.html

Gunter, B. (1987). Poor reception: misunderstanding and forgetting broadcast news. Hillsdale, N.J: L. Erlbaum Associates.

Hansen, K. M., \& Pedersen, R. T. (2014). Campaigns Matter: How Voters Become Knowledgeable and Efficacious During Election Campaigns. Political Communication, 31(2), 303-324. https://doi.org/10.1080/10584609.2013.815296

Hardy, B. W., Gottfried, J. A., Winneg, K. M., \& Jamieson, K. H. (2014). Stephen Colbert's Civics Lesson: How Colbert Super PAC Taught Viewers About 
Campaign Finance. Mass Communication and Society, 17(3), 329-353. https://doi.org/10.1080/15205436.2014.891138

Hardy, B. W., \& Scheufele, D. A. (2005). Examining differential gains from Internet use: Comparing the moderating role of talk and online interactions. Journal of Communication, 55(1), 71-84.

Harrington, S. (2012). The uses of satire: Unorthodox news, cultural chaos and the interrogation of power. Journalism: Theory, Practice \& Criticism, 13(1), 38-52. https://doi.org/10.1177/1464884911400847

Hermida, A., Fletcher, F., Korell, D., \& Logan, D. (2012). SHARE, LIKE, RECOMMEND: Decoding the social media news consumer. Journalism Studies, 13(5-6), 815-824. https://doi.org/10.1080/1461670X.2012.664430

Highet, G. (1962). The anatomy of satire. Princeton, NJ: Princeton Univ. Press.

Hmielowski, J. D., Holbert, R. L., \& Lee, J. (2011). Predicting the Consumption of Political TV Satire: Affinity for Political Humor, The Daily Show , and The Colbert Report. Communication Monographs, 78(1), 96-114. https://doi.org/10.1080/03637751.2010.542579

Hoffman, L. H., \& Thomson, T. L. (2009). The Effect of Television Viewing on Adolescents' Civic Participation: Political Efficacy as a Mediating Mechanism. Journal of Broadcasting \& Electronic Media, 53(1), 3-21.

https://doi.org/10.1080/08838150802643415

Hoffman, L. H., \& Young, D. G. (2011). Satire, Punch Lines, and the Nightly News: Untangling Media Effects on Political Participation. Communication Research Reports, 28(2), 159-168. https://doi.org/10.1080/08824096.2011.565278 
Holbert, R. L. (2005). A typology for the study of entertainment television and politics. American Behavioral Scientist, 49(3), 436-453.

Holbert, R. L. (2013). Breaking boundaries| Developing a normative approach to political satire: An empirical perspective. International Journal of Communication, 7, 19.

Holbert, R. L., Hmielowski, J., Jain, P., Lather, J., \& Morey, A. (2011). Adding nuance to the study of political humor effects: Experimental research on juvenalian satire versus horatian satire. American Behavioral Scientist, 55(3), 187-211.

Hong, Y.-H. (2016). The role of Facebook, Plurk, and YouTube in the two-step and $N$ step flows of communication and the effect on political efficacy. The Journal of International Communication, 22(1), 42-63.

https://doi.org/10.1080/13216597.2015.1114006

Hope, C., \& Turner, B. (2015). Curate. M/C Journal, 18(4). Retrieved from http://journal.media-culture.org.au/index.php/mcjournal/article/view/1017

Huff, C., \& Tingley, D. (2015). "Who are these people?” Evaluating the demographic characteristics and political preferences of MTurk survey respondents. Research \& Politics, 2(3), 205316801560464. https://doi.org/10.1177/2053168015604648

Hyun, K. D., \& Kim, J. (2015). Differential and interactive influences on political participation by different types of news activities and political conversation through social media. Computers in Human Behavior, 45, 328-334. https://doi.org/10.1016/j.chb.2014.12.031

Iyengar, S., \& Hahn, K. S. (2009). Red Media, Blue Media: Evidence of Ideological Selectivity in Media Use. Journal of Communication, 59(1), 19-39. https://doi.org/10.1111/j.1460-2466.2008.01402.x 
Jacobs, R. N., \& Wild, N. M. (2013). A cultural sociology of The Daily Show and The Colbert Report. American Journal of Cultural Sociology, 1(1), 69-95. https://doi.org/10.1057/ajcs.2012.7

Jenkins, H. (2006). Convergence culture: where old and new media collide. New York: New York University Press.

Jones, J. M. (2018, January 8). Americans’ Identification as Independents Back Up in 2017. Retrieved April 28, 2019, from Gallup.com website: https://news.gallup.com/poll/225056/americans-identification-independents-back2017.aspx

Jones, J. P., \& Baym, G. (2010). A Dialogue on Satire News and the Crisis of Truth in Postmodern Political Television. Journal of Communication Inquiry, 34(3), 278294. https://doi.org/10.1177/0196859910373654

Jung, N., Kim, Y., \& Gil de Zúñiga, H. (2011). The Mediating Role of Knowledge and Efficacy in the Effects of Communication on Political Participation. Mass Communication and Society, 14(4), 407-430.

https://doi.org/10.1080/15205436.2010.496135

Kalb, M. (1998). The Rise of the "new news": A case study of two root causes of the modern scandal coverage (p. 38). Cambridge, MA.

Katz, E., \& Lazarsfeld, P. F. (1955). Personal influence: the part played by people in the flow of mass communications. Glencoe, IL: Free Press.

Katz, J. E., \& Rice, R. E. (2002). Project syntopia: Social consequences of Internet use. IT \& Society, 1(1), 166-179. 
Kelly, E. (2018, April 10). Zuckerberg: Facebook in "arms race" with Russia over election meddling. Retrieved from https://www.usatoday.com/story/news/politics/2018/04/10/zuckerberg-facessenators-explain-facebook-data-breaches/502448002/

Keveney, B. (2018, November 1). Midterm elections are a big deal for late-night shows, too: Seth Meyers explains. USA TODAY. Retrieved from https://www.usatoday.com/story/life/tv/2018/11/01/late-night-comedy-hosts-golive-election-night-talk-trump-politics/1824861002/

Kilby, A. (2018). Provoking the Citizen: Re-examining the role of TV satire in the Trump era. Journalism Studies, 19(13), 1934-1944. https://doi.org/10.1080/1461670X.2018.1495573

Kim, Y. (2011). The contribution of social network sites to exposure to political difference: The relationships among SNSs, online political messaging, and exposure to cross-cutting perspectives. Computers in Human Behavior, 27(2), 971-977. https://doi.org/10.1016/j.chb.2010.12.001

Kim, Y., Chen, H.-T., \& Gil de Zúñiga, H. (2013). Stumbling upon news on the Internet: Effects of incidental news exposure and relative entertainment use on political engagement. Computers in Human Behavior, 29(6), 2607-2614. https://doi.org/10.1016/j.chb.2013.06.005

Kim, Y. M., \& Vishak, J. (2008). Just Laugh! You Dont Need to Remember: The Effects of Entertainment Media on Political Information Acquisition and Information Processing in Political Judgment. Journal of Communication, 58(2), 338-360. https://doi.org/10.1111/j.1460-2466.2008.00388.x 
Klapper, J. T. (1963). Mass communication research: An old road resurveyed. Public Opinion Quarterly, 27(4), 515-527.

Kline, R. B. (2011). Principles and practice of structural equation modeling (3rd ed). New York: Guilford Press.

Knight, C. A. (2004). The literature of satire. Cambridge ; New York: Cambridge University Press.

Knoke, D. (1990). Networks of political action: Toward Theory Construction. Social Forces, 68(4), 1041-1063.

Krause, G. A. (1997). Voters, Information Heterogeneity, and the Dynamics of Aggregate Economic Expectations. American Journal of Political Science, 41(4), 1170. https://doi.org/10.2307/2960486

Krcmar, M., \& Strizhakova, Y. (2009). Uses and gratifications as media choice. In T. Hartmann (Ed.), Media choice: a theoretical and empirical overview (pp. 53-69). New York: Routledge.

Krysa, J. (2006). CURATING IMMATERIALITY: THE WORK OF THE CURATOR IN THE AGE OF NETWORK SYSTEMS'. New York: Autonomedia.

LaMarre, H. L., Landreville, K. D., Young, D., \& Gilkerson, N. (2014). Humor Works in Funny Ways: Examining Satirical Tone as a Key Determinant in Political Humor Message Processing. Mass Communication and Society, 17(3), 400-423. https://doi.org/10.1080/15205436.2014.891137

Lazarsfeld, P. F., Berelson, B., \& Gaudet, H. (1948). The people's choice; how the voter makes up his mind in a presidential campaign (2nd ed). New York: Columbia University Press. 
Lee, A. M. (2013). News Audiences Revisited: Theorizing the Link Between Audience Motivations and News Consumption. Journal of Broadcasting \& Electronic Media, 57(3), 300-317. https://doi.org/10.1080/08838151.2013.816712

Lee, A. M., \& Chyi, H. I. (2014). Motivational Consumption Model: Exploring the Psychological Structure of News Use. Journalism \& Mass Communication Quarterly, 91(4), 706-724. https://doi.org/10.1177/1077699014550088

Lee, H. (2012). Communication Mediation Model of Late-Night Comedy: The Mediating Role of Structural Features of Interpersonal Talk Between Comedy Viewing and Political Participation. Mass Communication and Society, 15(5), 647-671. https://doi.org/10.1080/15205436.2012.664239

Lee, H., \& Kwak, N. (2014). The Affect Effect of Political Satire: Sarcastic Humor, Negative Emotions, and Political Participation. Mass Communication and Society, 17(3), 307-328. https://doi.org/10.1080/15205436.2014.891133

Little, T. D., Cunningham, W. A., Shahar, G., \& Widaman, K. F. (2002). To Parcel or Not to Parcel: Exploring the Question, Weighing the Merits. Structural Equation Modeling: A Multidisciplinary Journal, 9(2), 151-173. https://doi.org/10.1207/S15328007SEM0902_1

Little, T. D., Rhemtulla, M., Gibson, K., \& Schoemann, A. M. (2013). Why the items versus parcels controversy needn't be one. Psychological Methods, 18(3), 285300. https://doi.org/10.1037/a0033266

Lowry, P. B., D’Arcy, J., Hammer, B., \& Moody, G. D. (2016). "Cargo Cult” science in traditional organization and information systems survey research: A case for using nontraditional methods of data collection, including Mechanical Turk and online 
panels. The Journal of Strategic Information Systems, 25(3), 232-240.

https://doi.org/10.1016/j.jsis.2016.06.002

MacKuen, M. (1984). Exposure to Information, Belief Integration, and Individual Responsiveness to Agenda Change. American Political Science Review, 78(02), 372-391. https://doi.org/10.2307/1963370

Markus, H., \& Zajonc, R. B. (1985). The cognitive perspective in social psychology. In G. Lindzey \& E. Aronson (Eds.), Handbook of social psychology (3rd ed, pp. 137-230). New York : Hillsdale, N.J: Random House ; Distributed exclusively by L. Erlbaum Associates.

Marshall, P. D. (2009). New Media as Transformed Media Industry. In J. Holt \& A. Perren (Eds.), Media industries: history, theory, and method (pp. 81-89). Chichester, UK: Wiley-Blackwell.

Martinelli, K. A., \& Chaffee, S. H. (1995). Measuring New-Voter Learning Via Three Channels of Political Information. Journalism \& Mass Communication Quarterly, 72(1), 18-32. https://doi.org/10.1177/107769909507200103

Maza, C. (2017, April 3). Comedians have figured out the trick to covering Trump. Retrieved January 9, 2019, from Vox website: https://www.vox.com/2017/4/3/15163170/strikethrough-comedians-satire-trumpmisinformation

McCombs, M. E., \& Poindexter, P. (1983). The Duty to Keep Informed: News Exposure and Civic Obligation. Journal of Communication, 33(2), 88-96. https://doi.org/10.1111/j.1460-2466.1983.tb02391.x 
McCombs, M. E., \& Shaw, D. L. (1972). The Agenda-Setting Function of Mass Media. Public Opinion Quarterly, 36(2), 176. https://doi.org/10.1086/267990

Mcleod, J. M., Daily, K., Guo, Z., Eveland, W. P., Bayer, J., Yang, S., \& Wang, H. (1996). Community Integration, Local Media Use, and Democratic Processes. Communication Research, 23(2), 179-209. https://doi.org/10.1177/009365096023002002

McLeod, J. M., Kosicki, G. M., \& McLeod, D. M. (1994). The Expanding Boundaries of Political Communication Effects. In J. Bryant \& D. Zillmann (Eds.), Media effects: advances in theory and research (pp. 123-162). Hillsdale, N.J: Erlbaum. McLeod, J. M., \& McDonald, D. G. (1985). BEYOND SIMPLE EXPOSURE: Media Orientations and Their Impact on Political Processes. Communication Research, 12(1), 3-33. https://doi.org/10.1177/009365085012001001

Mcleod, J. M., Scheufele, D. A., \& Moy, P. (1999). Community, Communication, and Participation: The Role of Mass Media and Interpersonal Discussion in Local Political Participation. Political Communication, 16(3), 315-336. https://doi.org/10.1080/105846099198659

McLeod, J. M., Zubric, J., Keum, H., Deshpande, S., Cho, J., Stein, S., \& Heather, M. (2001). Reflecting and connecting: Testing a communication mediation model of civic participation. Paper Presented at the 84th Annual Conference of the Association for Education in Journalism and Mass Communication, Washington, DC.

McQuail, D. (1987). Mass communication theory: an introduction (2nd ed). London ; Newbury Park: Sage Publications. 
Mill, J. S. (1872). On liberty. Retrieved from https://books.google.com/books?id=jUu6GjuSzOEC\&pg=PA21\&lpg=PA21\&dq= John+Stuart+Mill,+\%E2\%80\%9Clearning+the+grounds+of+one $\%$ E2\%80\%99s+ own+opinions\&source=bl\&ots=Euhd76z3UN\&sig=FnEkBpmpSOa0fCydsxF1Kq kjhhY\&hl=ko\&sa=X\&ved=0ahUKEwik5YL39OfZAhVIq1kKHcDtDCcQ6AEIbj $\mathrm{AJ} \# \mathrm{v}=$ onepage $\& \mathrm{q}=$ learning $\% 20$ the $\% 20$ grounds $\% 20 \mathrm{of} \% 20 \mathrm{one} \% \mathrm{E} 2 \% 80 \% 99 \mathrm{~s} \% 2$ 0own \%20opinions \&f=false

Mitchell, A., Gottfried, J., \& Matsa, K. E. (2015). Millennials and Political News. Retrieved from Pew Research Center website: http://www.journalism.org/2015/06/01/millennials-political-news/

Mitchell, A., Kiley, J., Gottfried, J., \& Guskin, E. (2013). The Role of News on Facebook. Retrieved from http://www.journalism.org/2013/10/24/the-role-of-news-onfacebook/

Mitchelstein, E., \& Boczkowski, P. J. (2010). Online news consumption research: An assessment of past work and an agenda for the future. New Media \& Society, 12(7), 1085-1102. https://doi.org/10.1177/1461444809350193

Moeller, J., de Vreese, C., Esser, F., \& Kunz, R. (2014). Pathway to Political Participation: The Influence of Online and Offline News Media on Internal Efficacy and Turnout of First-Time Voters. American Behavioral Scientist, 58(5), 689-700. https://doi.org/10.1177/0002764213515220

Moran, L. (2019, February 16). John Oliver Explains Why Trump's 'Nonsense' Flipped The Script For Comedians. Retrieved February 17, 2019, from HuffPost website: 
https://www.huffpost.com/entry/john-oliver-donald-trumpinterview_n_5c681a1ae4b033a799431618

Morrell, M. E. (2003). Survey and Experimental Evidence for a Reliable and Valid Measure of Internal Political Efficacy. Public Opinion Quarterly, 67(4), 589-602. https://doi.org/10.1086/378965

Moy, P., Xenos, M. A., \& Hess, V. K. (2005). Communication and citizenship: Mapping the political effects of infotainment. Mass Communication \& Society, 8(2), 111131.

Moy, P., Xenos, M. A., \& Hess, V. K. (2006). Priming Effects of Late-Night Comedy. International Journal of Public Opinion Research, 18(2), 198-210. https://doi.org/10.1093/ijpor/edh092

Mutz, D. C. (2006). Hearing the other side: deliberative versus participatory democracy. Cambridge; New York: Cambridge University Press.

Niemi, R. G., Craig, S. C., \& Mattei, F. (1991). Measuring Internal Political Efficacy in the 1988 National Election Study. The American Political Science Review, 85(4), 1407. https://doi.org/10.2307/1963953

Niven, D., Lichter, S. R., \& Amundson, D. (2003). The political content of late night comedy. Harvard International Journal of Press/Politics, 8(3), 118-133.

Pallotta, F. (2015, February 11). With Jon Stewart's exit, late-night wars shift online. CNNMoney. Retrieved from http://money.cnn.com/2015/02/11/media/future-oflate-night-tv/index.html 
Papacharissi, Z., \& Rubin, A. M. (2000). Predictors of Internet Use. Journal of Broadcasting \& Electronic Media, 44(2), 175-196. https://doi.org/10.1207/s15506878jobem4402_2

Park, C. S. (2015). Pathways to Expressive and Collective Participation: Usage Patterns, Political Efficacy, and Political Participation in Social Networking Sites. Journal of Broadcasting \& Electronic Media, 59(4), 698-716. https://doi.org/10.1080/08838151.2015.1093480

Park, C. S., \& Kaye, B. K. (2018). News Engagement on Social Media and Democratic Citizenship: Direct and Moderating Roles of Curatorial News Use in Political Involvement. Journalism \& Mass Communication Quarterly, 95(4), 1103-1127. https://doi.org/10.1177/1077699017753149

Patterson, T. (2000). Doing well and doing good.

Peifer, J. T., \& Holbert, R. L. (2016). Appreciation of Pro-Attitudinal Versus CounterAttitudinal Political Humor: A Cognitive Consistency Approach to the Study of Political Entertainment. Communication Quarterly, 64(1), 16-35. https://doi.org/10.1080/01463373.2015.1078828

Pingree, R. J. (2007). How Messages Affect Their Senders: A More General Model of Message Effects and Implications for Deliberation. Communication Theory, 17(4), 439-461. https://doi.org/10.1111/j.1468-2885.2007.00306.x

Plasser, F. (2005). From Hard to Soft News Standards?: How Political Journalists in Different Media Systems Evaluate the Shifting Quality of News. Harvard International Journal of Press/Politics, 10(2), 47-68. https://doi.org/10.1177/1081180X05277746 
Poindexter, P. M., \& McCombs, M. E. (2001). Revisiting the Civic Duty to Keep Informed in the New Media Environment. Journalism \& Mass Communication Quarterly, 78(1), 113-126. https://doi.org/10.1177/107769900107800108

Pollock, P. H. (1983). The Participatory Consequences of Internal and External Political Efficacy: A Research Note. The Western Political Quarterly, 36(3), 400. https://doi.org/10.2307/448398

Popova, M. (2011). Maria Popova: In a new world of informational abundance, content curation is a new kind of authorship. Retrieved from http://www.niemanlab.org/2011/06/maria-popova-in-a-new-world-ofinformational-abundance-content-curation-is-a-new-kind-of-authorship/

Poundstone, W. (2016). Head in the cloud: why knowing things still matters when facts are so easy to look up. Retrieved from https://www.overdrive.com/search?q=08490B8C-34D5-419B-8E5BA739F25BC7EA

Preacher, K. J., \& Hayes, A. F. (2008). Asymptotic and resampling strategies for assessing and comparing indirect effects in multiple mediator models. Behavior Research Methods, 40(3), 879-891. https://doi.org/10.3758/BRM.40.3.879

Price, V., \& Cappella, J. N. (2002). Online deliberation and its influence: The electronic dialogue project in campaign 2000. IT \& Society, 1(1), 303-329.

Prior, M. (2003). Any Good News in Soft News? The Impact of Soft News Preference on Political Knowledge. Political Communication, 20(2), 149-171. https://doi.org/10.1080/10584600390211172 
Prior, M. (2005). News vs. entertainment: How increasing media choice widens gaps in political knowledge and turnout. American Journal of Political Science, 49(3), $577-592$.

Prior, M. (2007). Post-broadcast democracy: how media choice increases inequality in political involvement and polarizes elections. New York: Cambridge University Press.

Putnam, R. D. (1995). Tuning In, Tuning Out: The Strange Disappearance of Social Capital in America. PS: Political Science and Politics, 28(4), 664. https://doi.org/10.2307/420517

Reinemann, C., Stanyer, J., Scherr, S., \& Legnante, G. (2012). Hard and soft news: A review of concepts, operationalizations and key findings. Journalism: Theory, Practice \& Criticism, 13(2), 221-239. https://doi.org/10.1177/1464884911427803

Rosenbaum, S. C. (2011). Curation nation: how to win in a world where consumers are creators. New York: McGraw-Hill.

Rosenberg, M., \& Dance, G. J. X. (2018, April 8). 'You Are the Product': Targeted by Cambridge Analytica on Facebook - The New York Times. Retrieved from https://www.nytimes.com/2018/04/08/us/facebook-users-data-harvestedcambridge-analytica.html

Rosenstiel, T., Sonderman, J., Loker, K., Benz, J., Sterrett, D., Malato, D., ... Swanson, E. (2017). 'Who shared it?' How Americans decide what news to trust on social media. Retrieved from https://www.americanpressinstitute.org/publications/reports/survey-research/trustsocial-media/ 
Rosseel, Y. (2012). lavaan : An R Package for Structural Equation Modeling. Journal of Statistical Software, 48(2). https://doi.org/10.18637/jss.v048.i02

Rosseel, Y. (n.d.). The lavaan Project. Retrieved April 5, 2018, from http://lavaan.ugent.be/tutorial/est.html

Rubin, A. M. (1984). Ritualized and Instrumental Television Viewing. Journal of Communication, 34(3), 67-77. https://doi.org/10.1111/j.14602466.1984.tb02174.x

Rubin, A. M. (2009). Uses-and-gratifications perspective on media effects. In J. Bryant \& M. B. Oliver (Eds.), Media effects: advances in theory and research (3rd ed, pp. 165-184). New York: Routledge.

Rubin, A. M., \& Perse, E. M. (1987). Audience Activity and Television News Gratifications. Communication Research, 14(1), 58-84. https://doi.org/10.1177/009365087014001004

Russonello, G. (2018, December 26). Late-Night TV in 2018: Trump, Trump, Facebook and More Trump. The New York Times. Retrieved from https://www.nytimes.com/2018/12/26/arts/television/best-of-late-nighttrump.html

Sanders, C. (1971). The scope of satire. Glenview, IL: Scott, Foresman.

Satorra, A., \& Bentler, P. M. (2010). Ensuring Positiveness of the Scaled Difference Chisquare Test Statistic. Psychometrika, 75(2), 243-248. https://doi.org/10.1007/s11336-009-9135-y

Scheufele, D. A. (2002). Examining Differential Gains from Mass Media and their Implications for Participatory Behavior. COMMUNICATION RESEARCH, 20. 
Scheufele, D. A., Nisbet, M. C., Brossard, D., \& Nisbet, E. C. (2004). Social Structure and Citizenship: Examining the Impacts of Social Setting, Network Heterogeneity, and Informational Variables on Political Participation. Political Communication, 21(3), 315-338. https://doi.org/10.1080/10584600490481389

Shah, D. V. (2016). Conversation is the soul of democracy: Expression effects, communication mediation, and digital media. Communication and the Public, 1(1), 12-18. https://doi.org/10.1177/2057047316628310

Shah, D. V., Cho, J., Eveland, W. P., \& Kwak, N. (2005). Information and Expression in a Digital Age: Modeling Internet Effects on Civic Participation. Communication Research, 32(5), 531-565. https://doi.org/10.1177/0093650205279209

Shah, D. V., Cho, J., Nah, S., Gotlieb, M. R., Hwang, H., Lee, N. J., ... McLeod, D. M. (2007). Campaign Ads, Online Messaging, and Participation: Extending the Communication Mediation Model: Extending Communication Mediation. Journal of Communication, 57(4), 676-703. https://doi.org/10.1111/j.14602466.2007.00363.x

Shah, D. V., McLeod, D. M., Rojas, H., Cho, J., Wagner, M. W., \& Friedland, L. A. (2017). Revising the Communication Mediation Model for a New Political Communication Ecology: Communication Mediation Model. Human Communication Research, 43(4), 491-504. https://doi.org/10.1111/hcre.12115

Shearer, E., \& Gottfried, J. (2017). News Use Across Social Media Platforms 2017. Retrieved from Pew Research Center website: http://www.journalism.org/2017/09/07/news-use-across-social-media-platforms2017/ 
Shoemaker, P. J., \& Reese, S. D. (2014). Mediating the message in the 21st century: a media sociology perspective (Third edition). New York: Routledge/Taylor \& Francis Group.

Shoemaker, P. J., \& Vos, T. P. (2009). Gatekeeping theory. New York: Routledge. Snider, P. B. (1967). “Mr. Gates” Revisited: A 1966 Version of the 1949 Case Study. Journalism Quarterly, 44(3), 419-427. https://doi.org/10.1177/107769906704400301

Sotirovic, M., \& McLeod, J. M. (2001). Values, Communication Behavior, and Political Participation. Political Communication, 18(3), 273-300. https://doi.org/10.1080/10584600152400347

Southwell, B. G., \& Yzer, M. C. (2007). The Roles of Interpersonal Communication in Mass Media Campaigns. Annals of the International Communication Association, 31(1), 420-462. https://doi.org/10.1080/23808985.2007.11679072

Sparks, G. G. (2010). Media effects research: a basic overivew (3rd ed). Boston, MA: Wadsworth.

Steelman, Z. R., Hammer, B. I., \& Limayem, M. (2014). Data Collection in the Digital Age: Innovative Alternatives to Student Samples. MIS Quarterly, 38(2), 355-378. https://doi.org/10.25300/MISQ/2014/38.2.02

Steinberg, B. (2018, August 19). Late-night TV has a growing problem: Maybe there's too much of it. Chicago Tribune. Retrieved from https://www.chicagotribune.com/entertainment/tv/ct-late-night-tv-problem20180819-story.html 
Stroud, N. J. (2011). Niche news: the politics of news choice. New York: Oxford University Press.

Stroud, N. J., \& Collier, J. R. (2018). Selective exposure and homophily during the 2016 presidential campaign. In B. R. Warner, D. G. Bystrom, M. S. McKinney, \& M. C. Branwart (Eds.), An unprecedented election: media, communication, and the electorate in the 2016 campaign (pp. 40-60). Santa Barbara, California: Praeger, an imprint of ABC-CLIO, LLC.

Stroud, N. J., \& Muddiman, A. (2013). Selective Exposure, Tolerance, and Satirical News. International Journal of Public Opinion Research, 25(3), 271-290. https://doi.org/10.1093/ijpor/edt013

Sunstein, C. R. (2009). Republic.com 2.0 (1. pbk. print). Princeton, N.J.: Princeton Univ. Press.

Tang, G., \& Lee, F. L. F. (2013). Facebook Use and Political Participation: The Impact of Exposure to Shared Political Information, Connections With Public Political Actors, and Network Structural Heterogeneity. Social Science Computer Review, 31(6), 763-773. https://doi.org/10.1177/0894439313490625

Test, G. A. (1991). Satire: spirit and art. Tampa: University of South Florida Press.

Thorson, K. (2012). What Does It Mean to Be a Good Citizen? Citizenship Vocabularies as Resources for Action. The ANNALS of the American Academy of Political and Social Science, 644(1), 70-85. https://doi.org/10.1177/0002716212453264

Thorson, K., \& Wells, C. (2015). How gatekeeping still matters: understanding media effects in an era of curated flows. In T. P. Vos \& F. Heinderyckx (Eds.), 
Gatekeeping in transition (pp. 25-44). New York; London: Routledge, Taylor \& Francis Group.

Valenza, J. K., Boyer, B. L., \& Curtis, D. (2014). Curation outside the library world. Library Technology Reports, 50(7), 51-59.

Valenzuela, S. (2013). Unpacking the Use of Social Media for Protest Behavior: The Roles of Information, Opinion Expression, and Activism. American Behavioral Scientist, 57(7), 920-942. https://doi.org/10.1177/0002764213479375

Valkenburg, P. M. (2017). Understanding Self-Effects in Social Media: Self-Effects in Social Media. Human Communication Research, 43(4), 477-490. https://doi.org/10.1111/hcre.12113

Van Buskirk, E. (2010, May 14). Overwhelmed? Welcome the Age of Curation. WIRED. Retrieved from https://www.wired.com/2010/05/feeling-overwhelmed-welcomethe-age-of-curation/

Variety. (2018). John Oliver - 2018 Emmys - Full Backstage Speech. Retrieved from https://www.youtube.com/watch?v=U7b2qxd3HNg

Verba, S., \& Nie, N. H. (1972). Participation in America: political democracy and social equality. New York: Harper \& Row.

Verba, S., Schlozman, K. L., \& Brady, H. E. (1995). Voice and equality: civic voluntarism in American politics. Cambridge, Mass: Harvard University Press.

Villi, M. (2012). Social curation in audience communities: UDC (user-distributed content) in the networked media ecosystem. 9(2), 19.

Vos, T. P., \& Heinderyckx, F. (Eds.). (2015). Gatekeeping in transition. New York; London: Routledge, Taylor \& Francis Group. 
Wang, H., \& Shi, F. (2018). Weibo use and political participation: the mechanism explaining the positive effect of Weibo use on online political participation among college students in contemporary China. Information, Communication \& Society, 21(4), 516-530. https://doi.org/10.1080/1369118X.2017.1289234

Warner, Benjamin R., Hawthorne, H. J., \& Hawthorne, J. (2015). A dual-processing approach to the effects of viewing political comedy. HUMOR, 28(4). https://doi.org/10.1515/humor-2015-0099

White, D. M. (1950). The "gate keeper": A case study in the selection of news. Journalism Quarterly, 27, 383-390.

Wojcieszak, M., Bimber, B., Feldman, L., \& Stroud, N. J. (2016). Partisan News and Political Participation: Exploring Mediated Relationships. Political Communication, 33(2), 241-260. https://doi.org/10.1080/10584609.2015.1051608

Xenos, M. A., \& Becker, A. B. (2009). Moments of Zen: Effects of The Daily Show on Information Seeking and Political Learning. Political Communication, 26(3), 317-332. https://doi.org/10.1080/10584600903053569

Young, D. G. (2013). Laughter, Learning, or Enlightenment? Viewing and Avoidance Motivations Behind The Daily Show and The Colbert Report. Journal of Broadcasting \& Electronic Media, 57(2), 153-169. https://doi.org/10.1080/08838151.2013.787080

Young, D. G. (2016). Humor and Satire, Political. In G. Mazzoleni, K. G. Barnhurst, K. Ikeda, R. Maia, \& H. Wessler (Eds.), The international encyclopedia of political communication (pp. 487-494). Chichester, UK ; Malden, MA: John Wiley \& Sons. 
Young, D. G., Holbert, R. L., \& Jamieson, K. H. (2014). Successful practices for the strategic use of political parody and satire: Lessons from the P6 Symposium and the 2012 election campaign. American Behavioral Scientist, 58(9), 1111-1130.

Young, D. G., \& Tisinger, R. M. (2006). Dispelling Late-Night Myths: News

Consumption among Late-Night Comedy Viewers and the Predictors of Exposure to Various Late-Night Shows. Harvard International Journal of Press/Politics, 11(3), 113-134. https://doi.org/10.1177/1081180X05286042 
Table 1

Factor Loadings for Maximum Likelihood of Late-Night Talk Show Scales

\begin{tabular}{lcc}
\hline Scale & Gentle Satire & Harsh Satire \\
\hline Jimmy Kimmel Live & $\mathbf{. 7 4 3}$ & -.093 \\
The Tonight Show Starring Jimmy Fallon & $\mathbf{. 6 9 9}$ & -.310 \\
Late Late Show with James Corden & $\mathbf{. 6 4 6}$ & .089 \\
Last Call with Carson Daly & $\mathbf{. 5 9 1}$ & .031 \\
Late Night with Seth Meyers & $\mathbf{. 5 4 8}$ & .323 \\
Conan & $\mathbf{. 4 7 0}$ & .129 \\
Saturday Night Live & .372 & .112 \\
Last Week Tonight with John Oliver & -.113 & $\mathbf{. 7 1 8}$ \\
The Daily Show with Trevor Noah & .043 & $\mathbf{. 6 6 4}$ \\
Full Frontal with Samantha Bee & .039 & $\mathbf{. 5 8 0}$ \\
Late Show with Stephen Colbert & .196 & $\mathbf{. 5 6 4}$ \\
\hline
\end{tabular}

Note. Factor loadings $>.40$ are in boldface 


\section{Table 2}

Correlation Matrix of Key Variables in Model 1 (Hard News Use vs. Political Satire Viewing)

\begin{tabular}{|c|c|c|c|c|c|c|c|c|c|c|c|c|c|c|}
\hline & 1 & 2 & 3 & 4 & 5 & 6 & 7 & 8 & 9 & 10 & 11 & 12 & 13 & 14 \\
\hline 1. Rep & 1 & & & & & & & & & & & & & \\
\hline 2. Dem & $-.561^{\cdots}$ & 1 & & & & & & & & & & & & \\
\hline 3. Education & -.044 & $.107^{*}$ & 1 & & & & & & & & & & & \\
\hline 4. PI & .054 & $.167^{* * *}$ & $.152^{* * *}$ & 1 & & & & & & & & & & \\
\hline 5. AC & -.042 & $-165^{* * *}$ & -.051 & $-419^{* * *}$ & 1 & & & & & & & & & \\
\hline 6. HN & -.067 & $.085^{*}$ & $.115^{* *}$ & $.182^{* * * *}$ & -.064 & 1 & & & & & & & & \\
\hline 7. PS & $-.121^{* *}$ & $.199^{* * *}$ & $.115^{* *}$ & $.189^{* * *}$ & $-.136^{* *}$ & $.466^{* * *}$ & 1 & & & & & & & \\
\hline 8. NATT & -.018 & $.136^{* *}$ & $.172^{* * *}$ & $.569^{4 * *}$ & $-343^{4 *+}$ & $.265^{4 * 4}$ & $.273^{* t+}$ & 1 & & & & & & \\
\hline 9. PT & -.035 & $.114^{* *}$ & $.109^{* *}$ & $.421^{4 * *}$ & $-.091^{*}$ & $.253^{* * *}$ & $.226^{4 * t}$ & $.362^{* * *}$ & 1 & & & & & \\
\hline 10. SME & -.019 & $.082^{*}$ & .042 & $.327^{*+*}$ & -.048 & $.306^{* * *}$ & $.192^{* * t}$ & $.268^{* * *}$ & $.462^{*+*}$ & 1 & & & & \\
\hline 11. PK & -.064 & $.139^{* *}$ & $.203^{* *}$ & $.372^{* * *}$ & $-.200^{4 * 4}$ & $-.269^{* * *}$ & $-.093^{\circ}$ & $.218^{* * *}$ & $.115^{* *}$ & -.036 & 1 & & & \\
\hline 12. $\mathrm{PE}$ & .007 & $.085^{*}$ & $.101^{*}$ & $.633^{*+*}$ & $-.299^{4 * *}$ & $.084^{*}$ & .061 & $.437^{*+*}$ & $.345^{* * *}$ & $.236^{* * *}$ & $.413^{* * *}$ & 1 & & \\
\hline 13. OffP & -.066 & $.138^{* *}$ & $.144^{*}$ & $.403^{* * *}$ & $-.172^{* * *}$ & $.312^{* * *}$ & $.263^{*+*}$ & $334^{* * *}$ & $395^{* * *}$ & $.397^{* * *}$ & $.122^{* *}$ & $.305^{* * *}$ & 1 & \\
\hline 14. $\mathrm{OnP}$ & $-.090^{\circ}$ & $.191^{* * *}$ & $.162^{* * t}$ & $.420^{* * *}$ & $-.152^{* * *}$ & $.207^{* * *}$ & $.125^{* *}$ & $.291^{* * *}$ & $.338^{*+*}$ & $.363^{* * *}$ & $.222^{*+*}$ & $326^{* * *}$ & $.697^{* * *}$ & 1 \\
\hline
\end{tabular}

Note . Rep $=$ Republicans $;$ Dem $=$ Democrats $;$ PI $=$ Political Interest $;$ AC $=$ Alternative concepts of Citizenship; HN = Hard News Use; PS = Political Satire Viewing; NATT = News Attention; PT = Political Talk; SME = Social Media Expression; PK = Political Knowledge; $\mathrm{PE}=$ Political Efficacy; OffP = Offline Political Participation; OnP = Online Political Participation.

$* p<.05 . * * p<.01 . * * * p<.001$. 
Table 3

Latent Regression Paths for Final SEM Model 1 (Hard News Use vs. Political Satire Viewing)

\begin{tabular}{|c|c|c|c|c|c|c|c|c|c|}
\hline Path & $\begin{array}{l}\mathrm{HN} \\
\mathrm{B}(\text { S.E. })\end{array}$ & $\begin{array}{l}\mathrm{PS} \\
\mathrm{B}(\text { S.E. })\end{array}$ & $\begin{array}{l}\text { NATT } \\
\text { B (S.E.) }\end{array}$ & $\begin{array}{l}\mathrm{PT} \\
\mathrm{B}(\text { S.E. })\end{array}$ & $\begin{array}{l}\text { SEM } \\
\text { B (S.E.) }\end{array}$ & $\begin{array}{l}\mathrm{PK} \\
\mathrm{B}(\text { S.E. })\end{array}$ & $\begin{array}{l}\mathrm{PE} \\
\mathrm{B}(\text { S.E. })\end{array}$ & $\begin{array}{l}\text { OffP } \\
\text { B (S.E.) }\end{array}$ & $\begin{array}{l}\text { OnP } \\
\mathrm{B}(\text { S.E. })\end{array}$ \\
\hline \multicolumn{10}{|c|}{ Covariates } \\
\hline Age & $\begin{array}{l}-.010 \\
(.003)^{* *}\end{array}$ & $\begin{array}{l}-.008 \\
(.004)^{*}\end{array}$ & $\begin{array}{l}.001 \\
(.006)\end{array}$ & $\begin{array}{l}-.016 \\
(.004)^{* * *}\end{array}$ & $\begin{array}{l}-.005 \\
(.004)\end{array}$ & $\begin{array}{l}.021 \\
(.006)^{* *}\end{array}$ & $\begin{array}{l}-.003 \\
(.004)\end{array}$ & $\begin{array}{l}-.004 \\
(.007)\end{array}$ & $\begin{array}{l}.005 \\
(.004)\end{array}$ \\
\hline Female & $\begin{array}{l}-.281 \\
(.089) * *\end{array}$ & $\begin{array}{l}-.066 \\
(.089)\end{array}$ & $\begin{array}{l}-.276 \\
(.134)^{*}\end{array}$ & $\begin{array}{l}-.036 \\
(.094)\end{array}$ & $\begin{array}{l}.159 \\
(.092)\end{array}$ & $\begin{array}{l}-.389 \\
(.161)^{*}\end{array}$ & $\begin{array}{l}-.395 \\
(.102)^{* * *}\end{array}$ & $\begin{array}{l}.293 \\
(.163)\end{array}$ & $\begin{array}{l}.255 \\
(.098)^{* * *}\end{array}$ \\
\hline White & $\begin{array}{l}-.395 \\
(.122)^{* *}\end{array}$ & $\begin{array}{l}-.186 \\
(.119)\end{array}$ & $\begin{array}{l}-.192 \\
(.176)\end{array}$ & $\begin{array}{l}-.034 \\
(.114)\end{array}$ & $\begin{array}{l}.029 \\
(.106)\end{array}$ & $\begin{array}{l}.090 \\
(.206)\end{array}$ & $\begin{array}{l}.364 \\
(.129)^{* *}\end{array}$ & $\begin{array}{l}.239 \\
(.197)\end{array}$ & $\begin{array}{l}.155 \\
(.113)\end{array}$ \\
\hline PI & $\begin{array}{l}.261 \\
(.046)^{* * * *}\end{array}$ & $\begin{array}{l}.192 \\
(.051)^{* * * *}\end{array}$ & $\begin{array}{l}1.153 \\
(.147)^{* * *}\end{array}$ & $\begin{array}{l}.617 \\
(.072) * * *\end{array}$ & $\begin{array}{l}.420 \\
(.059)^{* * * *}\end{array}$ & $\begin{array}{l}.559 \\
(.163)^{* *}\end{array}$ & $\begin{array}{l}.734 \\
(.110)^{* * * *}\end{array}$ & $\begin{array}{l}.338 \\
(.156)^{*}\end{array}$ & $\begin{array}{l}.222 \\
(.098)^{*}\end{array}$ \\
\hline \multicolumn{10}{|c|}{ Independent Variables } \\
\hline Rep & $\begin{array}{l}-.097 \\
(.125)\end{array}$ & $\begin{array}{l}-.052 \\
(.117)\end{array}$ & $\begin{array}{l}-.369 \\
(.210)\end{array}$ & $\begin{array}{l}-.049 \\
(.123)\end{array}$ & $\begin{array}{l}.006 \\
(.119)\end{array}$ & $\begin{array}{l}-.347 \\
(.225)\end{array}$ & $\begin{array}{l}-.189 \\
(.151)\end{array}$ & $\begin{array}{l}-.220 \\
(.218)\end{array}$ & $\begin{array}{l}-.120 \\
(.130)\end{array}$ \\
\hline Dem & $\begin{array}{l}.059 \\
(.117)\end{array}$ & $\begin{array}{l}.289 \\
(.111)^{* * *}\end{array}$ & $\begin{array}{l}-.102 \\
(.171)\end{array}$ & $\begin{array}{l}.039 \\
(.118)\end{array}$ & $\begin{array}{l}.040 \\
(.109)\end{array}$ & $\begin{array}{l}.242 \\
(.199)\end{array}$ & $\begin{array}{l}-.132 \\
(.133)\end{array}$ & $\begin{array}{l}-.019 \\
(.200)\end{array}$ & $\begin{array}{l}.196 \\
(.119)\end{array}$ \\
\hline Edu & $\begin{array}{l}.218 \\
(.089)^{*}\end{array}$ & $\begin{array}{l}.186 \\
(.090)^{*}\end{array}$ & $\begin{array}{l}.293 \\
(.150)\end{array}$ & $\begin{array}{l}.072 \\
(.109)\end{array}$ & $\begin{array}{l}-.099 \\
(.099)\end{array}$ & $\begin{array}{l}.763 \\
(.179)^{* * * *}\end{array}$ & $\begin{array}{l}-.049 \\
(.115)\end{array}$ & $\begin{array}{l}.175 \\
(.162)\end{array}$ & $\begin{array}{l}.156 \\
(.100)\end{array}$ \\
\hline $\mathrm{AC}$ & $\begin{array}{l}.036 \\
(.051)\end{array}$ & $\begin{array}{l}-.048 \\
(.052)\end{array}$ & $\begin{array}{l}-.277 \\
(.106)^{* *}\end{array}$ & $\begin{array}{l}.168 \\
(.065)^{*}\end{array}$ & $\begin{array}{l}.141 \\
(.062)^{*}\end{array}$ & $\begin{array}{l}-.081 \\
(.107)\end{array}$ & $\begin{array}{l}-.071 \\
(.085)\end{array}$ & $\begin{array}{l}-.083 \\
(.101)\end{array}$ & $\begin{array}{l}.010 \\
(.071)\end{array}$ \\
\hline $\mathrm{HN}$ & & & $\begin{array}{l}.151 \\
(.069)^{*}\end{array}$ & $\begin{array}{l}.162 \\
(.057)^{* *}\end{array}$ & $\begin{array}{l}.287 \\
(.050)^{* * *}\end{array}$ & $\begin{array}{l}-.714 \\
(.135)^{* * *}\end{array}$ & $\begin{array}{l}-.109 \\
(.062)\end{array}$ & $\begin{array}{l}.379 \\
(.127)^{* *}\end{array}$ & $\begin{array}{l}.201 \\
(.074)^{* *}\end{array}$ \\
\hline PS & & & $\begin{array}{l}.133 \\
(.075)\end{array}$ & $\begin{array}{l}.099 \\
(.055)\end{array}$ & $\begin{array}{l}.019 \\
(.057)\end{array}$ & $\begin{array}{l}-.137 \\
(.097)\end{array}$ & $\begin{array}{l}-.150 \\
(.058)^{*}\end{array}$ & $\begin{array}{l}.133 \\
(.109)\end{array}$ & $\begin{array}{l}-.094 \\
(.061)\end{array}$ \\
\hline NATT & & & & & & $\begin{array}{l}.249 \\
(.128)\end{array}$ & $\begin{array}{l}.250 \\
(.094)^{* * *}\end{array}$ & $\begin{array}{l}.009 \\
(.127)\end{array}$ & $\begin{array}{l}.007 \\
(.070)\end{array}$ \\
\hline PT & & & & & & $\begin{array}{l}.094 \\
(.097)\end{array}$ & $\begin{array}{l}.091 \\
(.068)\end{array}$ & $\begin{array}{l}.305 \\
(.094)^{* *}\end{array}$ & $\begin{array}{l}.123 \\
(.054)^{*}\end{array}$ \\
\hline SME & & & & & & $\begin{array}{l}-.189 \\
(.080)^{*}\end{array}$ & $\begin{array}{l}.027 \\
(.061)\end{array}$ & $\begin{array}{l}.390 \\
(.095) * * *\end{array}$ & $\begin{array}{l}.239 \\
(.058) * * *\end{array}$ \\
\hline PK & & & & & & & & $\begin{array}{l}.082 \\
(.044)\end{array}$ & $\begin{array}{l}.079 \\
(.026)^{* *}\end{array}$ \\
\hline PE & & & & & & & & $\begin{array}{l}.067 \\
(.079)\end{array}$ & $\begin{array}{l}.054 \\
(.052)\end{array}$ \\
\hline
\end{tabular}

Note. Results were generated using MLR, a robust Maximum Likelihood estimation in Lavaan For R. Education was created as an indicator variable by coding 1 if the respondent has a college degree or beyond and 0 if not. Final model fit: $\chi 2(287)=$ 706.177, $p<.001, \mathrm{RMSEA}=.051(.046-.055), \mathrm{CFI}=.942, \mathrm{NNFI} / \mathrm{TLI}=.916, \mathrm{SRMR}$ $=.063$. PI $=$ Political Interest Rep $=$ Republicans $;$ Dem $=$ Democrats $;$ Edu $=$ Education; $\mathrm{AC}=$ Alternative concepts of Citizenship; $\mathrm{HN}=$ Hard News Use; PS = Political Satire Viewing; NATT $=$ News Attention; PT $=$ Political Talk; SME $=$ Social Media Expression; $\mathrm{PK}=$ Political Knowledge; $\mathrm{PE}=$ Political Efficacy $;$ OffP = Offline Political Participation; OnP = Online Political Participation.

$* p<.05 ; * * p<.01 ; * * * p<.001$. 
Table 4

Significant Indirect Effects of Hard News Use

\begin{tabular}{llcc}
\hline & \multicolumn{3}{c}{$95 \%$ CI } \\
\cline { 2 - 4 } Path & B (SE) & $L L$ & $U L$ \\
\hline Theoretical Model & $.011(.007)$ & .001 & $.027^{*}$ \\
Edu > HN > PT > OffP & $.004(.003)$ & .000 & $.012^{*}$ \\
Edu > HN > PT > OnP & $.024(.013)$ & .003 & $.052^{*}$ \\
Edu > HN > SME > OffP & $.015(.008)$ & .002 & $.033^{*}$ \\
Edu > HN > SME > OnP & Note. All estimates generated from 5000 bootstrapped resamples. Unstandardized \\
coefficients, standard errors, and 95\% confidence intervals are presented. *Indicates that \\
the confidence interval does not contain zero. Edu = Education; HN = Hard News Use; \\
PT = Political Talk; SME = Social Media Expression; OffP = Offline Political \\
Participation; OnP = Online Political Participation.
\end{tabular}


Table 5

Correlation Matrix of Key Variables in Model 2 (Harsh Satire Viewing vs. Gentle Satire Viewing)

\begin{tabular}{|c|c|c|c|c|c|c|c|c|c|c|c|c|c|c|}
\hline & 1 & 2 & 3 & 4 & 5 & 6 & 7 & 8 & 9 & 10 & 11 & 12 & 13 & 14 \\
\hline 1. Rep & 1 & & & & & & & & & & & & & \\
\hline 2. Dem & $-.561^{\cdots *}$ & 1 & & & & & & & & & & & & \\
\hline 3. Education & .010 & $.145^{\circ}$ & 1 & & & & & & & & & & & \\
\hline 4. PI & -.020 & $.248^{* * *}$ & $.177^{* *}$ & 1 & & & & & & & & & & \\
\hline 5. HN & .023 & .011 & $.122^{\circ}$ & $.149^{* *}$ & 1 & & & & & & & & & \\
\hline 6. HS & $-.227^{* * *}$ & $.330^{* * *}$ & $.189^{\circ *}$ & $.316^{* * *}$ & $.359^{* * *}$ & 1 & & & & & & & & \\
\hline 7. GS & .049 & .063 & .102 & $.116^{\circ}$ & $.495^{* * *}$ & $.290^{* * *}$ & 1 & & & & & & & \\
\hline 8. NATT & -.071 & $.192^{\circ *}$ & $.133^{\circ}$ & $.596^{* *}$ & $.227^{* *}$ & $.315^{* \cdots}$ & $.184^{* *}$ & 1 & & & & & & \\
\hline 9. PT & -.073 & $.136^{\circ}$ & .098 & $.397^{* *}$ & $.224^{* * *}$ & $.267^{* * \cdot}$ & $.255^{\cdots *}$ & $399^{* * *}$ & 1 & & & & & \\
\hline 10. SME & -.063 & $.140^{\circ}$ & .110 & $.342^{* *}$ & $.350^{* \cdots}$ & $.238^{* *}$ & $.256^{* *}$ & $.333^{\cdots \cdots}$ & $462^{* *}$ & 1 & & & & \\
\hline 11. PK & $-136^{\circ}$ & $.210^{\cdots *}$ & $.216^{* *}$ & $.351^{\cdots}$ & $-331^{\cdots}$ & $.155^{\circ *}$ & $-.226^{\cdots *}$ & $.206^{* *}$ & .095 & -.053 & 1 & & & \\
\hline 12. PE & -.108 & $.174^{* *}$ & .098 & $.618^{* *}$ & .084 & $.284^{* *}$ & .002 & $.477^{* * *}$ & $.313^{\cdots}$ & $.228^{* *}$ & $368^{* * *}$ & 1 & & \\
\hline 13. OffP & -.053 & .095 & $.131^{\circ}$ & $.372^{* *}$ & $.315^{* *}$ & $318^{* *}$ & $.170^{\circ}$ & $.352^{\cdots *}$ & $.394^{* *}$ & $448^{\cdots}$ & .077 & $.310^{* * *}$ & 1 & \\
\hline 14. OnP & -104 & $.190^{\circ}$ & $178^{* *}$ & $406^{* *}$ & $213^{* *}$ & $.270^{* * *}$ & -.032 & $289^{* *}$ & $326^{* *}$ & $424^{\cdots}$ & $207^{* * *}$ & $323^{* * *}$ & $675^{* * *}$ & 1 \\
\hline
\end{tabular}

Note . Rep $=$ Republicans $;$ Dem $=$ Democrats $;$ PI $=$ Political Interest $; \mathrm{HN}=$ Hard News Use; HS = Harsh Satire Viewing; GS = Gentle Satire Viewing; NATT = News Attention; PT = Political Talk; SME = Social Media Expression; PK = Political Knowledge; PE = Political Efficacy; OffP = Offline Political Participation; OnP = Online Political Participation.

$* p<.05 . * * p<.01 . * * * p<.001$. 
Table 6

Latent Regression Paths for Final SEM Model 2 (Harsh Satire Viewing vs. Gentle Satire Viewing)

\begin{tabular}{|c|c|c|c|c|c|c|c|c|c|}
\hline Path & $\begin{array}{l}\text { HS } \\
\mathrm{B}(S . E .)\end{array}$ & $\begin{array}{l}\text { GS } \\
\text { B }(\text { S.E. })\end{array}$ & $\begin{array}{l}\text { NATT } \\
\text { B (S.E. })\end{array}$ & $\begin{array}{l}\mathrm{PT} \\
\mathrm{B}(\text { S.E. })\end{array}$ & $\begin{array}{l}\text { SME } \\
\text { B (S.E.) }\end{array}$ & $\begin{array}{l}\text { PK } \\
\mathrm{B}(S . E .)\end{array}$ & $\begin{array}{l}\mathrm{PE} \\
\mathrm{B}(\text { S.E. })\end{array}$ & $\begin{array}{l}\text { OffP } \\
\text { B (S.E.) }\end{array}$ & $\begin{array}{l}\text { OnP } \\
\text { B (S.E.) }\end{array}$ \\
\hline \multicolumn{10}{|c|}{ Covariates } \\
\hline Age & $\begin{array}{l}-.001 \\
(.007)\end{array}$ & $\begin{array}{l}-.002 \\
(.007)\end{array}$ & $\begin{array}{l}.004 \\
(.007)\end{array}$ & $\begin{array}{l}-.016 \\
(.006)^{* *}\end{array}$ & $\begin{array}{l}-.015 \\
(.005)^{* *}\end{array}$ & $\begin{array}{l}.018 \\
(.008)^{*}\end{array}$ & $\begin{array}{l}-.010 \\
(.007)\end{array}$ & $\begin{array}{l}-.009 \\
(.010)\end{array}$ & $\begin{array}{l}.010 \\
(.006)\end{array}$ \\
\hline Female & $\begin{array}{l}-.482 \\
(.139)^{* * *}\end{array}$ & $\begin{array}{l}.154 \\
(.141)\end{array}$ & $\begin{array}{l}-.086 \\
(.192)\end{array}$ & $\begin{array}{l}-.059 \\
(.136)\end{array}$ & $\begin{array}{l}.123 \\
(.125)\end{array}$ & $\begin{array}{l}-.446 \\
(.206)^{*}\end{array}$ & $\begin{array}{l}-.298 \\
(.153)\end{array}$ & $\begin{array}{l}.530 \\
(.236)^{*}\end{array}$ & $\begin{array}{l}.441 \\
(.138)^{* * *}\end{array}$ \\
\hline White & $\begin{array}{l}-.084 \\
(.180)\end{array}$ & $\begin{array}{l}-.303 \\
(.170)\end{array}$ & $\begin{array}{l}-.539 \\
(.242)^{*}\end{array}$ & $\begin{array}{l}-.001 \\
(.174)\end{array}$ & $\begin{array}{l}.065 \\
(.134)\end{array}$ & $\begin{array}{l}.091 \\
(.281)\end{array}$ & $\begin{array}{l}.490 \\
(.216)^{*}\end{array}$ & $\begin{array}{l}.176 \\
(.328)\end{array}$ & $\begin{array}{l}-.056 \\
(.183)\end{array}$ \\
\hline PI & $\begin{array}{l}.364 \\
(.090)^{* * * *}\end{array}$ & $\begin{array}{l}.026 \\
(.082)\end{array}$ & $\begin{array}{l}1.462 \\
(.219)^{* * * *}\end{array}$ & $\begin{array}{l}.584 \\
(.102)^{* * * *}\end{array}$ & $\begin{array}{l}.441 \\
(.089)^{* * *}\end{array}$ & $\begin{array}{l}.514 \\
(.295)\end{array}$ & $\begin{array}{l}.626 \\
(.214)^{* * *}\end{array}$ & $\begin{array}{l}.190 \\
(.243)\end{array}$ & $\begin{array}{l}.276 \\
(.146)\end{array}$ \\
\hline \multicolumn{10}{|c|}{ Independent Variables } \\
\hline Rep & $\begin{array}{l}.342 \\
(.170)^{*}\end{array}$ & $\begin{array}{l}.389 \\
(.192)^{*}\end{array}$ & $\begin{array}{l}-.385 \\
(.304)\end{array}$ & $\begin{array}{l}-.197 \\
(.189)\end{array}$ & $\begin{array}{l}-.148 \\
(.167)\end{array}$ & $\begin{array}{l}-.263 \\
(.366)\end{array}$ & $\begin{array}{l}-.305 \\
(.228)\end{array}$ & $\begin{array}{l}-.049 \\
(.309)\end{array}$ & $\begin{array}{l}.035 \\
(.187)\end{array}$ \\
\hline Dem & $\begin{array}{l}.583 \\
(.173)^{* * *}\end{array}$ & $\begin{array}{l}.302 \\
(.167)\end{array}$ & $\begin{array}{l}.046 \\
(.226)\end{array}$ & $\begin{array}{l}.015 \\
(.169)\end{array}$ & $\begin{array}{l}.099 \\
(.155)\end{array}$ & $\begin{array}{l}.115 \\
(.256)\end{array}$ & $\begin{array}{l}-.205 \\
(.198)\end{array}$ & $\begin{array}{l}-.450 \\
(.289)\end{array}$ & $\begin{array}{l}.055 \\
(.166)\end{array}$ \\
\hline Edu & $\begin{array}{l}.249 \\
(.151)\end{array}$ & $\begin{array}{l}.059 \\
(.150)\end{array}$ & $\begin{array}{l}-.035 \\
(.210)\end{array}$ & $\begin{array}{l}.068 \\
(.161)\end{array}$ & $\begin{array}{l}.047 \\
(.139)\end{array}$ & $\begin{array}{l}.932 \\
(.232)^{*} * *\end{array}$ & $\begin{array}{l}-.036 \\
(.168)\end{array}$ & $\begin{array}{l}.043 \\
(.245)\end{array}$ & $\begin{array}{l}.117 \\
(.151)\end{array}$ \\
\hline $\mathrm{HN}$ & $\begin{array}{l}.029 \\
(.005)^{* * *}\end{array}$ & $\begin{array}{l}.044 \\
(.005)^{* * *}\end{array}$ & $\begin{array}{l}.010 \\
(.007)\end{array}$ & $\begin{array}{l}.001 \\
(.006)\end{array}$ & $\begin{array}{l}.020 \\
(.005)^{* * *}\end{array}$ & $\begin{array}{l}-.055 \\
(.010)^{* * *}\end{array}$ & $\begin{array}{l}-.005 \\
(.006)\end{array}$ & $\begin{array}{l}.024 \\
(.014)\end{array}$ & $\begin{array}{l}.022 \\
(.007)^{* * *}\end{array}$ \\
\hline HS & & & $\begin{array}{l}.092 \\
(.109)\end{array}$ & $\begin{array}{l}.066 \\
(.070)\end{array}$ & $\begin{array}{l}-.009 \\
(.069)\end{array}$ & $\begin{array}{l}.279 \\
(.123)^{*}\end{array}$ & $\begin{array}{l}.126 \\
(.083)\end{array}$ & $\begin{array}{l}.377 \\
(.137)^{* *}\end{array}$ & $\begin{array}{l}.181 \\
(.083)^{*}\end{array}$ \\
\hline GS & & & $\begin{array}{l}-.019 \\
(.112)\end{array}$ & $\begin{array}{l}.194 \\
(.082)^{*}\end{array}$ & $\begin{array}{l}.100 \\
(.081)\end{array}$ & $\begin{array}{l}-.289 \\
(.110)^{* *}\end{array}$ & $\begin{array}{l}-.143 \\
(.088)\end{array}$ & $\begin{array}{l}-.169 \\
(.167)\end{array}$ & $\begin{array}{l}-.378 \\
(.081)^{* * *}\end{array}$ \\
\hline NATT & & & & & & $\begin{array}{l}.161 \\
(.200)\end{array}$ & $\begin{array}{l}.373 \\
(.163)^{*}\end{array}$ & $\begin{array}{l}.034 \\
(.207)\end{array}$ & $\begin{array}{l}-.169 \\
(.112)\end{array}$ \\
\hline PT & & & & & & $\begin{array}{l}.113 \\
(.129)\end{array}$ & $\begin{array}{l}.014 \\
(.120)\end{array}$ & $\begin{array}{l}.325 \\
(.163)^{*}\end{array}$ & $\begin{array}{l}.210 \\
(.090)^{*}\end{array}$ \\
\hline SME & & & & & & $\begin{array}{l}-.196 \\
(.098)^{*}\end{array}$ & $\begin{array}{l}-.034 \\
(.099)\end{array}$ & $\begin{array}{l}.545 \\
(.134)^{* * *}\end{array}$ & $\begin{array}{l}.362 \\
(.078)^{* * * *}\end{array}$ \\
\hline PK & & & & & & & & $\begin{array}{l}.045 \\
(.066)\end{array}$ & $\begin{array}{l}.067 \\
(.036)\end{array}$ \\
\hline PE & & & & & & & & $\begin{array}{l}.113 \\
(.130)\end{array}$ & $\begin{array}{l}.090 \\
.075)\end{array}$ \\
\hline
\end{tabular}

Note. Results were generated using MLR, a robust Maximum Likelihood estimation in Lavaan For R. Education was created as an indicator variable by coding 1 if the respondent has a college degree or beyond and 0 if not. Final model fit: $\chi 2(252)=$ $398.920, p<.001, \mathrm{RMSEA}=.043(.036-.050), \mathrm{CFI}=.952, \mathrm{NNFI} / \mathrm{TLI}=.928, \mathrm{SRMR}$ $=.043$. PI $=$ Political Interest $;$ Rep $=$ Republicans; Dem $=$ Democrats; Edu $=$ Education; $\mathrm{HN}=$ Hard News Use; HS = Harsh Satire Viewing; GS = Gentle Satire Viewing; NATT $=$ News Attention; $\mathrm{PT}=$ Political Talk $; \mathrm{SME}=$ Social Media Expression $; \mathrm{PK}=$ Political Knowledge; $\mathrm{PE}=$ Political Efficacy; OffP = Offline Political Participation; OnP = Online Political Participation.

$* p<.05 ; * * p<.01 ; * * * p<.001$. 


\section{Table 7}

Significant Indirect Effects of Gentle Satire Viewing

\begin{tabular}{llcl}
\hline & \multicolumn{3}{c}{$95 \%$ CI } \\
\cline { 2 - 4 } Path & B (SE) & $L L$ & $U L$ \\
\hline Theoretical Model & & & \\
HN $>$ GS $>$ PT > OnP & $.002(.003)$ & .000 & $.005^{*}$ \\
\hline
\end{tabular}

Note. All estimates generated from 5000 bootstrapped resamples. Unstandardized coefficients, standard errors, and $95 \%$ confidence intervals are presented. *Indicates that the confidence interval does not contain zero. $\mathrm{HN}=$ Hard News Use; GS = Gentle Satire Viewing; PT = Political Talk; OnP = Online Political Participation. 
Table 8

Correlation Matrix of Key Variables in Model 3 (Self-viewing vs. Curated Viewing of Political Satire)

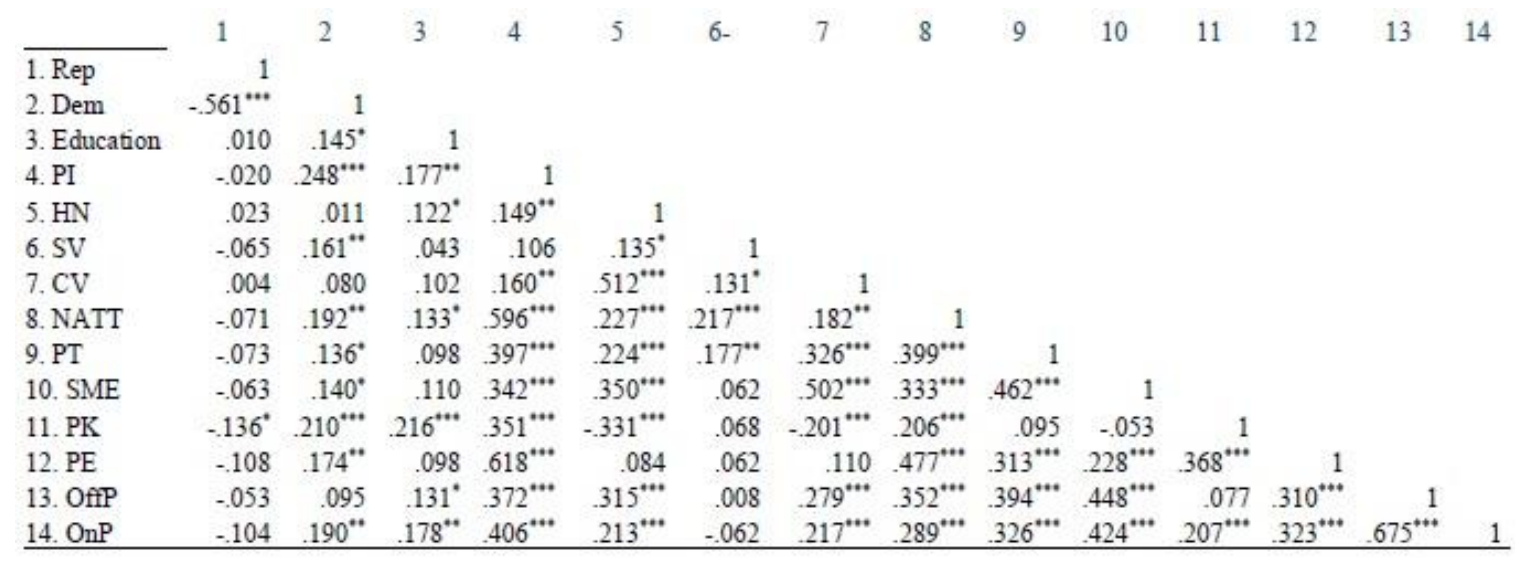

Note . Rep = Republicans; Dem = Democrats $;$ PI = Political Interest HN = Hard News Use; SV = Self-viewing of Political Satire; CV = Curated Viewing of Political Satire; NATT = News Attention; PT = Political Talk; SME = Social Media Expression; PK = Political Knowledge; PE = Political Efficacy; OffP = Offline Political Participation; OnP = Online Political Participation.

$* p<.05 . * * p<.01 . * * * p<.001$. 
Table 9

Latent Regression Paths for Final SEM Model 3 (Self-viewing vs. Curated Viewing of Political Satire)

\begin{tabular}{|c|c|c|c|c|c|c|c|c|c|}
\hline Path & $\begin{array}{l}\text { SV } \\
\mathrm{B}(\text { S.E. })\end{array}$ & $\begin{array}{l}\text { CV } \\
\mathrm{B}(\text { S.E. }) \\
\end{array}$ & $\begin{array}{l}\text { NATT } \\
\mathrm{B}(S . E .)\end{array}$ & $\begin{array}{l}\mathrm{PT} \\
\mathrm{B}(\text { S.E. }) \\
\end{array}$ & $\begin{array}{l}\text { SME } \\
\text { B (S.E.) }\end{array}$ & $\begin{array}{l}\mathrm{PK} \\
\mathrm{B}(\text { S.E. }) \\
\end{array}$ & $\begin{array}{l}\mathrm{PE} \\
\mathrm{B}(\text { S.E. })\end{array}$ & $\begin{array}{l}\text { OffP } \\
\text { B (S.E.) }\end{array}$ & $\begin{array}{l}\text { OnP } \\
\text { B (S.E.) }\end{array}$ \\
\hline \multicolumn{10}{|c|}{ Covariates } \\
\hline Age & $\begin{array}{l}.004 \\
(.005)\end{array}$ & $\begin{array}{l}-.017 \\
(.007)^{*}\end{array}$ & $\begin{array}{l}.006 \\
(.008)\end{array}$ & $\begin{array}{l}-.013 \\
(.006)^{*}\end{array}$ & $\begin{array}{l}-.008 \\
(.006)\end{array}$ & $\begin{array}{l}.016 \\
(.008)\end{array}$ & $\begin{array}{l}-.010 \\
(.007)\end{array}$ & $\begin{array}{l}-.010 \\
(.010)\end{array}$ & $\begin{array}{l}.009 \\
(.006)\end{array}$ \\
\hline Female & $\begin{array}{l}.116 \\
(.137)\end{array}$ & $\begin{array}{l}.079 \\
(.141)\end{array}$ & $\begin{array}{l}-.141 \\
(.191)\end{array}$ & $\begin{array}{l}-.095 \\
(.132)\end{array}$ & $\begin{array}{l}.123 \\
(.133)\end{array}$ & $\begin{array}{l}-.635 \\
(.203)^{* *}\end{array}$ & $\begin{array}{l}-.372 \\
(.145)^{*}\end{array}$ & $\begin{array}{l}.395 \\
(.231)\end{array}$ & $\begin{array}{l}.371 \\
(.134)^{* *}\end{array}$ \\
\hline White & $\begin{array}{l}.075 \\
(.160)\end{array}$ & $\begin{array}{l}.047 \\
(.175)\end{array}$ & $\begin{array}{l}-.564 \\
(.245)^{*}\end{array}$ & $\begin{array}{l}-.082 \\
(.178)\end{array}$ & $\begin{array}{l}.017 \\
(.160)\end{array}$ & $\begin{array}{l}.163 \\
(.280)\end{array}$ & $\begin{array}{l}.542 \\
(.218)^{*}\end{array}$ & $\begin{array}{l}.232 \\
(.340)\end{array}$ & $\begin{array}{l}.063 \\
(.189)\end{array}$ \\
\hline PI & $\begin{array}{l}.032 \\
(.092)\end{array}$ & $\begin{array}{l}.156 \\
(.085)\end{array}$ & $\begin{array}{l}1.504 \\
(.229)^{* * * *}\end{array}$ & $\begin{array}{l}.581 \\
(.099)^{* * *}\end{array}$ & $\begin{array}{l}.416 \\
(.089) * * *\end{array}$ & $\begin{array}{l}.589 \\
(.290)^{*}\end{array}$ & $\begin{array}{l}.626 \\
(.218)^{* *}\end{array}$ & $\begin{array}{l}.181 \\
(.264)\end{array}$ & $\begin{array}{l}.234 \\
(.152)\end{array}$ \\
\hline \multicolumn{10}{|c|}{ Independent Variables } \\
\hline Rep & $\begin{array}{l}.061 \\
(.190)\end{array}$ & $\begin{array}{l}.110 \\
(.172)\end{array}$ & $\begin{array}{l}-.418 \\
(.294)\end{array}$ & $\begin{array}{l}-.177 \\
(.185)\end{array}$ & $\begin{array}{l}-.176 \\
(.175)\end{array}$ & $\begin{array}{l}-.454 \\
(.332)\end{array}$ & $\begin{array}{l}-.399 \\
(.223)\end{array}$ & $\begin{array}{l}-.166 \\
(.326)\end{array}$ & $\begin{array}{l}-.104 \\
(.182)\end{array}$ \\
\hline Dem & $\begin{array}{l}.374 \\
(.172)^{*}\end{array}$ & $\begin{array}{l}.266 \\
(.165)\end{array}$ & $\begin{array}{l}.036 \\
(.233)\end{array}$ & $\begin{array}{l}.008 \\
(.170)\end{array}$ & $\begin{array}{l}.016 \\
(.158)\end{array}$ & $\begin{array}{l}.187 \\
(.263)\end{array}$ & $\begin{array}{l}-.161 \\
(.194)\end{array}$ & $\begin{array}{l}-.206 \\
(.273)\end{array}$ & $\begin{array}{l}.120 \\
(.162)\end{array}$ \\
\hline Edu & $\begin{array}{l}-.024 \\
(.160)\end{array}$ & $\begin{array}{l}.047 \\
(.151)\end{array}$ & $\begin{array}{l}-.005 \\
(.211)\end{array}$ & $\begin{array}{l}.094 \\
(.158)\end{array}$ & $\begin{array}{l}.030 \\
(.144)\end{array}$ & $\begin{array}{l}.993 \\
(.239)^{* * *}\end{array}$ & $\begin{array}{l}-.013 \\
(.170)\end{array}$ & $\begin{array}{l}.080 \\
(.247)\end{array}$ & $\begin{array}{l}.098 \\
(.145)\end{array}$ \\
\hline $\mathrm{HN}$ & $\begin{array}{l}.012 \\
(.004)^{* *}\end{array}$ & $\begin{array}{l}.049 \\
(.007)^{* * * *}\end{array}$ & $\begin{array}{l}.009 \\
(.008)\end{array}$ & $\begin{array}{l}-.002 \\
(.006)\end{array}$ & $\begin{array}{l}.002 \\
(.006)\end{array}$ & $\begin{array}{l}-.055 \\
(.009) * * *\end{array}$ & $\begin{array}{l}-.008 \\
(.007)\end{array}$ & $\begin{array}{l}.036 \\
(.013)^{* *}\end{array}$ & $\begin{array}{l}.017 \\
(.007)^{*}\end{array}$ \\
\hline SV & & & $\begin{array}{l}.122 \\
(.108)\end{array}$ & $\begin{array}{l}.122 \\
(.059)^{*}\end{array}$ & $\begin{array}{l}-.051 \\
(.056)\end{array}$ & $\begin{array}{l}.103 \\
(.089)\end{array}$ & $\begin{array}{l}-.037 \\
(.071)\end{array}$ & $\begin{array}{l}-.192 \\
(.104)\end{array}$ & $\begin{array}{l}-.188 \\
(.056)^{* *}\end{array}$ \\
\hline $\mathrm{CV}$ & & & $\begin{array}{l}.055 \\
(.098)\end{array}$ & $\begin{array}{l}.264 \\
(.093)^{* *}\end{array}$ & $\begin{array}{l}.538 \\
(.098) * * *\end{array}$ & $\begin{array}{l}-.153 \\
(.125)\end{array}$ & $\begin{array}{l}.018 \\
(.095)\end{array}$ & $\begin{array}{l}-.077 \\
(.192)\end{array}$ & $\begin{array}{l}-.027 \\
(.095)\end{array}$ \\
\hline NATT & & & & & & $\begin{array}{l}.183 \\
(.194)\end{array}$ & $\begin{array}{l}.401 \\
(.167)^{*}\end{array}$ & $\begin{array}{l}.083 \\
(.233)\end{array}$ & $\begin{array}{l}-.130 \\
(.120)\end{array}$ \\
\hline PT & & & & & & $\begin{array}{l}.073 \\
(.129)\end{array}$ & $\begin{array}{l}-.005 \\
(.117)\end{array}$ & $\begin{array}{l}.352 \\
(.157)^{*}\end{array}$ & $\begin{array}{l}.175 \\
(.087)^{*}\end{array}$ \\
\hline SME & & & & & & $\begin{array}{l}-.121 \\
(.111)\end{array}$ & $\begin{array}{l}-.049 \\
(.099)\end{array}$ & $\begin{array}{l}.487 \\
(.148)^{* * *}\end{array}$ & $\begin{array}{l}.310 \\
(.077)^{* * *}\end{array}$ \\
\hline PK & & & & & & & & $\begin{array}{l}.086 \\
(.066)\end{array}$ & $\begin{array}{l}.111 \\
(.036)^{* *}\end{array}$ \\
\hline PE & & & & & & & & $\begin{array}{l}.137 \\
(.139)\end{array}$ & $\begin{array}{l}.124 \\
(.076)\end{array}$ \\
\hline
\end{tabular}

Note. Results were generated using MLR, a robust Maximum Likelihood estimation in Lavaan For R. Education was created as an indicator variable by coding 1 if the respondent has a college degree or beyond and 0 if not. Final model fit: $\chi 2(200)=$ $371.765, p<.001, \mathrm{RMSEA}=.052(.045-.060), \mathrm{CFI}=.939, \mathrm{NNFI} / \mathrm{TLI}=.901, \mathrm{SRMR}$ $=.043$. PI $=$ Political Interest; Rep = Republicans; Dem = Democrats; Edu = Education; $\mathrm{HN}=$ Hard News Use; SV = Self-viewing of Political Satire; CV = Curated Viewing of Political Satire; NATT $=$ News Attention; PT $=$ Political Talk $;$ SME = Social Media Expression; $\mathrm{PK}=$ Political Knowledge; $\mathrm{PE}=$ Political Efficacy; OffP = Offline Political Participation; OnP = Online Political Participation.

$* p<.05 ; * * p<.01 ; * * * p<.001$. 
Table 10

Significant Indirect Effects of Curated Viewing of Political Satire

\begin{tabular}{llll}
\hline & \multicolumn{3}{c}{$95 \%$ CI } \\
\cline { 2 - 4 } Path & B (SE) & $L L$ & $U L$ \\
\hline Theoretical Model & $.013(.015)$ & .004 & $.025^{*}$ \\
HN > CV > SME > OffP & $.008(.006)$ & .003 & $.015^{*}$ \\
HN > CV > SME > OnP &
\end{tabular}

Note. All estimates generated from 5000 bootstrapped resamples. Unstandardized coefficients, standard errors, and $95 \%$ confidence intervals are presented. *Indicates that the confidence interval does not contain zero. $\mathrm{HN}=$ Hard News Use; $\mathrm{CV}=$ Curated Viewing of Political Satire; SME = Social Media Expression; OffP = Offline Political Participation; OnP = Online Political Participation. 


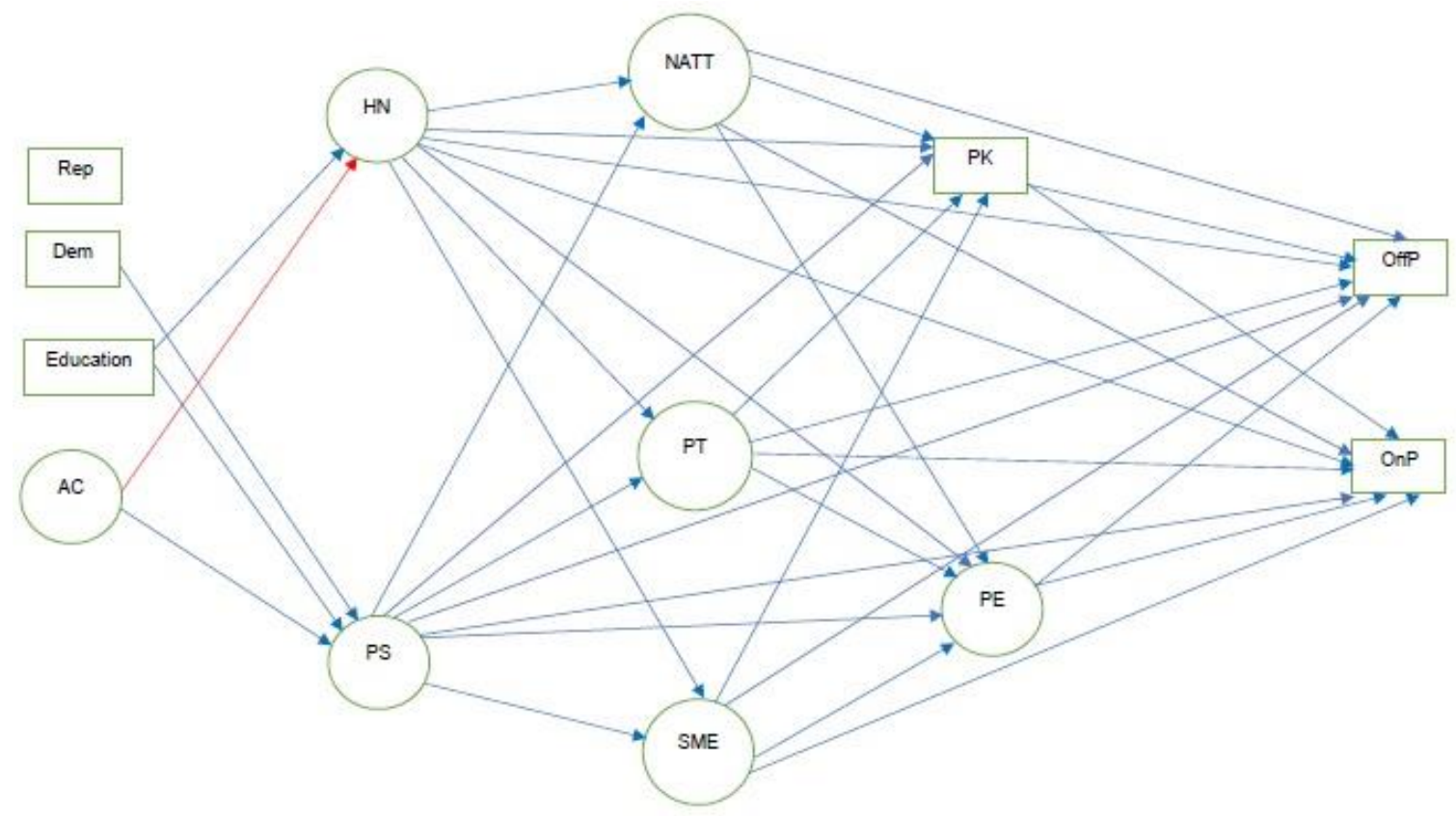

Figure 1. Hypothesized model for Model 1 (Hard News Use vs. Political Satire Viewing).

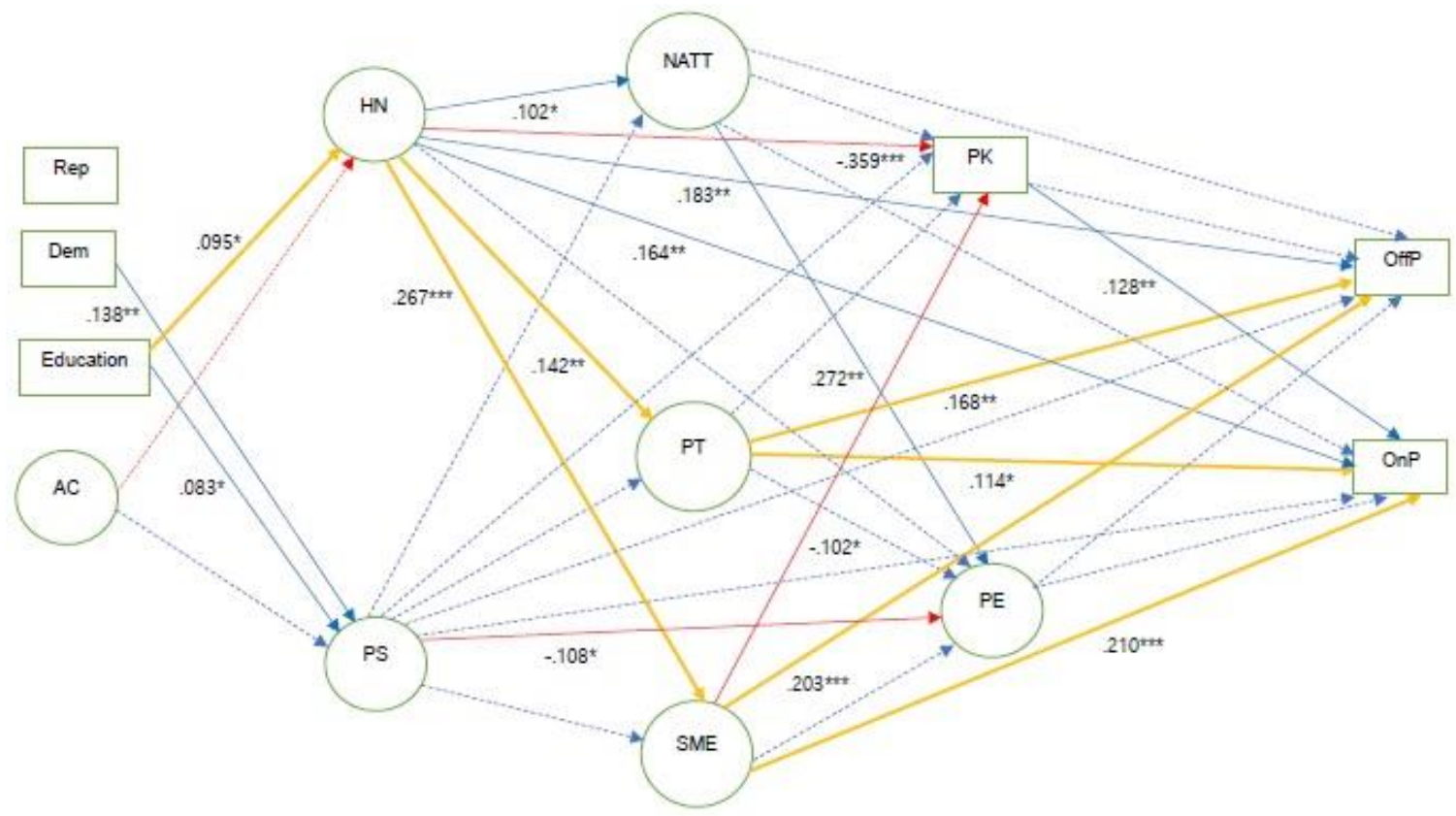

Figure 2. Final model for Model 1 (Hard News Use vs. Political Satire Viewing). Note. Solid lines indicate significant paths. Red solid lines indicate significant negative association. Blue solid lines indicate significant positive association. Dashed lines indicate nonsignificant paths. Yellow lines indicate significant indirect paths. $* p<.05 . * * p<.01 . * * * p<.001$. 


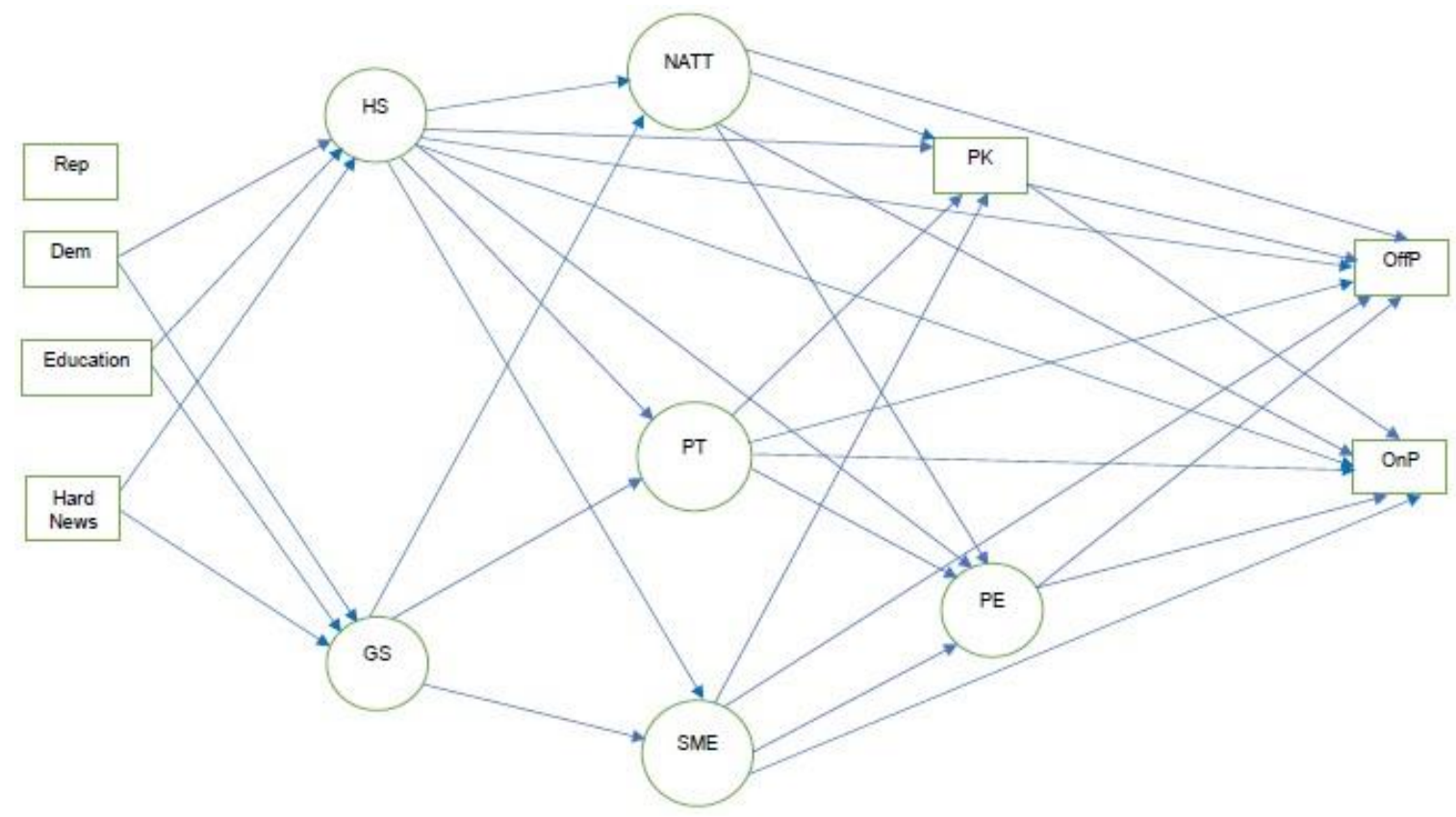

Figure 3. Hypothesized model for Model 2 (Harsh Satire Viewing vs. Gentle Satire Viewing).

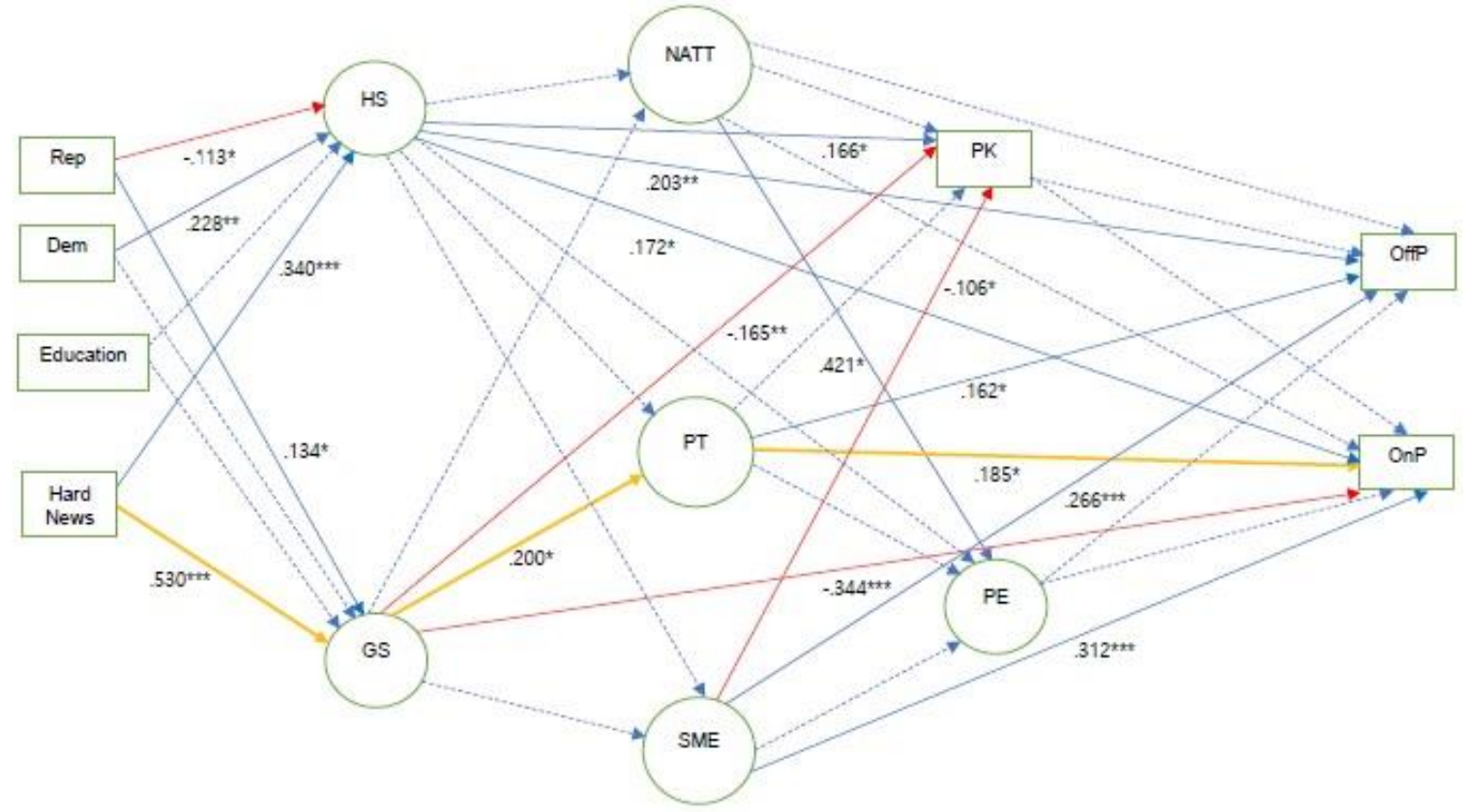

Figure 4. Final model for Model 2 (Harsh Satire Viewing vs. Gentle Satire Viewing). Note. Solid lines indicate significant paths. Red solid lines indicate significant negative association. Blue solid lines indicate significant positive association. Dashed lines indicate nonsignificant paths. Yellow lines indicate significant indirect paths.

$* p<.05 . * * p<.01 . * * * p<.001$. 


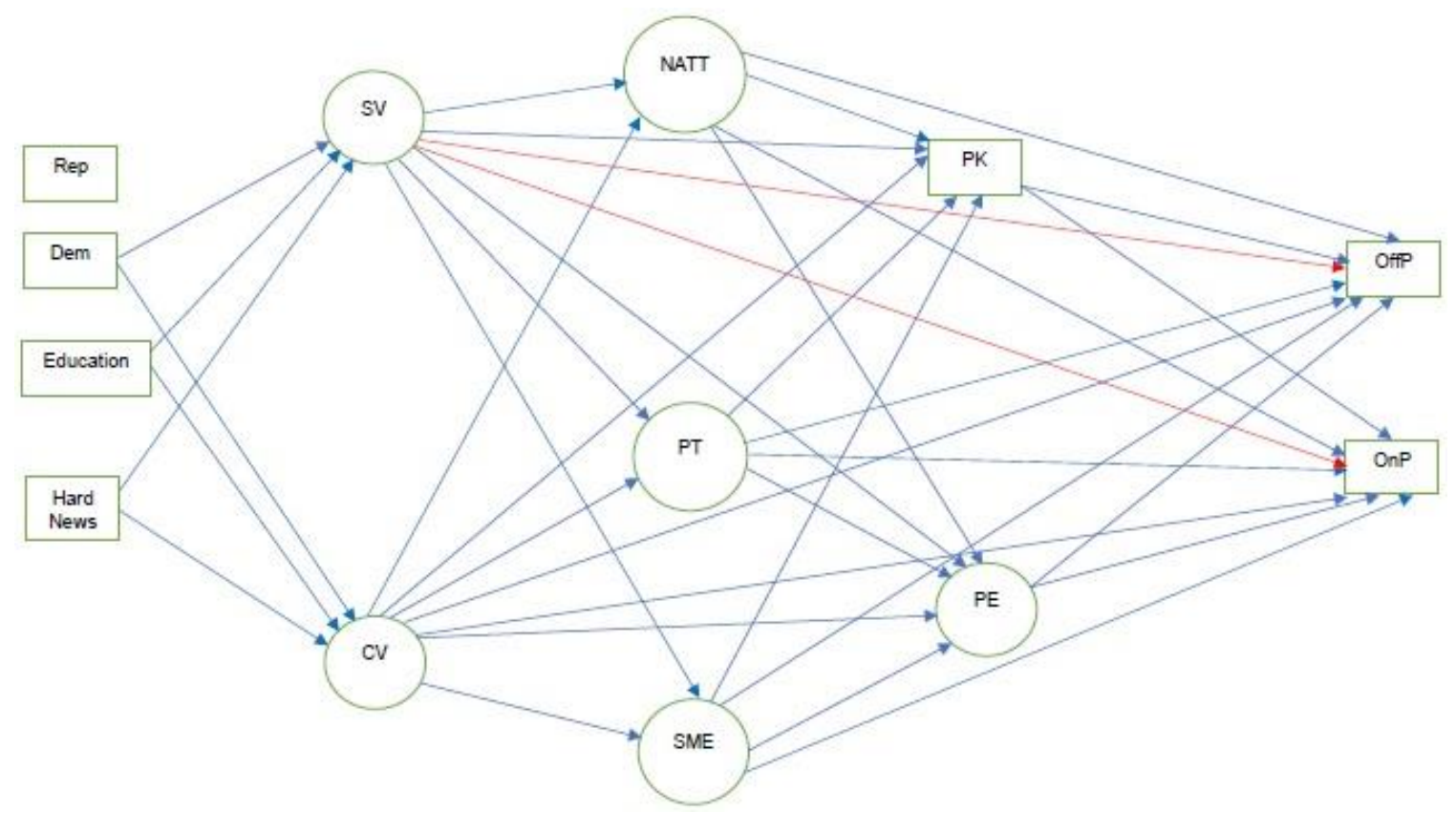

Figure 5. Hypothesized model for Model 3 (Self-viewing vs. Curated Viewing of Political Satire).

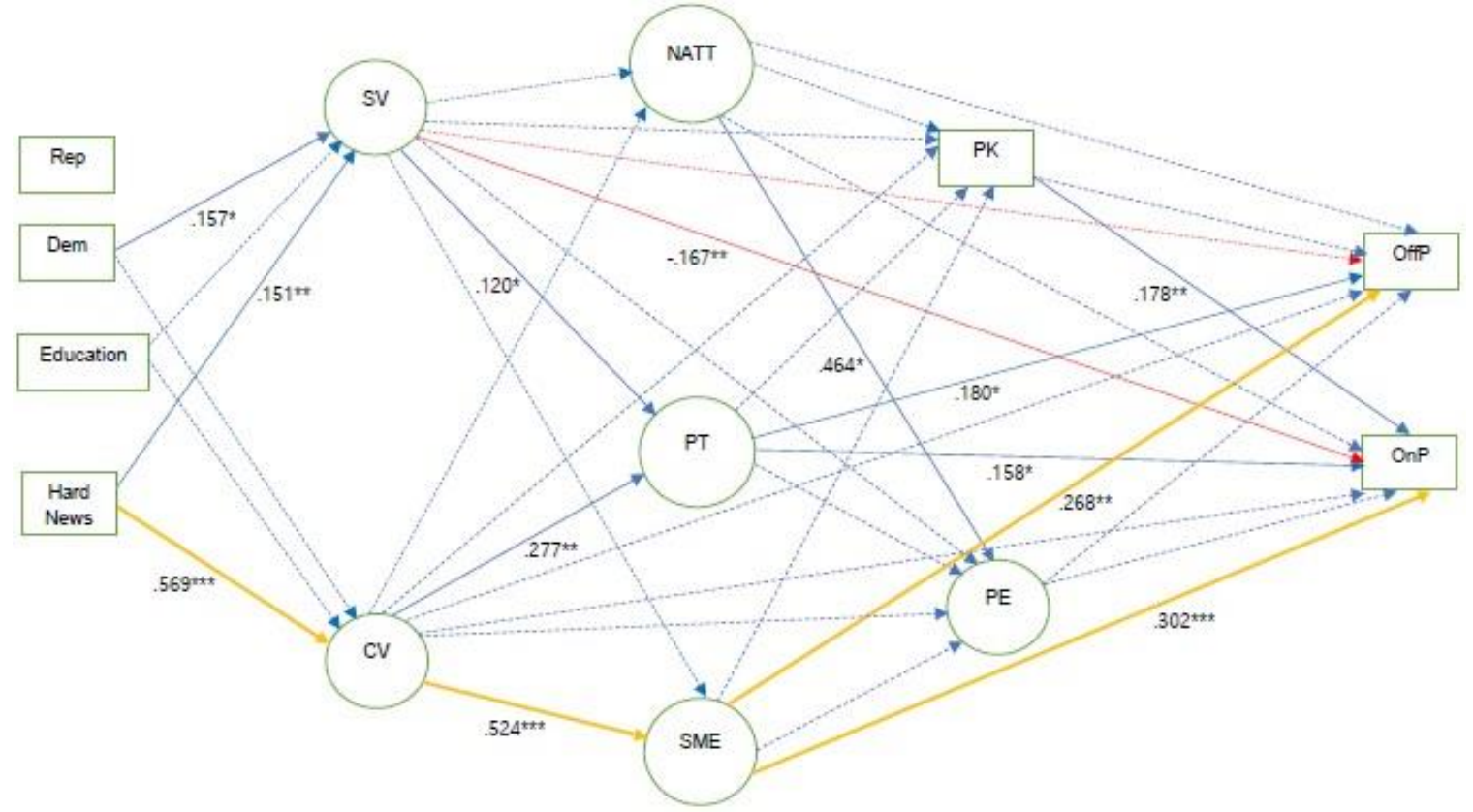

Figure 6. Final model for Model 3 (Self-viewing vs. Curated Viewing of Political Satire). Note. Solid lines indicate significant paths. Red solid lines indicate significant negative association. Blue solid lines indicate significant positive association. Dashed lines indicate nonsignificant paths. Yellow lines indicate significant indirect paths. $* p<.05 . * * p<.01 . * * * p<.001$. 


\section{Appendix}

Survey Instrument

(Note: Some questions in the survey were not used.)

\section{[DISPLAY]}

Thank you for agreeing to participate in this study. During this study, you will be asked questions about your media use and how you feel about certain kinds of issues. Please read each question carefully to answer, all at once and by yourself.

I would appreciate it if you complete the survey in one sitting, if possible.

When you are ready, please click on the next button.

\section{General Media Use}

[Q] About how many days in the past week did you read or look at the following types of media? (8-point (0-7) scale)

- The printed version of The New York Times

- The New York Times online

- The printed version of The Wall Street Journal

- The Wall Street Journal online

- The printed version of The Washington Post

- The Washington Post online

- The printed version of your local newspaper

- Your local newspaper online

[Q] About how many days in the past week did you watch or look at each of the following news? (8-point (0-7) scale)

- NBC Nightly News with Lester Holt on television

- NBC Nightly News with Lester Holt online

- ABC World News Tonight with David Muir on television

- ABC World News Tonight with David Muir online

- CBS Evening News with Scott Pelley on television

- CBS Evening News with Scott Pelley online

- PBS NewsHour on television

- PBS NewsHour online

- Local news programs on your local TV stations

- Local news programs online 
[Q] About how many days in the past week did you listen to or look at these radio news programs? (8-point (0-7) scale)

- National Public Radio on radio

- National Public Radio online

[Q] About how many days in the past week did you watch or look at each of these television news programs? (8-point (0-7) scale)

- CNN on television

$-\mathrm{CNN}$ online

- Fox News on television

- Fox news online

- MSNBC on television

- MSNBC online

\section{Political Satire Viewing}

[Q] Do you watch late-night talk shows (e.g., The Daily Show, Samantha Bee, Jimmy Fallon, John Oliver, Stephen Colbert, Saturday Night Live)?

- Yes

- No

(Note: The respondents who answered "No" were directed to the questions of News and Citizenship)

[Q] Please indicate how often you tended to watch the following late-night talk shows during the past 12 months? $(0=$ never and $4=$ a great deal $)$

- The Tonight Show Starring Jimmy Fallon (NBC)

- Late Show with Stephen Colbert (CBS)

- Jimmy Kimmel Live (ABC)

- Late Night with Seth Meyers (NBC)

- Late Late Show with James Corden (CBS)

- Last Call with Carson Daly (NBC)

- The Daily Show with Trevor Noah (Comedy Central)

- Conan (TBS)

- Saturday Night Live (NBC)

- Last Week Tonight with John Oliver (HBO)

- Full Frontal with Samantha Bee (TBS)

[Q] Please indicate the extent to which you agree/disagree with each of the following statements $(1=$ strongly disagree and $7=$ strongly agree $)$.

- I watch late-night talk shows purely for entertainment.

- I watch late-night talk shows purely for news and information.

- I watch late-night talk shows for both entertainment, and news and information.

[Q] About how often during the past 12 months did you watch $(0=$ never and $4=a$ great deal)

- late-night talk shows on television (live or recorded) 
- late-night talk shows on the programs' official websites (e.g., www.cc.com for The Daily Show).

[Q] About how often during the past 12 months did you watch $(0=$ never and $4=a$ great deal)

- late-night talk shows or segments of the shows on Facebook?

- late-night talk shows or segments of the shows on other online platforms (e.g., YouTube) after hearing about it on Facebook?

- late-night talk shows or segments of the shows on Twitter

- late-night talk shows or segments of the shows on other online platforms (e.g., YouTube) after hearing about it on Twitter

- late-night talk shows or segments of the shows on YouTube

- late-night talk shows or segments of the shows after hearing about it via email?

- late-night talk shows or segments of the shows after hearing about it via instant messaging?

- late-night talk shows or segments of the shows when you were guided to them by news sources like the Wall Street Journal, ABC news, and your local newspapers, or other news media online (e.g., Politico, Huffington Post)?

[Q] About how often was each of the following reasons why you watched the late-night talk shows on the media platforms you said you tended to watch the shows during the past 12 months? $(0=$ never and $4=a$ great deal $)$

- to be the first person to watch the shows

- to watch the shows at your convenience

- to watch the popular shows only

\section{News and Citizenship}

[Q] To what extent do you agree/disagree with each of the following statements? $(1=$ strongly disagree and $7=$ strongly agree)

- News should be serious.

- News should be accurate.

- News should be objective.

- News should not be entertaining.

- News should be credible.

- News should be unbiased.

- News should not be funny.

[Q] To what extent do you agree/disagree with each of the following statements $(1=$ strongly disagree and $7=$ strongly agree).

- News is a dominant source of political information and a good citizen should follow news to be informed of public and civic affairs.

- Citizens should be informed about public and civic affairs by following news media.

- Programs like late-night talk shows (e.g., The Daily Show, Late Show with Stephen Colbert, Saturday Night Live) can supplement, but not replace news media. 
- Programs like late-night talk shows (e.g., The Daily Show, Late Show with Stephen Colbert, Saturday Night Live) can replace news media.

\section{News Exposure \& Attention}

[Q] About how many days in the past week did you use newspapers (8-point (0-7) scale) - to read articles about the presidential transition process?

- to read state and national politics?

- to read editorial and opinion columns?

[Q] In the past week how much attention did you pay to $(1=$ very little attention and $7=$ very close attention)

- newspaper stories about the presidential transition process?

- newspaper stories about state and national politics?

- editorial and opinion columns in newspaper?

[Q] About how many days in the past week did you use television (8-point (0-7) scale)

- to watch/listen to stories about the presidential transition process?

- to watch/listen to stories about state and national politics?

[Q] In the past week how much attention did you pay to $(1=$ very little attention and $7=$ very close attention)

- television news stories about the presidential transition process?

- television news stories about state and national politics?

[Q] About how many days in the past week did you go online (8-point (0-7) scale)

- to $\mathrm{read} / \mathrm{watch} / \mathrm{listen}$ to news stories about the presidential transition process?

- to read /watch/listen to news stories about state and national politics?

[Q] In the past week how much attention did you pay to $(1=$ very little attention and $7=$ very close attention)

- online news stories about the presidential transition process?

- online news stories about state and national politics?

\section{Political Talk}

[Q] About how often during the past 12 months did you talk about politics with each of the following groups of people? $(0=$ never and $4=$ a great deal $)$

- friends and family

- coworkers and acquaintances

- strangers

- people who agree with me

- people who disagree with me

- people who are more knowledgeable about politics than I am

- people who are less knowledgeable about politics than I am 
- people outside my family who do not share my ethnicity, socioeconomic status, or gender

- people who back up their arguments with evidence

- people who are unreasonable and illogical when stating their point of view

- people who propose alternatives or policies for problem solving

\section{Social Media Expression}

[Q] About how often during the past 12 months did you $(0=$ never and $4=$ a great deal $)$ - post or share comments or opinions about current political events and public affairs on social media (e.g., Facebook, Twitter, YouTube)

- post or share videos about current political events and public affairs on social media (e.g., Facebook, Twitter, YouTube)

- post or share articles about current political events and public affairs on social media (e.g., Facebook, Twitter, YouTube)

\section{Offline Political Participation}

[Q] During the past 12 months, did you (yes/no)

- speak to a public official in person

- call or send a letter to an elected public official

- participate in any demonstrations, protests, or marches

- attend a political meeting, rally, or speech

- encourage someone to vote

- wear a campaign button or T-shirt

- display a campaign bumper sticker or yard sign

- work for a political party or candidate

- get involved in political action groups, political clubs, or party committees

- participate in groups that took any local action for social or political reform

\section{Voting}

[Q] In talking to people about elections, we often find that a lot of people were not able to vote because they weren't registered, they were sick, or they didn't have time. How about you? Did you vote in the presidential election this past November? Which of the following statements best describes you? (4-point $(0-3)$ scale) (I did not vote - I thought about voting this time but didn't - I usually vote but didn't this time - I am sure I voted)

\section{Online Political Participation}

[Q] During the past 12 months, did you (yes/no)

- send e-mails to politicians

- visit a campaign or candidate advocacy website

- make contributions to a political campaign online

- subscribe to a political listserv 
- sign up online to volunteer for the activities of political parties

\section{Political Efficacy}

[Q] How much do you agree/disagree with each of the following statements? $(1=$ strongly disagree and $7=$ strongly agree)

- I consider myself to be well qualified to participate in politics

- I feel that I have a pretty good understanding of the important political issues facing our country

- I think that I am as much informed about politics and government as most people.

\section{Political Interest}

[Q] About how much interested are you in $(0=$ not at all interested and $4=$ extremely interested):

- the presidential election?

- elections for officials in your state?

- political news (non-election related)?

\section{Political Knowledge}

(Note: Respondents were given 15 seconds per each question.)

[Q] Which of these is the governor of Indiana?

[Mike Pence, Tim Kaine, John Kasich, Ben Carson]

[Q] Which of these served as a Secretary of State?

[Hillary Clinton, Donald Trump, Gary Jonhson, Jill Stein];

[Q] Which of these was born in New York City and graduated from New York Military Academy?

[Donald Trump, Gary Jonhson, Mike Pence, John Kasich]

[Q] Who says global warming and climate change are a hoax?

[Hillary Clinton, Donald Trump, Al Gore, Ban Ki-moon]

[Q] Who cast doubt on Russia's hacking role and praised Russian President Vladimir Putin during the presidential campaign?

[Donald Trump, Hillary Clinton, Gary Johnson, Jill Stein]

[Q] Who initiated the vote recount efforts in Michigan, Wisconsin, and Pennsylvania after the presidential election?

[Hillary Clinton, Gary Johnson, Jill Stein, Donald Trump]

[Q] Which political party has a majority in the U.S. House of Representatives?

[Democratic, Republican, Libertarian, Green] 
[Q] Whose responsibility is it to nominate judges to the Federal Courts?

[President, Congress, Supreme Court, Don't know].

[Q] How much of a majority is needed for the U.S. Senate and House to override a presidential veto?

[Bare majority (one more than half the votes), Two-thirds majority, Three-fourths majority, Don't know].

[Q] What job is currently held by Paul Ryan?

[Speaker of the U.S. House of Representatives, Senate Majority Leader, Senate Minority Leader, House Majority Leader].

[Q] Who has the final responsibility to decide if a law is Constitutional or not? [President, Congress, Supreme Court, Don't know].

[Q] In which institution does a presidential candidate have to get a majority votes to win the election?

[Registered voters, Electoral College, The House of Representatives, The Senate]

\section{[INSTRUCTION]}

The following items are being used for multiple studies exploring individual differences in media use. Please keep in mind that there are no "right" or "wrong" answers for these questions.

\section{Issue Attitudes}

\section{[MIXED QUESTIONS 1]}

How much do you agree/disagree with each of the following statements? $(1$ = strongly disagree and $5=$ strongly agree)

- Men have privileges that women do not have in the United States.

- Men automatically have more opportunities than women in employment and education.

- Men are at an advantage because they hold most of the positions of power in society.

- Marriage should only be between a man and a woman

- The Affordable Care Act is a good way of providing health care to Americans

- Immigrants who did not come to this country legally should have a pathway to citizenship

- Human activity is causing global warming.

- Government spending needs to be drastically reduced.

- Carbon pollution needs to be regulated to stop global warming.

- The science behind global warming has been exaggerated.

- At this point, there is nothing humans can do to curtail global warming.

- White people in the U.S. have certain advantage because of the color of their skin.

- Race is very important in determining who is successful and who is not.

- Race plays an important role in who gets sent to prison. 
- Race plays a major role in the type of social services (such as type of health care or day care) that people receive in the U.S.

- Racial and ethnic minorities do not have the same opportunities as White people in the U.S.

- Everyone who works hard, no matter what race they are, has an equal chance to become rich.

- Poor people often lack a good work ethic.

\section{[MIXED QUESTIONS 2]}

To what extent do you agree/disagree with each of the following statements? $(1=$ strongly disagree and $5=$ strongly agree)

- America's government has gotten way too big.

- Government uses tax dollars to provide things we all need (e.g., highways and parks).

- Diversity of religions is one of the things that make this country great.

- Social policies, such as affirmative action, discriminate unfairly against White people.

- English should be the only official language in the U.S.

- White people in the U.S. are discriminated against because of the color of their skin.

- Due to racial discrimination, programs such as affirmative action are necessary to help create equality.

- Racial and ethnic minorities in the U.S. have certain advantages because of the color of their skin.

- Racial problems in the U.S. are rare, isolated situations.

- The government should provide everyone with health care and pay for it with tax dollars.

- Companies should be required to provide health insurance for their employees and the government should provide subsidies for those who are not working or retired.

- Health insurance should be voluntary left up to individuals.

- We need stricter firearms laws to protect Americans from gun violence.

- We need tightened background check requirements on would-be gun buyers.

- No limits on guns are needed. They save lives.

\section{[MIXED QUESTIONS 3]}

To what extent do you agree/disagree with each of the following statements? $(1=$ strongly disagree and $5=$ strongly agree)

- Gay, lesbian, and bisexual individuals lack power in the legal system.

- Heterosexuals have access to more resources than gay, lesbian, and bisexual individuals.

- Some individuals are devalued in society because of their sexual orientation.

- I think gay, lesbian, and bisexual individuals exaggerate their hardships.

- Racial diversity makes it harder for Americans to get along.

- A major cause of America's problems is that so few people have most of the country's wealth.

- We need stricter voting laws to cut back on election fraud in our country.

- It is important to make voting easy and accessible to as many Americans as possible.

- Many people are poor through no fault of their own.

- Too many Americans expect others to provide them with life's needs. 
- The law should permit abortion only in case of rape, incest, or when the woman's life is in danger.

- Talking about racial issues causes unnecessary tension.

- Racism is a major problem in the U.S.

- It is important for public schools to teach about the history and contributions of racial and ethnic minorities.

- It is important for political leaders to talk about racism to help work through or solve society's problems.

- Racism may have been a problem in the past, it is not an important problem today.

- By law, abortion should never be permitted.

- By law, a woman should always be able to obtain an abortion as a matter of personal choice.

[DISPLAY]

Lastly, we would like to ask you about your social media use and background.

\section{General SNS Use}

(No time at all - up to 15 minutes - up to 30 minutes - more than 30 minutes and up to an hour - up to two hours - up to three hours - more than three hours) (7-point (0-6) scale)

[Q] On a typical day, about how much time do you spend on Facebook?

[Q] On a typical day, about how much time do you spend on Twitter?

[Q] On a typical day, about how much time do you spend on YouTube?

\section{Demographics}

Age

[Q] How old are you?

Gender

[Q] [Assigned sex at birth] What sex were you assigned at birth, on your original birth certificate?

-Male

-Female

[Q] [Current gender identity] How do you describe yourself? (check one)

-Male

-Female

-Transgender

-Do not identify as female, male, or transgender] 


\section{Education}

[Q] What is the highest level of education you have completed?

- Less than high school

- High school incomplete

- High school graduate or GED certificate

- Some college, no degree (including community college)

- Two-year associate degree from a college or university

- Some university, no degree

- University degree/Bachelor's degree

- Some graduate studies, no degree

- Master's degree

- Doctorate degree

Race

[Q] Which of the following describes your race? You can select as many as apply.

- White (e.g., Caucasian, European, Irish, Italian, Arab, Middle Eastern)

- Black or African-American (e.g., Kenyan, Nigerian, Haitian)

- Asian or Asian-American (e.g., Asian Indian, Chinese, Filipino, Vietnamese or other Asian origin groups)

- Native American/American Indian/Alaska Native

- Pacific Islander/Native Hawaiian

- Hispanic/Latino (e.g., Mexican, Puerto Rican, Cuban)

- Don't know

Income

[Q] In 2016, what was your total family income from all sources, before taxes?

- Less than $\$ 10,000$

- 10 to under $\$ 20,000$

- 20 to under $\$ 30,000$

- 30 to under $\$ 40,000$

- 40 to under $\$ 50,000$

- 50 to under $\$ 75,000$

- 75 to under $\$ 100,000$

- 100 to under $\$ 150,000$

- $\$ 150,000$ or more

Political Ideology

[Q] The term "liberal" and "conservative" may mean different things to people, depending on the type of issue one is considering. In general, would you describe your political views as (7-point (-3-3) scale)

(Very conservative - Conservative - Somewhat conservative - Moderate - Somewhat liberal - Liberal - Very liberal) 
Party Identification

[Q] In politics today, do you consider yourself (Strong Republican - Republican Leaning Republican - Independent - Leaning Democrat - Democrat - Strong Democrat)? (7-point (-3-3) scale)

Residence

[Q] Which state do you live in?

This is the end of the survey. Thank you very much for your time and participation. 
Heesook Choi was born and raised in Gangneung, South Korea. Before attending the University of Missouri-Columbia, she attended Gangneung-Wonju National University in South Korea, where she earned a Bachelor of Arts in English Language and Literature in 1995. From 2003 to 2005 , she also attended the University of Texas at Austin, where she received a Master of Arts in Journalism.

At the University of Missouri-Columbia, Choi was invited to join Kappa Tau Alpha, the national honor society in journalism and mass communication, for her fine academic record in 2019.

After completing her doctoral program at the University of Missouri-Columbia in 2019, Choi will join the Department of Communication at Mississippi State University in Starkville, Mississippi, as an Assistant Professor. 